\title{
Temporal variation of large intraplate earthquakes in coupled subduction zones
}

\author{
Thorne Lay ${ }^{1}$, Luciana Astiz ${ }^{2}$, Hiroo Kanamori ${ }^{2}$ \\ and Douglas H. Christensen ${ }^{1}$ \\ ' Department of Geological Sciences, University of Michigan, Ann Arbor, MI 48109 (U.S.A.) \\ ${ }^{2}$ Seismological Laboratory, California Institute of Technology, Pasadena, CA 91109 (U.S.A.)
}

(Received October 30, 1987; revision accepted November 24, 1987)

Lay, T., Astiz, L., Kanamori, H. and Christensen, D.H., 1989. Temporal variation of large intraplate earthquakes in coupled subduction zones. Phys. Earth Planet. Inter., 54: 258-312.

\begin{abstract}
The focal mechanisms of intraplate earthquakes within subducting lithosphere are frequently used to infer large-scale stress regimes induced by slab-pull, bending or unbending, and lateral segmentation and undulations of the slab. Numerous studies have further postulated that the intraplate activity is influenced by transitory regional stress regimes such as those associated with interplate thrust events. Temporal variations of the latter type may potentially play an important role in assessing regions of uncertain seismic potential, and possibly even in earthquake forecasting. A systematic analysis of 1130 focal mechanisms for intraplate earthquakes with $m_{\mathrm{b}} \geq 5.0$ in the depth range $0-300 \mathrm{~km}$ is conducted for nine circum-Pacific subduction zones, all of which are known to have large interplate thrust events. The spatial and temporal relationships of the earthquakes within the subducting slab to the large thrust events in each region are appraised. The earthquake catalog assembled contains all published focal mechanisms, and is probably complete for $m_{\mathrm{b}} \geq 6.5$ for the years 1963-1986. For many of the localized regions considered in detail the catalog is complete to lower thresholds of $m_{\mathrm{b}} \geq 6.0$ or $m_{\mathrm{b}} \geq 5.5$. This analysis provides compelling evidence for a temporal link between large interplate thrust activity and intraplate seismicity. For the seismically coupled regions considered here, outer rise compressional events have occurred prior to several large thrust events or are associated with seismic gaps, while outer rise tensional events generally only follow interplate ruptures. In the intermediate depth range, large down-dip tensional events generally precede interplate thrusts, and are often concentrated at the down-dip edge of the coupled zone. A transition to down-dip compressional stress or diminished tensional activity at intermediate depth is observed after several large thrust events (e.g., 1960 Chile, 1974 Peru, 1957 Aleutian, 1971 New Britain). These examples support the notion that the intraplate stress environment responds viscoelastically to the temporally varying interplate stress regime. Assuming that this concept is correct, the seismic potential of several seismic gaps is considered on the basis of both outer rise and intermediate depth earthquake activity.
\end{abstract}

\section{Introduction}

The classic works of Isacks and Molnar (1969, 1971), Isacks et al. (1969) and Oike (1971) established the general characteristics of the stress regime within subducting lithosphere by analysis of earthquake focal mechanisms. Their work provided the basic notion that intraplate earthquakes serve as stress gauges for the large-scale deformation involved in subduction. With the exception of
Tonga, the intermediate depth activity in most regions of the world is dominated by down-dip tensional mechanisms, which reflect the slab-pull stresses due to the negative buoyancy and tensile coherence of the lithosphere. As the earthquake mechanism data set has expanded, important additional features of the intraplate stress regime have been divulged, such as the presence of double Benioff zones (e.g., Tsumura, 1973; Veith, 1974; Hasegawa and Umino, 1978), as well as 
detailed mapping of the contorted subducted slabs (e.g., Billington, 1980; Giardini and Woodhouse, 1984). Earthquake mechanisms in the outer rise have also been considered, with the observations that most outer rise events have horizontal tension axes oriented sub-perpendicular to the arc, and when events with horizontal compression axes do occur, they usually have greater source depths (Stauder, 1968b; Chapple and Forsyth, 1979; Ward, 1983). These facts are consistent with large-scale bending stresses in quasi-elastic slabs resulting from slab-pull stresses.

While the stress regimes induced by the largescale subduction processes such as bending, unbending, sinking, and lateral tearing or warping appear to account for most intraplate subduction zone activity, there are numerous examples of temporal variations in the intraplate behavior, most commonly associated with large subduction zone thrust events. The most dramatic examples, and the easiest to interpret, involve outer rise activity. There are many examples of sequences of outer rise tensional events following large thrust earthquakes, such as the 1960 Chile (Stauder, 1973), 1957 Aleutian (Stauder, 1968b), 1965 Rat Island (Stauder, 1968a; Abe, 1972a; Spence, 1977) 1963 Kurile Island (Stauder and Mualchin, 1976), and 1971 Solomon Island (Christensen and Ruff, 1988) events. Detailed examination of the global occurrence of outer rise events has established that only a few small outer rise tensional events are found within a few decades preceding a large interplate thrust event, while there are four examples of compressional events preceding large thrust events (Christensen and Ruff, 1988). The significance of this observation is bolstered by the fact that no outer rise compressional events have been detected within 30 years after a large thrust event, nor have any outer rise compressional events been identified in regions of the southwest Pacific which are believed to be seismically 'uncoupled' in the sense of not producing great thrust earthquakes (Christensen and Ruff, 1988).

Intraplate activity at intermediate depths also appears to exhibit some temporal variations associated with large interplate thrust events (e.g., Spence, 1977, 1987). Mogi (1973) presented evidence for a temporal affinity between large earth- quakes near $300 \mathrm{~km}$ depth and great shallow events along the Japan-Kurile-Kamchatka arc. The intermediate depth activity increased for several years prior to the shallow events in several instances. Mogi (1973) also provided evidence for migration of seismic activity from shallow to great depths within the Mariana and Tonga arcs, inferring a migration velocity of $50 \mathrm{~km} \mathrm{a}^{-1}$.

Seno and Pongswat (1981) and Kawakatsu and Seno (1983) defined a third seismic zone in northern Japan, and suggested that the focal mechanisms of the events in this zone respond to changes of stress on the interplate boundary. Temporal fluctuations in the stress orientation of small earthquakes in the Benioff zone in the Aleutian arc have also been reported (Hauksson et al., 1984). Recently, McNally and Gonzalez-Ruiz (1985) and McNally et al. (1986) have constructed spatio-temporal cross-sections of shallow and intermediate depth events that occur along the Mexican subduction zone, from which they inferred that stress transfer takes place between the intraplate region and the shallow interplate boundary.

One might anticipate that the best candidate interplate thrust event which should have influenced the intraplate stress regime is the great $\left(M_{\mathrm{w}}=9.5\right) 1960$ Chile event. The tremendous rupture area and large displacement during this event may conceivably have involved regional stress perturbations comparable to the static stresses associated with bending and slab-pull. Figure 1 indicates the spatial and temporal behavior of intraplate stresses in the subducting Nazca plate (as manifested in moderate size earthquakes) associated with this great thrust event. Stauder (1973) and Christensen and Ruff (1988) studied the sequence of outer rise tensional earthquakes that followed this event, but do not report any mechanisms for outer rise events prior to the thrust. Astiz and Kanamori (1986) studied the intraplate activity down-dip of the thrust zone, finding evidence for a temporal change from down-dip tensional mechanisms (in 1934 and 1949; note that an error in fig. 1 of Astiz and Kanamori (1986) is corrected) prior to the mainshock, to down-dip compressional behavior (in 1971) afterward. We have identified an additional large 


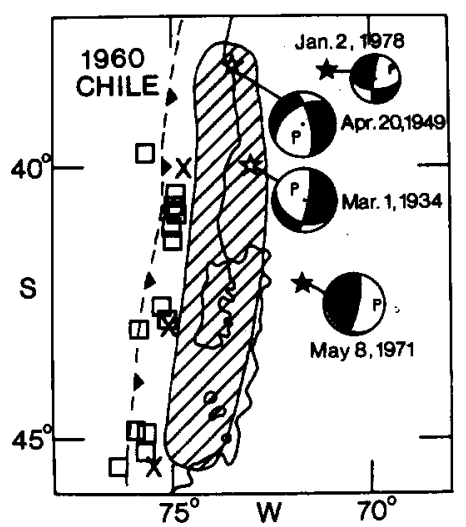

Fig. 1. Intraplate earthquakes within the subducting Nazca slab in the region of the $1960\left(M_{\mathrm{w}}=9.5\right)$ underthrusting event. The approximate rupture area of the thrust event is hachured. Lower hemisphere equal area projections are shown for the intermediate depth events. Open stars indicate down-dip tensional events and solid stars indicate down-dip compressional events. The location of outer rise events in the catalog of Christensen and Ruff (1988) are also shown, with open boxes indicating tensional events and $\times s$ indicating oblique mechanisms which are neither simple tensional nor compressional type. All of the outer rise events follow the 1960 mainshock.

intraplate event in 1978, which is also predominantly down-dip compressional. The tensional events occurred at shallower depths than the compressional events, close to the leading edge of the locked region that slipped in the mainshock. Unlike the observations of Mogi (1973), there is no temporal clustering of intraplate activity (other than in the outer rise), but this segment of the Nazca plate does not extend as deep as in the western Pacific arc.

Motivated by these observations, Astiz and Kanamori (1986), Christensen and Ruff (1988) and Astiz et al. (1988) have proposed a simple model of intraplate stresses in regions with strong seismic coupling. In this model, we conceptually separate the ambient stress regimes associated with the 'static' deformation of the subducting slab, from the temporally varying 'dynamic' regional stresses. The static field (Fig. 2a) is associated with large-scale bending, unbending, thermal equilibration, and slab-pull stresses. The term static applies only in the sense that the large-scale processes proceed on a time-scale much greater than that of the relatively rapidly varying regional stresses associated with the interplate contact zone. The dynamic stresses (Fig. 2b) associated with interplate locking and unlocking (i.e., thrusting) interact with the large-scale stress environment. When the coupled zone is locked, tensional stresses due to slab-pull and unbending may concentrate at the down-dip edge of the coupled zone. In turn, stresses in the outer rise may become compres-
STATIC

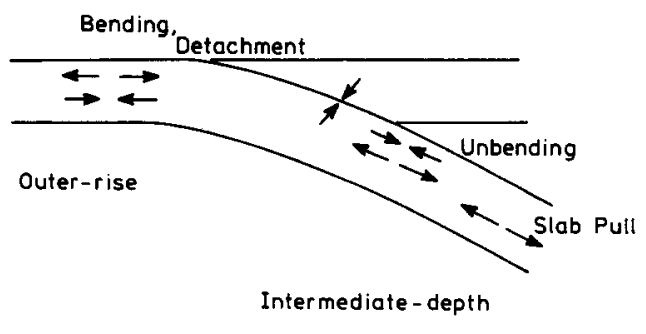

DYNAMIC

Before Thrust
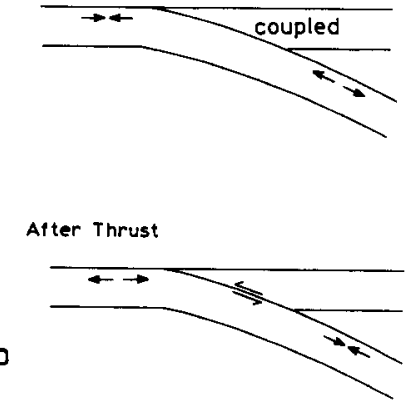

Fig. 2. (a) A two-dimensional model of the stress distribution within the outer rise and intermediate depth region of subducting lithosphere resulting from bending, unbending and slab-pull effects. It is assumed that ridge-push effects are negligible. (b) A dynamic stress model that would apply to a region with strong seismic coupling involving temporally varying stresses that would be superimposed on the static stress fields in (a). Prior to the thrust, the locked region causes extensional stresses to concentrate on the down-dip edge of the coupled zone and compressional stresses to concentrate in the outer rise. Following the thrust, the down-dip slab-pull is transmitted to the outer rise, producing tension, while the intermediate depth region is under transient compression (or diminished tensional) stress. 
sional, or at least the shallow tensional stresses due to bending and slab-pull may be reduced. This does not necessarily imply a significant component of ridge-push stresses, for there may be lateral loading of the outer rise region up-dip of a coupled zone arising from previous thrust events in adjacent areas along the arc strike. When the thrust event occurs, the slab-pull and tensional bending stresses in the outer rise are enhanced and the region will have concentrated outer rise tensional activity. The intermediate depth region may undergo a transition to down-dip compressional activity, which might only be anticipated to overwhelm the ambient slab-pull tensional regime in the case of the largest thrust events such as the 1960 Chile rupture. More commonly, a reduction in the occurrence of intraplate tensional activity in the vicinity of the interplate contact may be observed. The presence of double Benioff zones as well as lateral segmentation and distortion of the slab must clearly complicate the temporal pattern, but by restricting our attention to the largest events, as did Astiz and Kanamori (1986), Christensen and Ruff (1988) and Astiz et al. (1988), it should be possible to seek any general consistency with this model.
In this paper we address the question of whether there is any global validity to the simple model in Fig. 2 by considering the stress orientation of intraplate events in seismically coupled subduction zones. The general structure of this analysis is indicated by Fig. 3, which summarizes many of the observations described in detail below. In Fig. 3 the intraplate earthquake activity in the outer rise and at intermediate depths that has preceded or followed large interplate thrust events is separated into two categories. These are tensional and compressional type mechanisms, based on which stress axis is more closely aligned with the local plate motion vector. The outer rise observations are taken from Christensen and Ruff (1988), and exhibit a remarkable temporal separation of compressional and tensional events seaward of large thrust rupture zones. This is clearly consistent with the dynamic stress model in Fig. 2b. Many of the interesting characteristics of this figure, such as the lack of compressional outer rise activity before the very largest thrusts, are considered in detail below and in the paper by Christensen and Ruff (1988). While the intermediate depth activity presents a comparably consistent pattern for thrust events with $M_{\mathrm{w}}>8.5$ (large tensional events prior
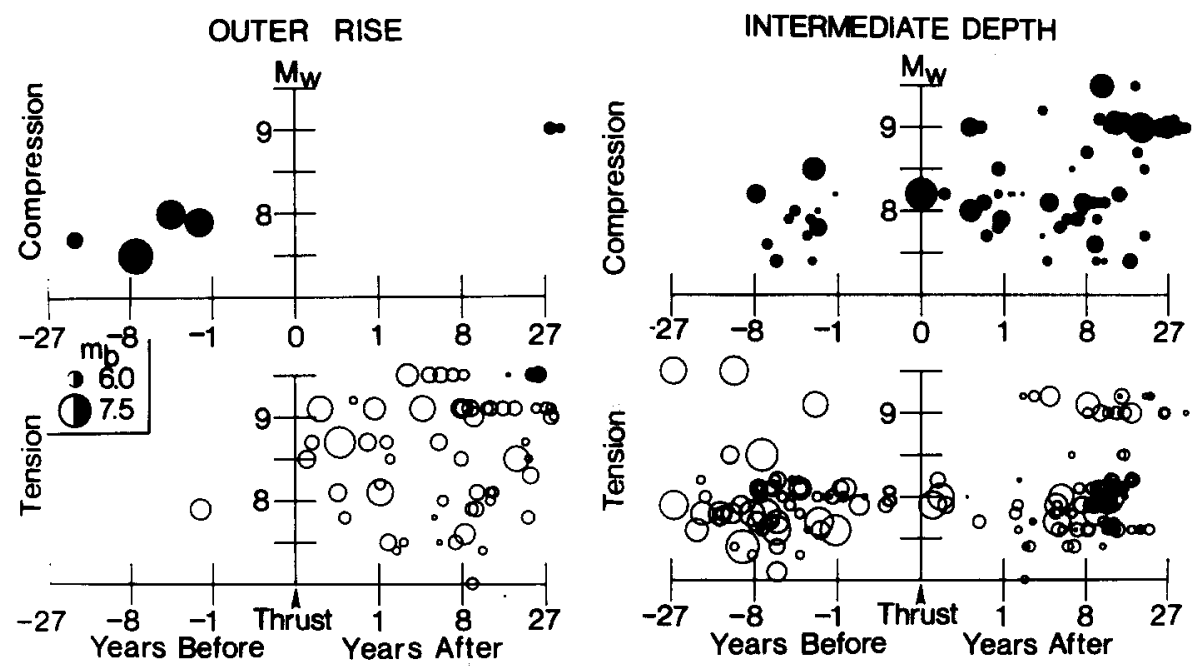

Fig. 3. Composite diagrams of outer rise (left) and intermediate depth (right) earthquakes within subducting slabs that occur seaward or down-dip of large interplate thrust events. The vertical axis indicates the moment magnitude of the thrust event. The intraplate activity is separated into two categories of compressional (solid symbols) and tensional (open symbols) mechanisms on the basis of which stress axis is more closely aligned with the local plate motion vector. The sizes of the symbols are scaled linearly with the magnitude of the intraplate event. 
to thrusting, and large compressional or smaller tensional events afterward), the pattern is more complex for smaller thrust events. Given the additional complexity of the stress regime at intermediate depths, it is clearly important to analyze carefully the individual earthquake sequences in order to assess the validity of the dynamic stress model for the intermediate depth environment. After doing so we will consider the seismic potential and earthquake prediction implications of this earthquake cycle approach to understanding the subduction process.

\section{Analysis of intraplate earthquake mechanisms}

The purpose of this work is to conduct a preliminary global analysis of temporal variation of earthquake-related stresses in subducting slabs in regions which have large interplate thrust events. Figure 4 indicates the subduction zones of the
circum-Pacific to which we restrict our attention. On the basis of maximum thrust event moment in each region, Kanamori (1977) and Lay et al. (1982) considered southern Chile, Alaska and Kamchatka to be the most strongly seismically coupled regions, and the central Aleutians, Colombia, Peru, northern Chile and the Kurile Islands to be well coupled. The Middle America, New Hebrides, Solomon Islands-New Britain, and TongaKermadec regions are believed to be moderately coupled, given that maximum interplate thrust events are seldom greater than $M_{\mathrm{w}}=8.0$ in these regions.

Any analysis of temporal variations in seismic occurrence encounters major difficulties in acquiring a comprehensive, complete earthquake catalog. In this study, we draw upon two recently compiled lists of intraplate earthquakes as well as on an extensive literature search to construct our database. Christensen and Ruff (1988) have presented a listing of known outer rise earthquake

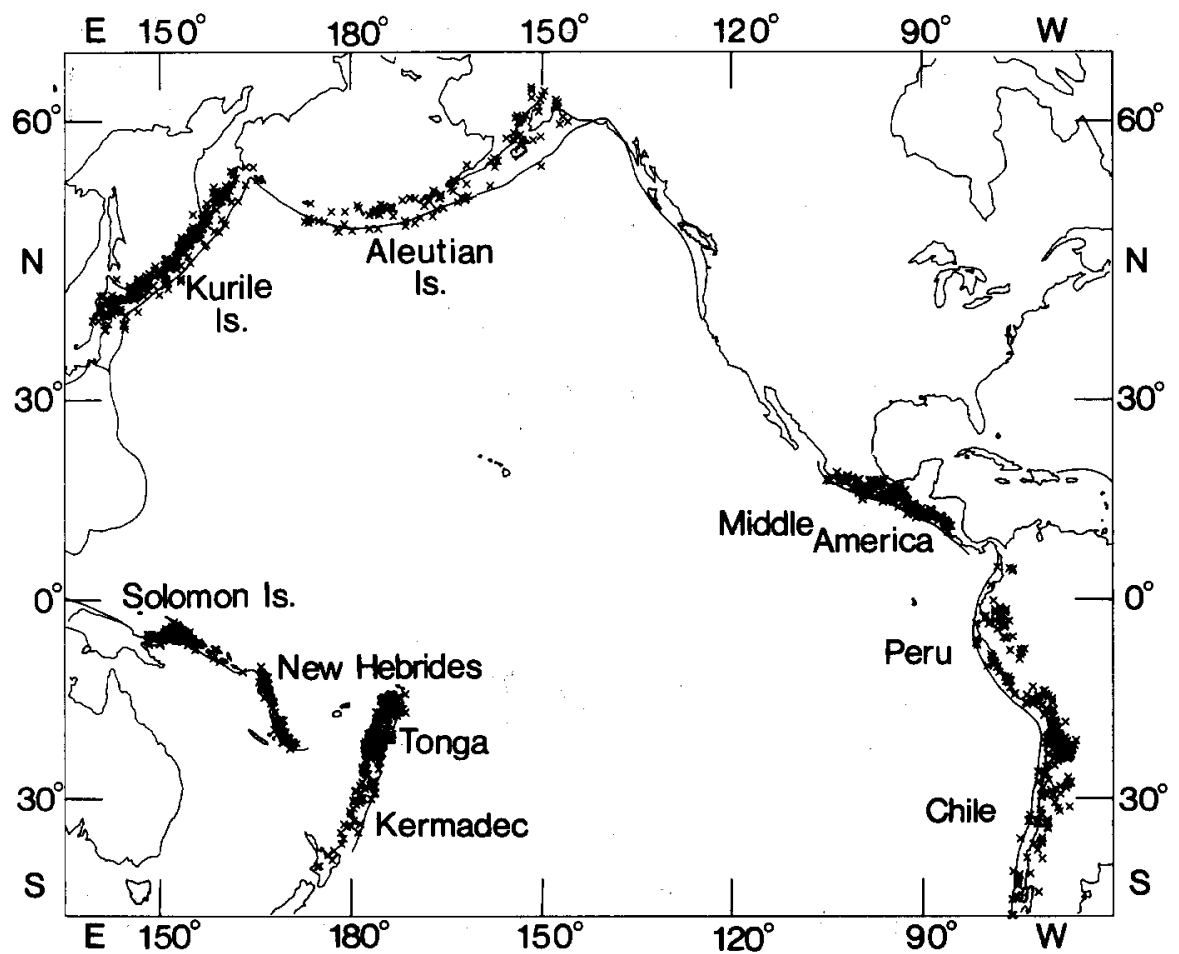

Fig. 4. A map showing the circum-Pacific subduction zones considered in this study and the location of all shallow and intermediate depth $(0-300 \mathrm{~km})$ intraplate events with $m_{b} \geq 5.0$ in these regions for which focal mechanisms have been determined. 
focal mechanisms in all circum-Pacific subduction zones, which is probably complete for magnitudes of 7.0 and greater since 1963. Smaller magnitude events have been included in their list, but many additional earthquakes with magnitudes less than 6.5 located in the outer rise are contained in the ISC and NOAA catalogs. Similarly, Astiz et al. (1988) have presented a comprehensive catalog of intermediate depth earthquake focal mechanisms with depths from 40 to $200 \mathrm{~km}$, with $m_{\mathrm{b}} \geq 6.0$. This list is believed to be complete for $m_{\mathrm{b}} \geq 6.5$ for the years 1963-1984. There are again many events with $m_{\mathrm{b}}<6.5$ listed in the seismicity catalogs, which do not have published mechanisms.

For each of the seismic zones in Fig. 4, we assembled a catalog of all known focal mechanisms for events with $m_{\mathrm{b}} \geq 5.0$ which occurred within the subducting slab at depths from 0 to 300 $\mathrm{km}$. Many detailed studies of focal mechanisms in each region have been conducted, and we based the interpretation of the intraplate character on the earthquake location, depth, focal mechanism, and appraisal of the authors of the detailed studies. The larger events in this catalog are mostly from the studies of Christensen and Ruff (1987) and Astiz et al. (1988). By restricting our attention to events with $m_{\mathrm{b}} \geq 5.0$, we feel that most of the focal mechanisms are sufficiently reliable for our purpose of characterizing predominantly down-dip tensional or down-dip compressional categories. The greatest difficulty in screening out the interplate events is encountered in the southwest Pacific subduction zones in the Solomon Islands and New Hebrides, which have very steeply dipping interplate contacts. In these regions, interplate thrusts and down-dip tensional intraplate events have very similar mechanisms. Those events with apparently reliable depths (based on surface-reflected phases and number of recordings in the ISC and NOAA catalogs) $>60 \mathrm{~km}$ were included in our list of intraplate events. Fortunately, numerous studies have performed body wave modeling to constrain more accurately the depths of many of the events (e.g., Chinn and Isacks, 1983; Astiz et al., 1988), so our designations are often based on more than just catalog travel times.

The final catalog of intraplate events (Appendix B) contains 994 focal mechanisms apart from the 135 outer rise events in these regions listed by Christensen and Ruff (1988). A small number of mechanisms are included for events before 1960 , most of which were tabulated by Fujita and Kanamori (1981), but many focal mechanisms of older events were not considered sufficiently reliable to include in our list. For the particular regions we selected, it appears that this catalog is complete for $m_{b} \geq 6.5$ for the years 1963-1986. The comprehensive centroid moment tensor solution catalog produced by Harvard (e.g., Dziewonski and Woodhouse, 1983) ensures completeness for $m_{\mathrm{b}} \geq 5.5$ for the years 1977-1978, 1981-1986 at the time of writing. For several regions, such as Middle America and Tonga, the threshold for completeness is $m_{\mathrm{b}} \geq 6.0$ (and possibly $m_{\mathrm{b}} \geq 5.5$ ) for 1963-1986 owing to the many detailed studies of these regions. For other zones, there is often a gap in temporal coverage from 1972 to 1976 owing to the quirks of the seismic literature. It is important to acknowledge at the outset of this analysis that ultimate confirmation of the existence of temporal patterns in any particular region will require exhaustive completeness of the focal mechanism catalog in each region down to lower magnitude thresholds than $m_{\mathrm{b}}=6.5$, which is beyond the scope of the present exploratory study.

The focal mechanism catalog that we will analyze thus comprises essentially all published focal mechanisms of events within the subducting slabs with $m_{b} \geq 5.0$ for the years $1963-1986$, as well as some earlier events. The locations of these events are shown in Fig. 4. We will consider each region in the following manner. First, the gross spatial characteristics of the intraplate activity will be considered in map view, with the events segregated into three categories:

(1) tensional events, which in the outer rise involve predominantly horizontal tension axes that are suborthogonal to the trench, and which for intermediate depth events have tensional axes within $30^{\circ}$ of the down-dip direction;

(2) compressional events, which satisfy similar criteria for the compression axes; and

(3) oblique/tear events which do not satisfy either of the above criteria or have strike-slip mechanisms. We adhere to the tensional/ compressional designations assigned by Christen- 
sen and Ruff (1988) for the events in their catalog except for a few events which we redesignate in our oblique/tear category for consistency. We then consider the temporal aspects of the catalog in relation to the occurrence of the largest interplate thrust events in each region.

As in all such global discussions it is easy for the reader to become bogged down by the many details which must be considered. We recommend that the reader frequently refer back to Figs. 2 and 3 to help keep in mind the relevance of the individual earthquake occurrences discussed to the simple physical model being tested. For those readers who are interested in only a summary of the observations, the discussion section will briefly recap the important aspects of the lengthy regional analysis.

\section{Southern Chile}

The intraplate earthquake mechanisms for the Chile trench south of $25^{\circ} \mathrm{S}$ are shown in Fig. 5. The left panel indicates the events in the tensional category, while the right panel shows both the compressional and oblique events. For all events other than the outer rise events of Christensen and Ruff (1988), the trend of the tension axis (diverging arrows) is indicated for tensional events and the trend of the compressional axis (converging arrows) is indicated for compressional events. Oblique mechanisms are indicated by an $x$. The approximate rupture areas of large interplate thrusts, based on a variety of detailed studies, are shown for reference. The pressure, tension, and intermediate axes of all events except those in the outer rise are shown in lower hemisphere, equal area projections to convey the consistency of the event categorizations. Large symbols are used for the events with $m_{\mathrm{b}} \geq 6.0$. An average dip of the subducting slab at intermediate depths along this region is indicated in the focal sphere for reference, with the dip varying along the trench by $\pm 10^{\circ}$ about this dip.

Our purpose is to appraise the general spatial relation between the large interplate thrusts and the intraplate mechanisms, not to infer details of the subducting plate geometry. Astiz et al. (1988)

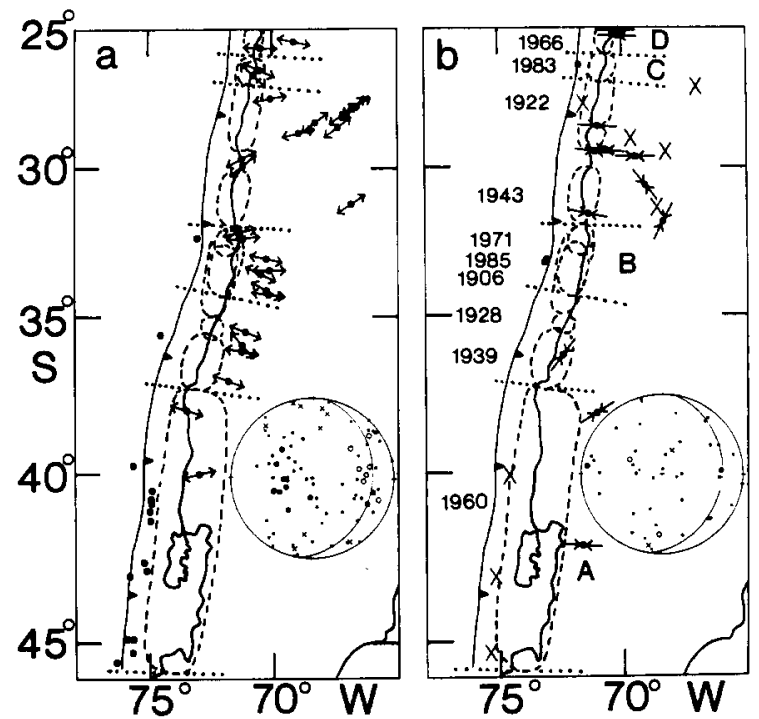

Fig. 5. Intraplate earthquakes within the subducting Nazca plate in southern Chile. The rupture zones of large interplate thrust events are indicated by the dashed lines. (a) Events identified as predominantly down-dip tension at intermediate depths or as outer rise tensional events. The trends of the tension axes are indicated by diverging arrows for events in Appendix B. Symbols without arrows are identified as outer rise tensional events by Christensen and Ruff (1988). The tension (open circles), compression (solid circle) and null $(X)$ axes for the events from Appendix B are shown in the lower hemisphere equal area projection. Larger symbols are used for events with $m_{\mathrm{b}} \geq 6.0$. (b) A similar map for the down-dip compressional events (converging arrows indicate the trends of the compression axes) as well as events which have oblique mechanisms $(\times s)$. The dip of the subducting plate at intermediate depths is indicated in the focal sphere. The dotted lines and associated letters indicate the arc segments for which cross-sections are shown in Fig. 7.

give a general review with references to many of the detailed studies of each region that addresses the latter aspect. With this in mind, we can immediately make several general observations from Fig. 5. First of all, tensional activity is more abundant for $m_{\mathrm{b}} \geq 6.0$ (larger symbols in the focal spheres) than compressional activity in the region. Given that source depths increase toward the right in each panel, it is apparent that compressional events tend to occur near the coupled interface, with the exception of the two events along the 1943 rupture zone near $30^{\circ} \mathrm{S}$, where the intraplate activity appears to reflect lateral warping of the subducted slab. There has been abundant ten- 


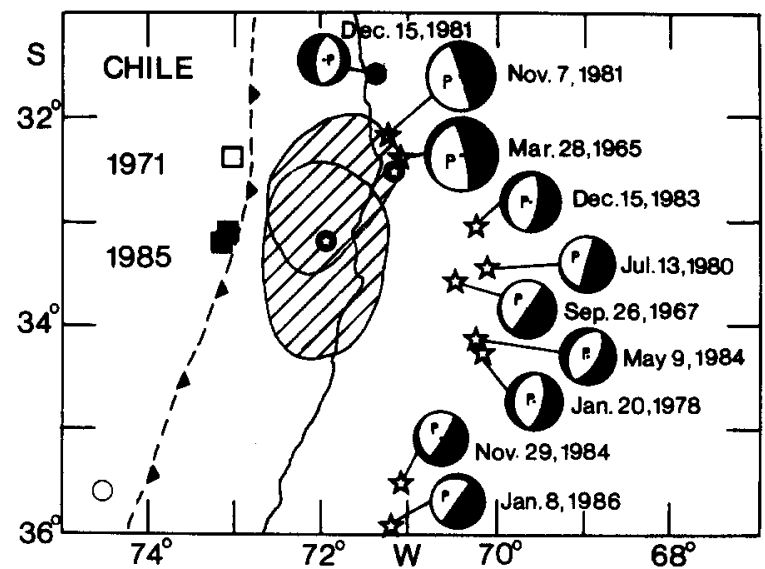

Fig. 6. Intraplate earthquake activity associated with the 1971 and 1985 underthrusting events in central Chile. The aftershock areas of the thrusts are shown, with the mainshock epicenters being indicated by circled stars. The symbol convention for the intraplate events is the same as in Fig. 1, with the addition that outer rise compressional events are indicated by solid boxes. Outer rise tensional events that occur more than $30 \mathrm{yr}$ after an underthrusting event are indicated by open circles, and downdip compressional events following a thrust by more than 30 years are indicated by solid circles.

sional activity along the down-dip edge of the coupled interface throughout central Chile, with particularly uniform character in the overlapping $1971 / 1985$ and 1906 rupture zones and along the seismic gaps in the 1928 and 1939 zones. The southern portions of the 1922 and 1943 regions have predominantly compressional events. Regions with both tensional and compressional activity in close proximity include the 1966 rupture zone and the region around $30^{\circ} \mathrm{S}$, which may be suggestive of a double Benioff zone (Malgrange and Madariaga, 1983). We will explore the temporal characteristics of these events below.

Having considered the events associated with the 1960 thrust in Fig. 1, it is of interest to consider in greater detail the intraplate activity along the $1985\left(M_{\mathrm{w}}=8.0\right)$ rupture zone. Figure 6 shows the interesting sequence of events in this region. Christensen and Ruff $(1983,1988)$ have discussed the two outer rise compressional events (in 1981 and 1982) that preceded the 1985 underthrust, as well as the outer rise tensional event (in 1971) which followed the $1971\left(M_{w}=7.8\right)$ thrust.
These events are consistent with the dynamic model in Fig. 2b. The occurrence of outer rise compressional events is unusual in general, and Christensen and Ruff (1986, 1988) suggest that lateral loading of the locked 1985 zone owing to slip in the adjacent 1971 thrust is responsible for the compressional regime. Prior to the 1971 event, a large $\left(M_{\mathrm{w}}=7.5\right)$ down-dip tensional event took place in 1965 (Malgrange et al., 1981). This event occurred at $72 \mathrm{~km}$ depth, below the eventual hypocenter of the 1971 thrust. In 1981, a similar tensional event occurred in the region, indicating that the moderate size of the thrust was insufficient to put the slab into compression.

The 1981 intraplate event is very similar to the group of tensional events which occurred just to the south, down-dip of the 1985 interplate rupture. The events directly down-dip of the thrust have depths around $100 \mathrm{~km}$, and all occurred before 1985. There were no tensional events right at the edge of the coupled zone.

The southernmost intraplate events in Fig. 6 occurred down-dip of the seismic gap in the 1928 zone (Fig. 5), at a depth near $100 \mathrm{~km}$. While these events are similar to those preceding the 1985 thrust, there is an outer rise tensional event in this region, which indicates that compressional stresses due to a locked interplate contact were not predominant. The northernmost intraplate event took place in the southern part of the 1943 thrust zone, and is a compressional event. This earthquake is hard to interpret in the dynamic stress model context, but may be an unbending event.

The temporal behavior of intraplate activity with known focal mechanisms for large events along central and southern Chile is shown in Fig. 7. These figures present depth and time profiles of all events within the arc segment defined by the associated interplate thrust rupture zones, as indicated in Fig. 5. The distances are measured relative to a pole perpendicular to the local stretch of arc, which was usually about $80^{\circ}$ away. The depths of the events are of variable reliability, many being the result of detailed modeling studies, but most being NOAA catalog locations. Events with $m_{\mathrm{b}} \geq 6.0$ are indicated with larger symbols, and the rupture zone of the interplate events are indicated. 

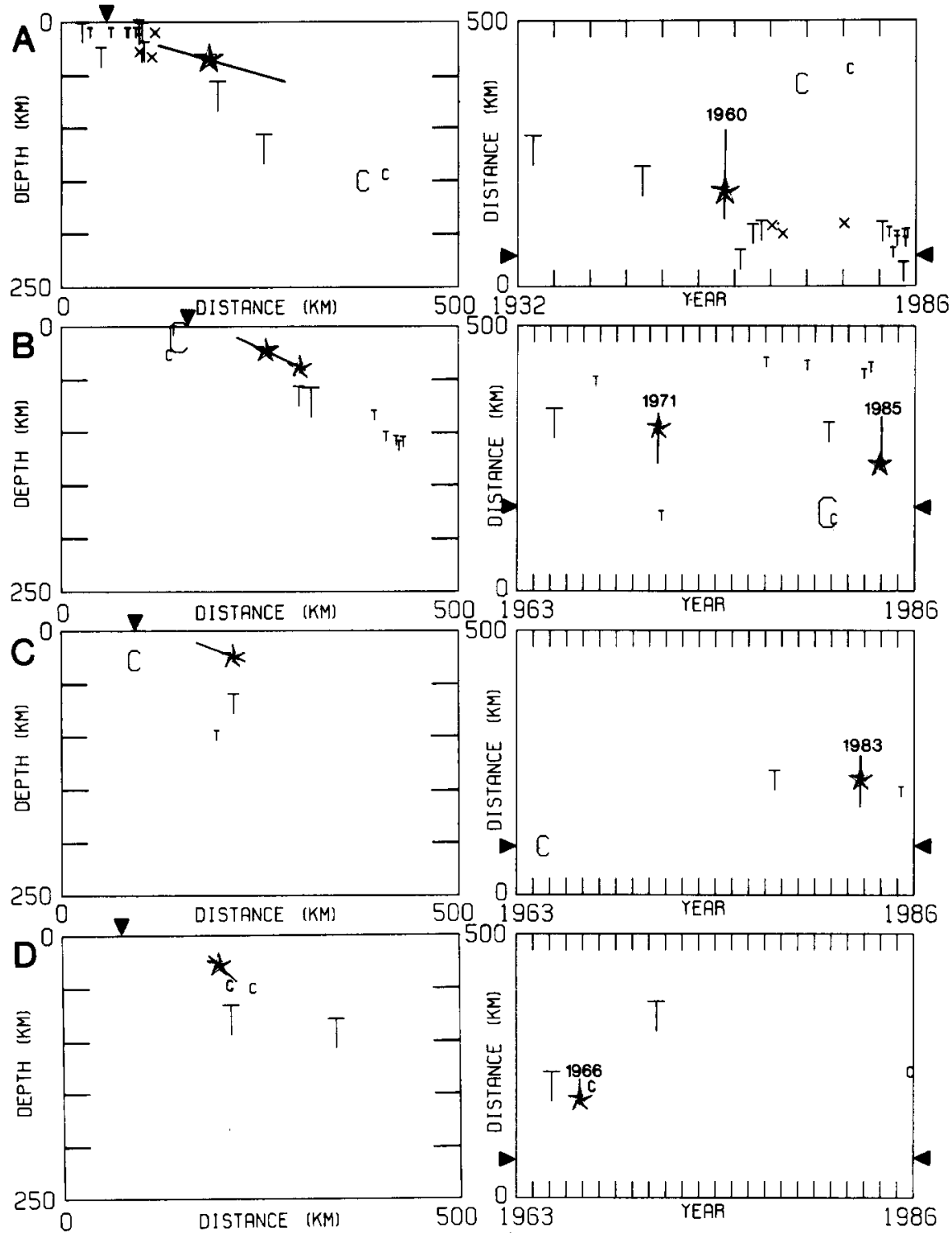

Fig. 7. Depth and time profiles of intraplate activity associated with large thrust events in southern Chile in 1960 (Row A), 1971/1985 (Row B), 1983 (Row C) and 1966 (Row D). The corresponding arc segments are indicated in Fig. 5. The distances are measured relative to a distant pole to the arc for each segment, with all intraplate events along the corresponding interplate rupture zones being included. The location of the trench is indicated by the solid triangles. The thrust events are indicated by the stars, with the thrust planes shown by the solid lines. Tensional outer rise and intermediate depth events are indicated by Ts, with three increasing sizes indicating $5 \leq m_{\mathrm{b}}<6,6 \leq m_{\mathrm{b}}<7$, and $7 \leq m_{\mathrm{b}}<8$ respectively. Compressional (Cs) and tear/oblique $(\times \mathrm{s})$ mechanisms are shown with similar magnitude scaling.

The 1960 event (Row A) exhibits a clear temporal transition from tension to compression at intermediate depths and activation of the outer rise tensional behavior following the mainshock.
While the detection level is particularly bad in this region for older seismicity, no other intermediate depth events with $m_{\mathrm{b}} \geq 5.5$ are listed after 1963 in the NOAA catalog for this region. The 1971 and 
1985 events (Row B) exhibit tensional down-dip activity prior to the ruptures, outer rise tension following the 1971 thrust, and outer rise compression preceding the 1985 event. The NOAA catalog lists eight additional events in the region prior to 1976 with $5.5 \leq m_{\mathrm{b}}<6.0$, which do not have published mechanisms, but there are no missing events with $m_{\mathrm{b}} \geq 6.0$.

The $1983\left(M_{\mathrm{w}}=7.7\right)$ rupture (Row C) was preceded by an outer rise compressional event in 1967 and a down-dip tensional event in 1978 located below the thrust hypocenter. A small, relatively deep tensional event occurred in 1986 below the rupture zone. This activity represents all of the events with $m_{\mathrm{b}} \geq 6.0$ in this region since 1963 . Row D shows that the $1966\left(M_{\mathrm{w}}=7.7\right)$ thrust was preceded by a large tensional intraplate event near the down-dip edge of the coupled zone in 1965 , and followed by a compressional event in the same region in 1967. This sequence has been interpreted as possible evidence for a double Benioff zone by Malgrange and Madariaga (1983), but is also consistent with the temporal variation expected for the dynamic model. These interpretations are by no means mutually exclusive, for the transitory regional stress field induced by the thrust may simply overprint that of an ambient double Benioff zone, leading to temporal variation in the size of events in the upper and lower zones. This may explain why this fairly small thrust event would induce compressional activity at intermediate depths. A distant down-dip tensional event occurred several years after the mainshock, and a small recent compressional event occurred near the 1967 location. Only four additional intermediate depth events, all with $m_{\mathrm{b}}<6.0$, are listed in the NOAA catalog for this region.

\section{Northern Chile}

The South American subduction zone between $15^{\circ} \mathrm{S}$ and $25^{\circ} \mathrm{S}$ curves around a substantial bend, as shown in Fig. 8. This is a region of several historical great underthrusting earthquakes (McCann et al., 1979). Astiz et al. (1988) review the general characteristics of intraplate activity in this region. Only five events along this segment are

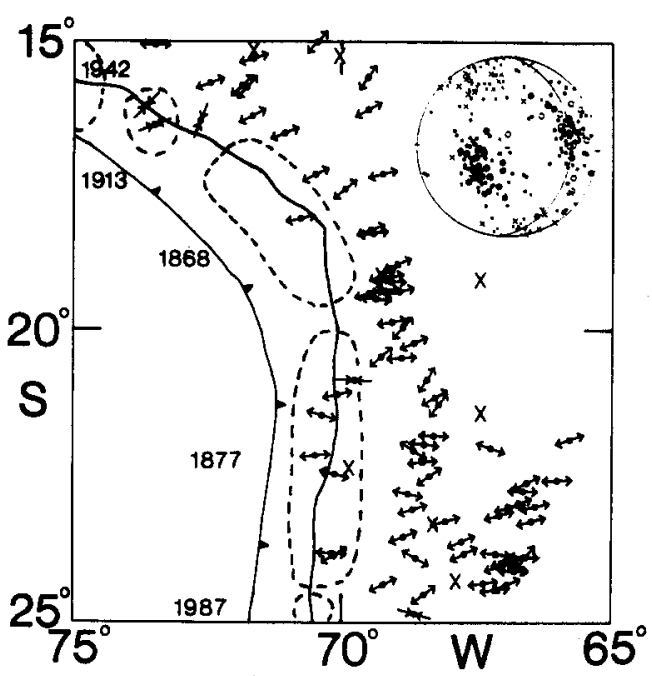

Fig. 8. Intraplate earthquakes within the subducting plate in northern Chile. The approximate rupture zones of large interplate thrusts are indicated, as well as the trend of the characteristic stress axis for tensional (diverging arrows), compressional (converging arrows) and tear/oblique $(X s)$ mechanisms. The principle axes are indicated in the lower hemisphere projection using the convention in Fig. 5. The dip of the subducting plate at intermediate depths south of $20^{\circ} \mathrm{S}$ is shown in the focal sphere.

intraplate compressional events, and there are no published mechanisms for outer rise events, so all of the mechanisms from Appendix B are shown together in Fig. 8. Note the large 1868 and 1877 rupture zones, which are presumably seismic gaps of substantial maturity. Three of the down-dip compressional events are located in the relatively small 1913 rupture zone, where the only tensional events are at greater depths. One compressional event (November 28, 1970) is located in the northern portion of the 1877 rupture zone, in close proximity to two tensional events of December 25 , 1967, and June 19, 1970. A moderate-sized thrust event $\left(M_{\mathrm{s}}=6.3\right)$, which took place in this area on December 21, 1967, was the largest event in the gap since 1922. The two tensional events were located slightly trenchward of this thrust (Malgrange and Madariaga, 1983). This activity is suggestive of a double Benioff zone, given that the small size of the 1967 thrust is unlikely to have induced a temporal change in intraplate stress.

Other activity along the 1877 and 1868 zones is comprised of abundant tensional events of re- 
markably uniform character. These events occur at greater depths, near $100 \mathrm{~km}$, than the activity below the interplate contact. The intraplate activity can be interpreted as the result of slab-pull stresses yielding dominant tension throughout the intermediate depth region. It is plausible that the interplate contact is strongly coupled along the entire region, accentuating the uniformity of the intraplate stress regime. One outer rise event is listed in the NOAA catalog near $22^{\circ} \mathrm{S}$, but the mechanism of this event is unknown. A moderate number of events with $m_{\mathrm{b}} \geq 5.5$ in the NOAA catalog do not have published mechanisms, of which about 10 are located near the 1877 rupture zone and thus merit future analysis. The general spatial distribution of all activity with $m_{\mathrm{b}} \geq 5.5$ is well represented by the events in Fig. 8. When a future great thrust event occurs in this region, it will provide a strong test of the dynamic stress model.

\section{Peru-Colombia}

The intraplate activity within the subducting Nazca plate along northern South America exhibits a variety of behavior. Figure 9 shows that tensional activity predominates in most of the region, with most compressional events located down-dip of the plate interface along the moderately coupled zone in Peru. The extensive gap in large interplate thrust activity between Peru and Colombia, site of subduction of the Carnegie Ridge and numerous fracture zones, has intraplate activity at large distances from the trench. The region along Colombia had large thrust events in 1906 $\left(M_{\mathrm{s}}=8.7\right), 1942,1958$ and $1979\left(M_{\mathrm{w}}=8.2\right)$, but there are remarkably few intraplate events, except on the northern limit of the 1906 and 1979 rupture zones. The distribution of all intraplate seismic activity with $m_{\mathrm{b}} \geq 5.5$ is rather well represented by the known mechanisms in Fig. 9.

Outer rise events in the region are infrequent, with only two mechanisms being known for events associated with interplate thrusts. These are the events of September 3, 1967 (a compressional event north of the 1966 rupture zone) and January 2, 1981 (a tensional event which followed the 1979

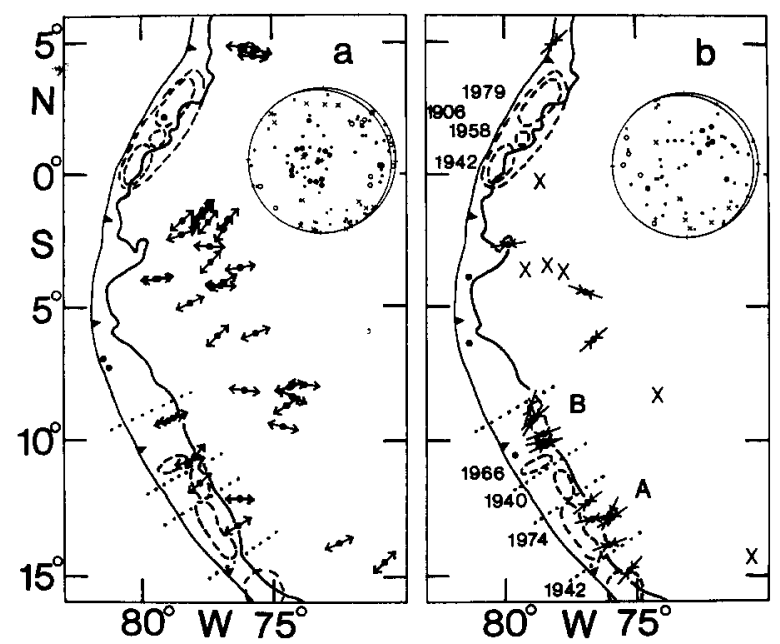

Fig. 9. Intraplate earthquakes within the subducting plate along Peru, Ecuador and Colombia. The symbol conventions are the same as in Fig. 5 for (a) tensional and (b) compressional or tear/oblique events. The dip of the subducting plate at intermediate depths along Peru is indicated in the focal spheres along with the principle stress axes. The dotted lines and associated letters indicate the arc segments for which cross-sections are shown in Fig. 11.

Colombia event). Christensen and Ruff (1988) have discussed the outer rise events within the seismic gap along Ecuador from $0^{\circ} \mathrm{S}$ to $10^{\circ} \mathrm{S}$, finding that they involve both tension and compression. Although the tensional events occurred earlier, the proximity of tensional and compressional events near $7^{\circ} \mathrm{S}$ is consistent with the bending model (Chapple and Forsyth, 1979), while the compressional event (January 17,1984$)$ near $4^{\circ} \mathrm{S}$ occurred in a region where a large $\left(M_{\mathrm{s}}=7.6\right)$ event took place on December 10, 1970 (Stauder, 1975). The 1970 event has been assigned shallow depths by the ISC $(15 \mathrm{~km})$ and USCGS $(25 \mathrm{~km})$, which may place it in the upper plate. Stauder (1975) gives a solution with a north-south trending compression axis, while Pennington (1981) gives a solution with east-west compression that could be consistent with underthrusting. We follow Stauder (1975) in inferring that the 1970 event is in the upper plate, and do not include it in our list of events within the Nazca plate. We also note that the outer rise compressional event in 1984 has a NE-SW trending compression axis, so it may reflect the lateral 


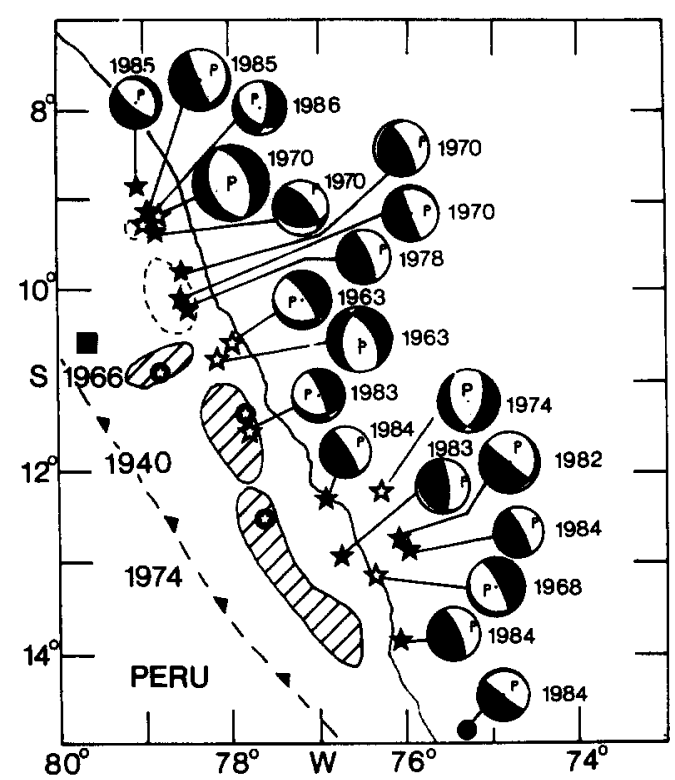

Fig. 10. Intraplate activity associated with large thrust events along Peru. The symbol conventions are the same as in Figs. 1 and 6. The dashed aftershock area is that for the 1970 intraplate event (Dewey and Spence, 1979).

warping of the slab around the bend in the coastline.

It is reasonable to infer that both the outer rise and deeper intraplate activity in the Ecuador region are controlled principally by slab-pull and lateral distortion of the subducting plate in this region (for detailed discussions, see Stauder, 1975; Isacks and Barazangi, 1979; Pennington, 1981). The lateral distortion appears to result in the numerous tear faults at intermediate depths. It is thus difficult to use intraplate events to appraise the seismic coupling of the interplate contact.

The tensional activity in northern Colombia occurred both before and after the 1979 thrust event, but a particularly large $\left(m_{\mathrm{B}}=7.2\right)$ event took place just a few weeks before the thrust. It is possible that lateral loading of the locked zone occurred as a result of aseismic subduction in the region north of the 1906 rupture zone.

Focusing now on the intraplate activity along Peru, Fig. 10 shows the known focal mechanisms for events in this area. The $1974\left(M_{\mathrm{w}}=8.1\right)$ thrust event was preceded by a tensional event at $70 \mathrm{~km}$ depth in 1968, as well as a large tensional event
$\left(m_{\mathrm{B}}=7.1\right)$ at $105 \mathrm{~km}$ depth that occurred a month before the thrust. Following the 1974 event, all intraplate activity has been unambiguously compressional (Beck et al., 1986) throughout the depth range $70-110 \mathrm{~km}$. South of the 1974 thrust zone, a down-dip compressional event took place along the 1942 rupture zone (Fig. 8), while to the north, a tensional event occurred near the down-dip edge of the 1940 rupture zone. The strong lateral gradient from compression to tension at intermediate depths is consistent with strong present coupling of the 1940 rupture zone. Two intermediate depth tensional events occurred in 1963 down-dip of the $1966\left(M_{\mathrm{w}}=8.1\right)$ thrust event, and no subsequent large events have taken place down-dip of the rupture zone.

The temporal and spatial variation of the intraplate stress regime is much more difficult to interpret north of the 1966 rupture zone. Here, the very large $\left(M_{\mathrm{w}}=7.9\right)$ May 31,1970 , normal faulting event (Abe, 1972b) took place. This event, which occurred down-dip of the compressional outer rise event that occurred north of and after the 1966 thrust, produced aftershock activity in two distinct clusters (Dewey and Spence, 1979). With the exception of a recent event in 1986 near the 1970 hypocenter, the known aftershock mechanisms for the larger events are all compressional, while some of the smaller events are tensional (Dewey and Spence, 1979; Isacks and Barazangi, 1977). At depths near $150 \mathrm{~km}$, tensional activity has occurred both before and after the 1970 rupture (Fig. 9), but, owing to the flattening out of the slab, this activity is located several hundred kilometers away, and hence is difficult to relate to the shallow activity. Beck and Ruff (1984) have proposed that the 1970 rupture was complex, with the stress axes changing during the rupture, but it is not clear whether any slip occurred on the plate interface during the mainshock. Thus, while it is possible that a locked interface exists up-dip of the 1970 event (Christensen and Ruff, 1988), the seismic potential of the interplate contact is quite uncertain.

The intraplate activity along Peru is shown in depth and time profiles in Fig. 11. The 1974 event exhibits a clear temporal change in intraplate stress regime. No other intermediate depth events with 

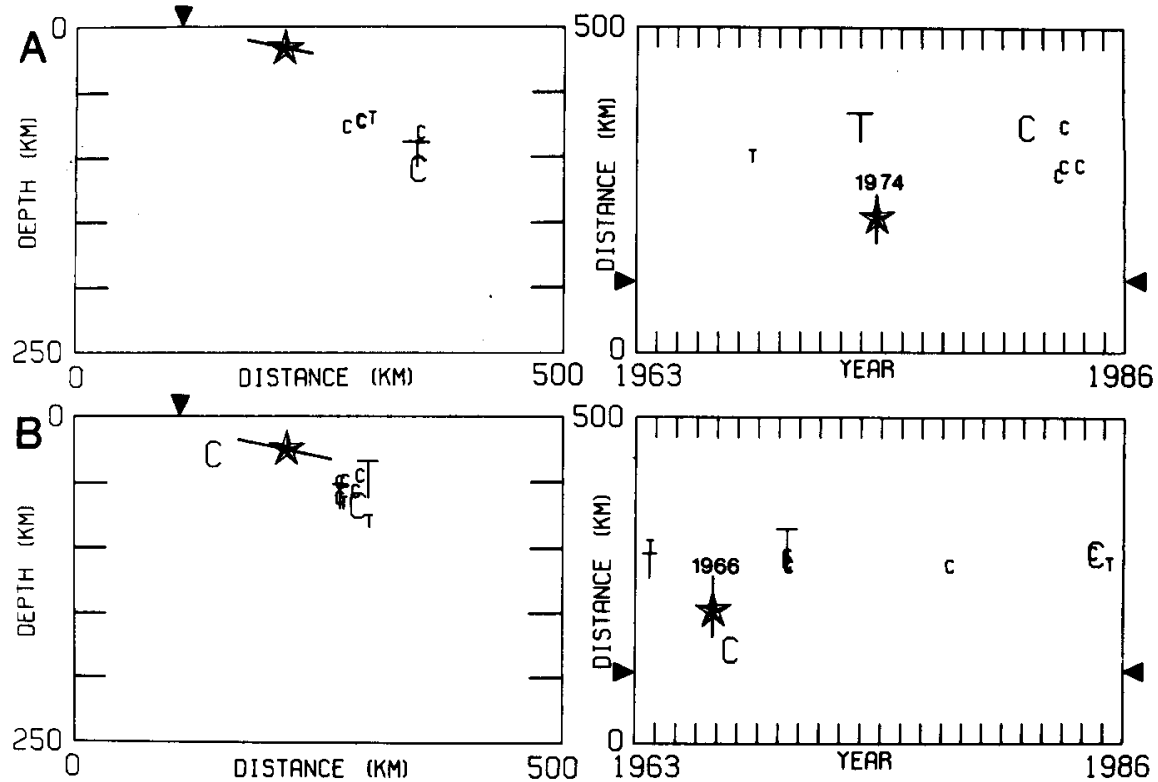

Fig. 11. Depth and time profiles of intraplate activity associated with large thrust events in Peru in 1974 (Row A) and 1966 (Row B). The corresponding arc segments are indicated in Fig. 9. The symbol conventions are the same as in Fig. 7.

$m_{\mathrm{b}} \geq 6.0$ are listed in the NOAA catalog for this period, and only two events with $m_{\mathrm{b}} \geq 5.5$ lack focal mechanisms, so this pattern is rather robust.

The temporal pattern of the 1966 and 1970 thrust events is also interesting, with intermediate depth tensional events followed by the 1966 thrust, and all other activity being located to the north along the trench. The outer rise compressional and the 1970 tensional event are suggestive of a locked plate interface, but clearly the compressional aftershocks of the 1970 event complicate this interpretation. All events with $m_{\mathrm{b}} \geq 6.0$ in this region and time interval have known focal mechanisms, while about 8-10 events with magnitudes $5.5 \leq m_{\mathrm{b}}<6.0$, most of which are aftershocks of the 1970 event, lack published focal mechanisms.

\section{Middle America}

The subduction zone along Mexico and Central America exhibits concentrated tensional activity within the subducting Cocos plate (Fig. 12). All of the events with $m_{\mathrm{b}} \geq 6.0$ are classified as tensional mechanisms, with the exception of the 1980 Huajuapan event ( $M_{\mathrm{w}}=7.2$ ), which is categorized

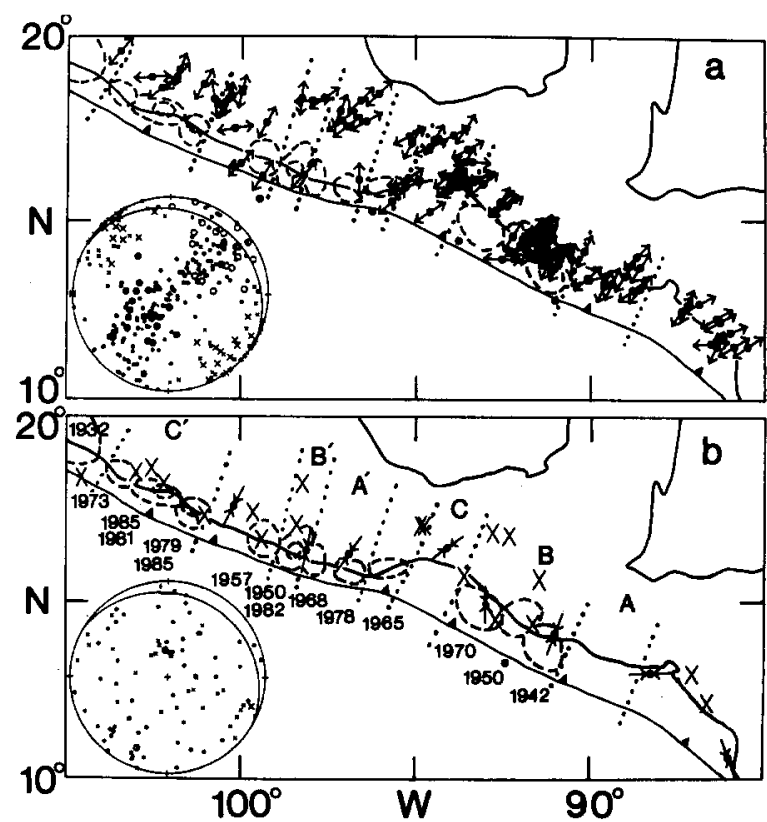

Fig. 12. Intraplate earthquakes within the subducting Cocos plate along Middle America. The conventions are the same as in Fig. 5 for (a) tensional and (b) compressional or tear/oblique category events. The dip of the subducting plate at intermediate depths along Mexico is shown in the focal spheres; the dip is steeper along the Central America zone. The dotted lines and associated letters indicate the arc segments for which cross-sections are shown in Figs. 13 (unprimed letters) and 14 (primed letters). 
as an oblique mechanism because neither the tension nor the compression axis plots in the down-dip direction. This event is located several hundred kilometers north of the 1982 Ometepec doublet, and is discussed in detail in Appendix $A$ and by Gonzalez-Ruiz (1986). Only nine known compressional events are located in the region, with one being in the outer rise offshore from the seismic gap in the 1950 Guatemala rupture zone. The other compressional events were located near the coupled interface and are sparsely distributed along the entire trench, as are numerous strike slip. and oblique tearing events. The catalog in this region for events since 1963 is probably complete down to $m_{\mathrm{b}} \geq 5.5$, and mechanisms for many smaller events in the region are available (Motá,
1979; LeFevre and McNally, 1985). The entire region is only moderately coupled in that the largest interplate thrusts have rupture areas $<150$ km long.

The region of the 1957 Acapulco thrust event (near $99^{\circ} \mathrm{W}$ ) has relatively little intraplate activity, while tensional events are common along the Guerrero gap to the northwest. The gap between the 1965 Oaxaca $\left(M_{\mathrm{w}}=7.5\right)$ and 1970 Chiapas $\left(M_{\mathrm{w}}=7.4\right)$ thrust events (region C in Fig. 12) is in the region where the Tehuantepec Ridge intersects the trench, which may result in aseismic subduction (LeFevre and McNally, 1985), while just southeast of the 1942 Guatemala event there is an extensive seismic gap along El Salvador (region A). The latter arc segment has uncertain seismic
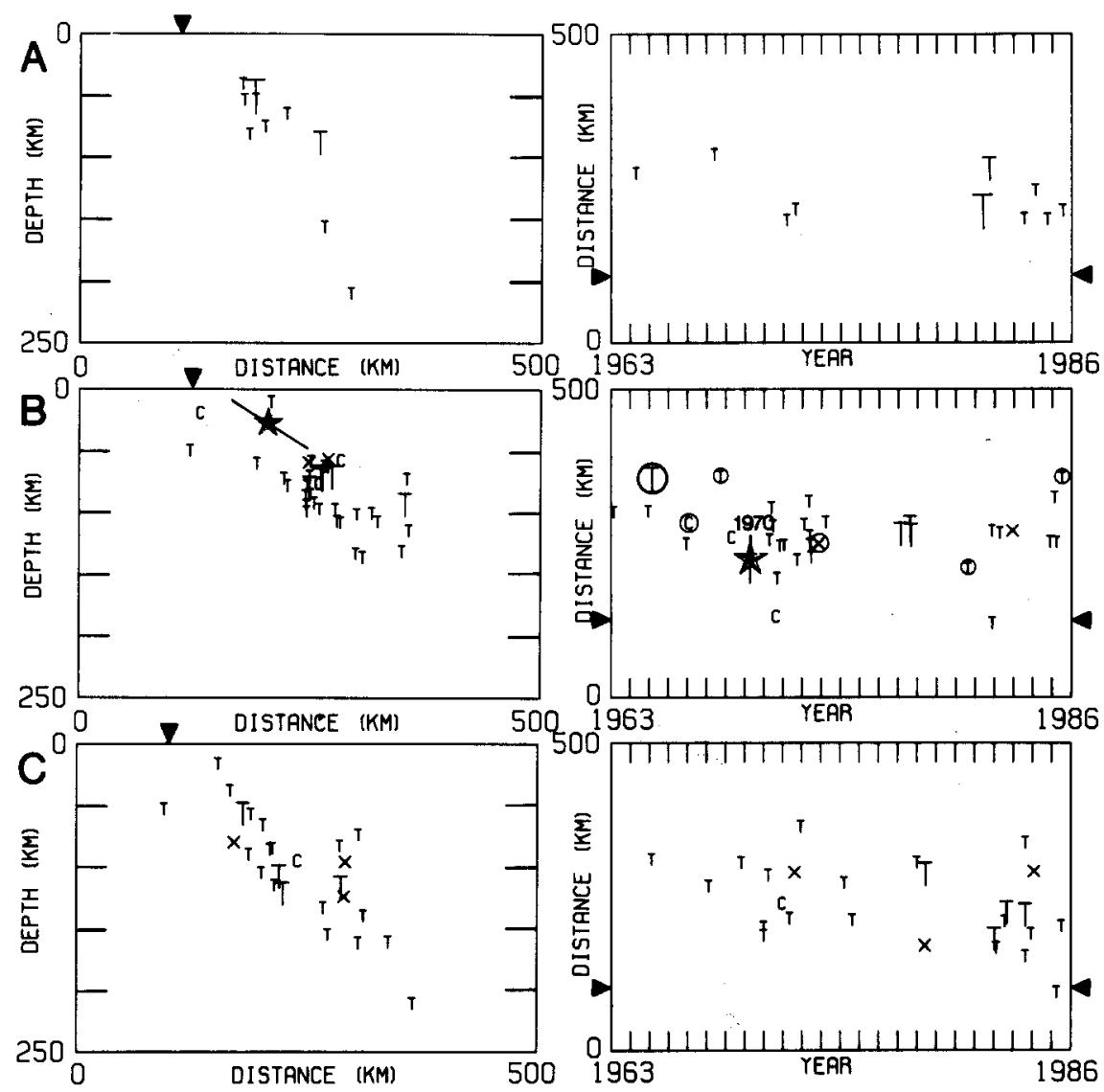

Fig. 13. Depth and time profiles of intraplate activity associated with seismic gaps or large thrust events in Central America for El Salvador (Row A), 1942/1950/1970 Guatemala (Row B) and Tehuantepec (Row C) regions. The corresponding arc segments are indicated by the unprimed letters in Fig. 12. The symbol conventions are the same as in. Fig. 7. The oxents in Row B on the right which are directly down-dip of the 1970 event are circled. 
potential for thrust events, but numerous large events did occur in the region between 1900 and 1930 (e.g., Astiz and Kanamori, 1984), as is true further south along the Nicaraguan coast.

Profiles of the time and depth history for events along Central America are shown in Fig. 13. The profile in Row A is for activity along $\mathrm{El} \mathrm{Salvador,}$ from $88^{\circ} \mathrm{W}$ to $90.5^{\circ} \mathrm{W}$. This region is a seismic gap in which tensional activity is very active and extends up to the down-dip edge of the interplate contact. A large $\left(M_{\mathrm{w}}=7.3\right)$ event occurred on June 19, 1982, at a depth near $52 \mathrm{~km}$, the detailed mechanism of which is given in Appendix A. This activity is consistent with the presence of a coupled interface, but no outer rise activity has occurred in the region to test this interpretation further. The arc segment along Nicaragua shows very similar intraplate activity (Fig. 12).

The intraplate mechanisms along Guatemala are shown in Row B of Fig. 13. The 1970 thrust event was preceded by an $m_{\mathrm{b}}=6.1$ tensional event in 1965 and a smaller tensional event in 1968 (the intraplate events near the 1970 rupture are circled to clarify the spatial relationships). A small outer rise tensional event occurred in 1981, and a small intermediate depth tensional event occurred in 1986. This region is thus consistent with a reduction in the intermediate depth tensional regime following the 1970 thrust. The 1970 thrust was also followed by an outer rise compressional event in 1971, which was located near the 1950 seismic gap (Christensen and Ruff, 1988). This suggests
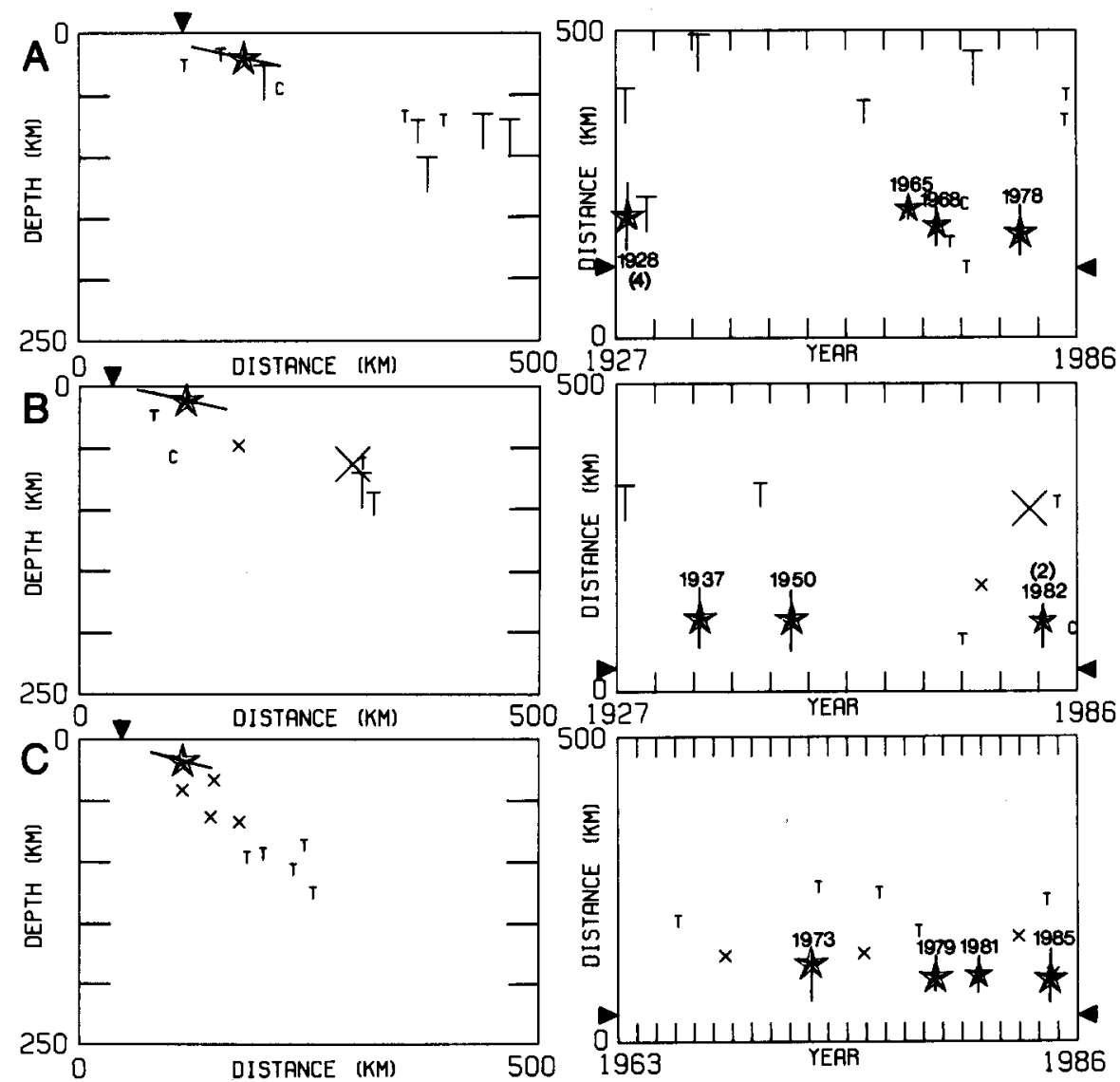

Fig. 14. Depth and time profiles of intraplate activity associated with large thrust events in Mexico in Oaxaca (Row A), Ometepec (Row B) and Michoacan (Row C). The corresponding arc segments are indicated by the primed letters in Fig. 12. The symbol conventions are the same as in Fig. 7. 
lateral loading of the outer rise of a locked zone by slip in an adjacent interplate segment, similar to that for the 1985 Chile and 1970 Peru regions. Other than one small compressional event in the 1942 zone, tensional activity has been dominant along the down-dip edge of the 1950 and 1942 rupture zones.

An example of intraplate activity in a region which may be subducting aseismically is shown in Row C, which is for the Tehuantepec region. Tensional events occur as deep as $200 \mathrm{~km}$, and extend right up to shallow depths, such as the January $24,1983\left(M_{\mathrm{w}}=6.8\right)$ event at a depth of $36 \mathrm{~km}$. It appears that there is no locked interface to disrupt the intraplate tensional stresses. Christensen and Ruff (1988) and Astiz et al. (1988) argue that in regions with weak seismic coupling, down-dip slab-pull can transfer all the way to shallow depths, even to the outer rise, possibly resulting in large trench events such as the 1977 Sumbawa and 1933 Sanriku earthquakes. Since the coupling on either side of the Tehuantepec Ridge is evidently moderately strong, it appears that in this region large tensional activity is distributed over a depth range of $150 \mathrm{~km}$ rather than concentrating at shallow depths.

Subduction along Mexico results in a complex distribution of intraplate activity, as shown in Fig. 14. Along Oaxaca (Row $A$ and region $A^{\prime}$ in Fig. 12) and Ometepec (Row B and region $B^{\prime}$ in Fig. 12) the historic record of focal mechanisms for large intraplate events has been extended back to 1928 by the work of Jimenez (1977), Singh et al. (1985) and Gonzalez-Ruiz (1986). The seismic record in Oaxaca covers two cycles of rupture of the interplate contact. Four events with $M_{\mathrm{s}}>7.4$ occurred in the region in 1928 (Singh et al., 1981). A large tensional event occurred several hundred kilometers down-dip after the first of these events. In 1931, a great normal faulting event $\left(M_{\mathrm{w}}=8.0\right)$ occurred in the region of the 1928 and 1978 thrusts (Singh et al., 1985). This tensional event may be located inland from the interplate contact, in which case it is not consistent with the dynamic stress model. However, the location of the event is somewhat uncertain, and the event is large enough to represent a lithospheric detachment event. Tensional events in 1937 and 1959 occurred in the distant down-dip region followed by the 1965 $\left(M_{\mathrm{w}}=7.5\right)$ and $1968\left(M_{\mathrm{w}}=7.3\right)$ interplate thrust events. An outer rise tensional event followed the 1968 thrust and a small compressional event occurred in 1972 down-dip of the future $1978\left(M_{\mathrm{w}}\right.$ $=7.6)$ thrust event. The 1973 Orizaba $\left(M_{\mathrm{w}}=7.0\right)$ tensional event also preceded the 1978 thrust, and smaller tensional activity has continued in the distant down-dip region. Any temporal relationship between intraplate and interplate activity in the region is clearly rather complex. The 200-300 $\mathrm{km}$ distance between the down-dip activity and the thrust interface, combined with the moderate size of the thrust activity, may account for the lack of temporal coupling.

A somewhat clearer temporal pattern is exhibited in the Ometepec region, northwest of Oaxaca (Fig. 14, Row B). Gonzalez-Ruiz (1986) documented the occurrence of normal faulting events down-dip (about $200 \mathrm{~km}$ ) from the Ometepec region within varying time intervals before four interplate thrusts. The earliest of these events occurred in the 1880s and focal mechanisms could not be determined; however, Jimenez (1977) did determine mechanisms for the tensional intraplate events in 1928 and 1945, which preceded interplate thrusts in 1937 and 1950. The large Huajuapan normal faulting event in $\mathbf{1 9 8 0}$ occurred just before the 1982 doublet thrust events (Astiz and Kanamori, 1984). However, as shown in Appendix A and by Gonzalez-Ruiz (1986), the Huajuapan event does not fit in the tensional category. Gonzalez-Ruiz has argued that continental loading may be responsible for the mechanism of this event. A small compressional event occurred adjacent to the 1982 doublet $\left(M_{\mathrm{w}}=7.0\right.$, 6.9) in 1986. The temporal connection between the interplate activity and the distant intraplate activity normal faulting events is certainly stronger than in the Oaxaca region, but it remains very difficult to establish the significance of the temporal pattern.

Along the Michoacan region (Fig. 14, Row C and region $C^{\prime}$ in Fig. 12) there have been five recent large thrust events: $1973\left(M_{\mathrm{w}}=7.6\right), 1979$ $\left(M_{\mathrm{w}}=7.6\right), 1981\left(M_{\mathrm{w}}=7.3\right)$, September 19, 1985 $\left(M_{\mathrm{w}}=8.0\right)$ and September 21, $1985\left(M_{\mathrm{w}}=7.6\right)$, indicating moderately strong coupling in the re- 
gion of the subducting Orozco fracture zone. The 1973 Colima event was preceded by a tensional event on February 27, 1966, while a tensional event occurred 6 months after the event northwest of the rupture zone (Fig. 12). A tensional event occurred in 1976 down-dip of the 1979 Petatlan thrust, while in 1973 and 1978 tensional events occurred down-dip of the 1981 Playa Azul rupture. Eastward from the Petatlan event, down-dip of the Guerrero gap, tensional events occurred in $1964\left(M_{\mathrm{w}}=7.3\right), 1967,1976$ and 1978 , which may reflect a strongly coupled interface in the seismic gap region. A small $\left(m_{\mathrm{b}}=5.2\right)$ event on May 28 , 1985, down-dip of the Playa Azul event preceded the 1985 thrusts (McNally et al., 1986). The latter thrusts ruptured on both sides of the 1981 failure zone. McNally and Gonzalez-Ruiz (1985) and McNally et al. (1986) have interpreted the intraplate activity along the Michoacan region in the context of a whole earthquake cycle, in which there is an up-dip migration of tensional stress, seismic quiescence on the future thrust rupture zone, and subsequent large thrusting. The observations along Michoacan in Fig. 14 are basically consistent with the stress gauge dynamic stress model in Fig. 2, which does not necessarily imply migration of activity, but does predict temporal modulation of activity within the slab.

\section{Alaska-Aleutian Islands}

The subduction zone along Alaska is believed to be a region of very strong seismic coupling on the basis of the great $1964\left(M_{\mathrm{w}}=9.2\right)$ thrust event. Figure 15 demonstrates the interesting sparseness of large intraplate ruptures in this region, similar to that for the 1960 Chile zone (Fig. 5), but with far less outer rise activity. All intermediate depth events with $m_{b} \geq 6.0$ since 1963 have mechanisms included in Fig. 15. The sole outer rise event seaward of the 1964 zone is a tensional event (Christensen and Ruff, 1988) that followed the thrust. All of the activity shown near the 1964 rupture zone occurred after the thrust event, with the exception of a single oblique event in 1954. Unlike the 1960 Chile event, intermediate depth tensional activity has occurred in the region fol-

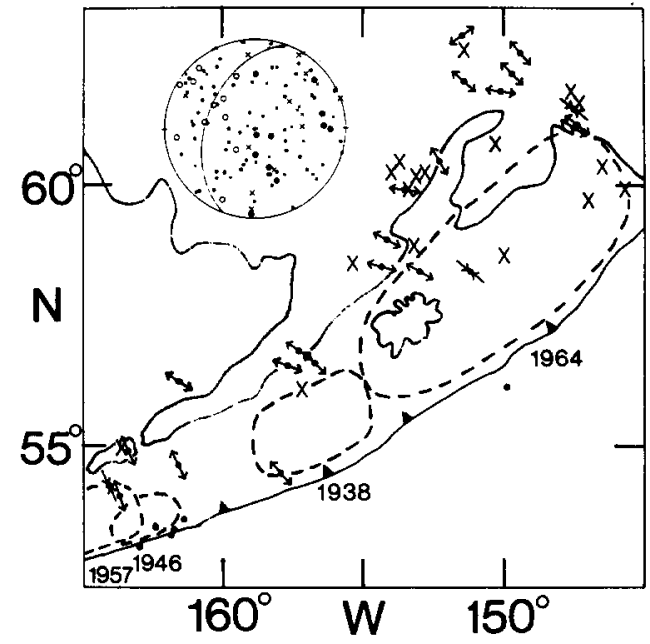

Fig. 15. Intraplate earthquakes within the subducting plate along Alaska. The conventions are the same as in Fig. 5.

lowing the main thrust, with a single small compressional event in 1967 located within the rupture zone. Most mechanisms near the northeastern end of the rupture zone involve complex deformation and tearing of the Pacific plate.

Only tensional activity has occurred down-dip of the 1938 rupture zone and the adjacent Shumagin seismic gap, consistent with down-dip slab-pull concentrating stress at the edge of a coupled interplate contact. Several tensional outer rise events occurred following the 1957 Fox Island ( $M_{\mathrm{w}}=9.1$ ) rupture at the easternmost end of the aftershock area, which overlaps the 1946 rupture zone. There is evidence for a double Benioff zone in this region, given the close proximity of the compressional and tensional events at the downdip edge of the easternmost end of the 1957 zone (House and Jacob, 1983; Hudnut and Taber, 1987).

The rupture zone of the great 1957 Aleutian event extends westward along the Aleutian arc to $180^{\circ} \mathrm{W}$. The intraplate activity in this region, and along the westward extension of the arc where the 1965 Rat Island $\left(M_{\mathrm{w}}=8.7\right)$ event ruptured, is shown in Fig. 16. While there are only four intermediate depth events with $m_{\mathrm{b}} \geq 6.0$ in the region, it is clear that, unlike most subduction zones in which seismicity extends to a maximum depth of $300 \mathrm{~km}$, compressional activity dominates in the Aleutian arc. The outer rise has had numerous 


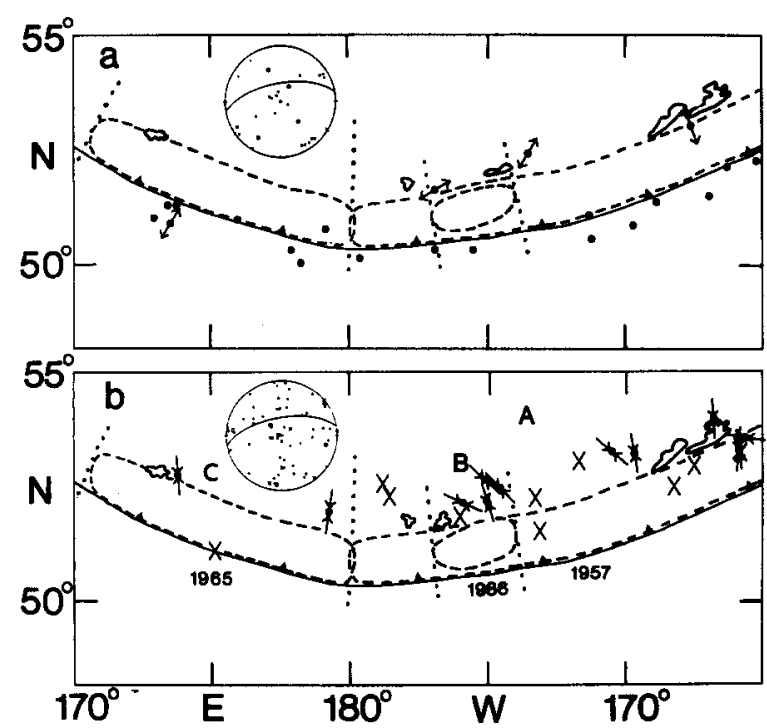

Fig. 16. Intraplate earthquakes within the subducting Pacific plate along the Aleutian Islands. The symbol conventions are the same as in Fig. 5 for (a) tensional and (b) compressional and tear/oblique events. The dip of the subduction zone at intermediate depth along the eastern Aleutians is shown in the focal sphere. The dotted lines and associated letters indicate the arc segments for which cross-sections are shown in Fig. 18. Note that region A extends along the entire 1957 rupture zone.

tensional events, all of which followed either the 1957 or 1965 thrusts (Stauder, 1968a, b, 1972; Abe, 1972a; Spence, 1977; Christensen and Ruff, 1988). Compressional activity at intermediate depth has been distributed all along the arc, but no outer rise compressional events have been detected in the region.

The concentration of activity in the vicinity of the 1986 thrust is rather intriguing. The focal mechanisms of the intermediate depth events in this region are shown in Fig. 17. The 1955 tensional event preceded the 1957 thrust, with subsequent activity in the region up until 1976 all being of compressional or oblique category, with the exception of the two outer rise tensional events. The latter events occurred in $1958\left(175.4^{\circ} \mathrm{W}\right)$ and $1984\left(176.8^{\circ} \mathrm{W}\right)$. The two 1986 events in Fig. 17 follow the thrust event, and are located near the edges of the rupture zone. The temporal pattern of this activity is generally consistent with the dynamic model.
The time and depth characteristics of the Aleutian Island activity are presented in Fig. 18. Both the 1957 (Row A) and 1965 (Row C) thrusts show striking activation of the outer rise tensional activity following the interplate events. The 1957 event was preceded by one large tensional event at intermediate depth in 1955, and subsequent activity has been predominantly compressional, although the latter events are located at greater depths than the tensional events that preceded and followed the thrust. House and Jacob (1983) noted this temporal pattern and discussed the possibility that the large thrust event was responsible for the compressional activity, but preferred to interpret. the variation in mechanism in terms of a double Benioff zone. The 1986 event (Row B), located as it is within the 1957 rupture zone, provides a strong suggestion of temporal variation in activity from deeper compressional events to quiescence at intermediate depths preceding the thrust. The 1965 Rat Island event was followed by sparse compres-

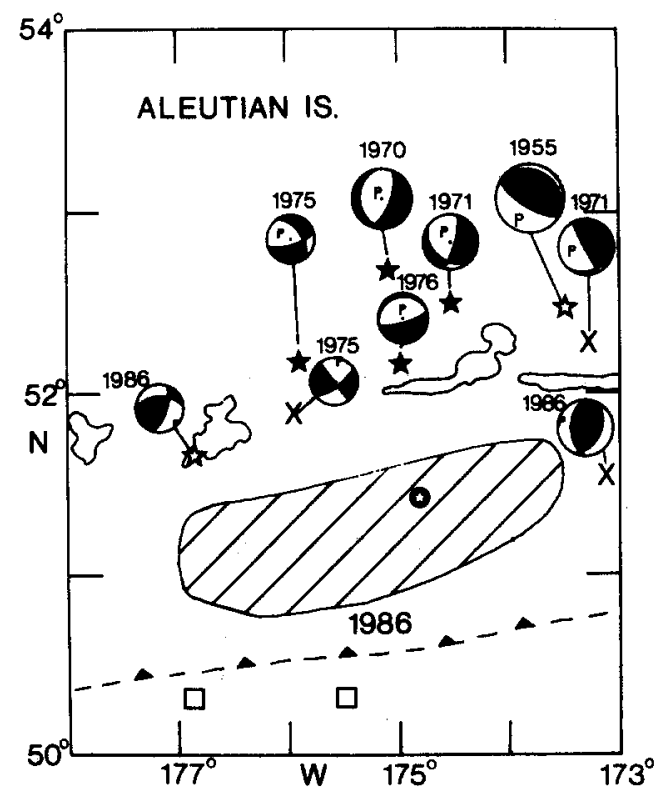

Fig. 17. Intraplate activity associated with the 1986 Aleutian event. The symbol conventions are the same as in Figs. 1 and 6. The outer rise events are actually tensional events that followed the 1957 rupture, and thus occurred before the 1986 event. 

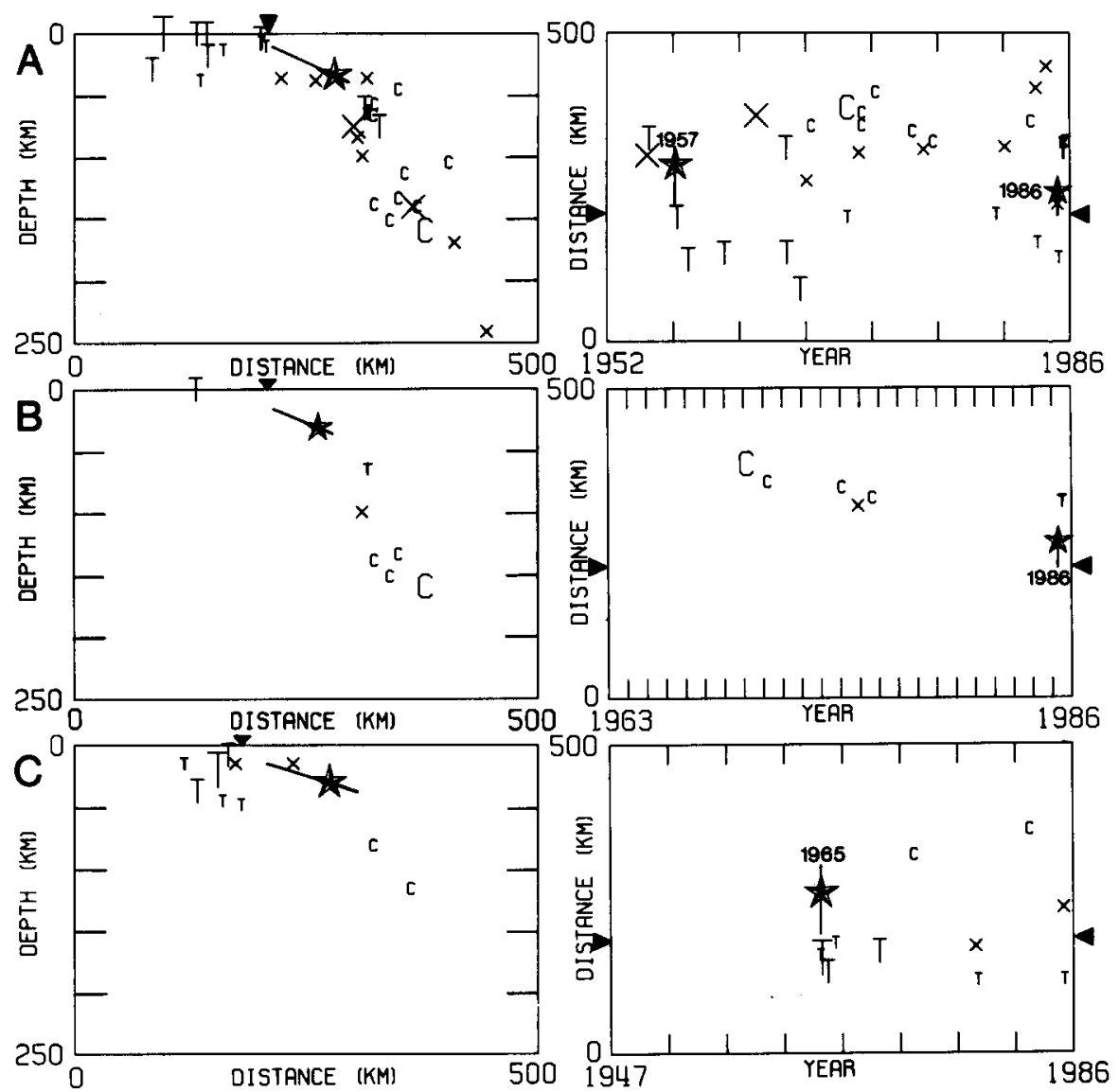

Fig. 18. Depth and time profiles of intraplate activity associated with large thrust events along the Aleutians in 1957/1986 (Row A), 1986 (Row B) and 1965 (Row C). The corresponding arc segments are indicated in Fig. 16. The symbol conventions are the same as in Fig 7.

sional activity at intermediate depths and tensional activity in the outer rise.

\section{Kamchatka-Kurile Islands-northern Japan}

The subducting Pacific plate along the Kurile Islands arc has bountiful intraplate activity, as shown in Fig. 19. This catalog of known mechanisms gives a good spatial representation of the regional seismicity with $m_{\mathrm{b}} \geq 5.5$ since 1963 in the NOAA catalog. A few intermediate depth events with $m_{\mathrm{b}} \geq 6.0$ do lack published focal mechanisms. This region is characterized as being strongly coupled along the $1952\left(M_{\mathrm{w}}=9.0\right)$ rup- ture zone and well-coupled along the rest of the trench, with a region of uncertain seismic coupling between the 1963 Kurile Island and 1952 Kamchatka events. The latter region, which we call the Kurile gap (see McCann et al., 1979, for discussion) is of particular interest in that several outer rise compressional events have occurred along the gap, including the large $\left(M_{\mathrm{s}}=7.7\right)$ event of March 16, 1963 (Christensen and Ruff, 1987). It is intriguing that the northern half of this gap has active tensional and compressional intermediate depth intraplate activity, indicative of a double Benioff zone (Veith, 1974; Stauder and Mualchin, 1976), while the southern half of the gap, directly down-dip of the 1963 outer rise com- 


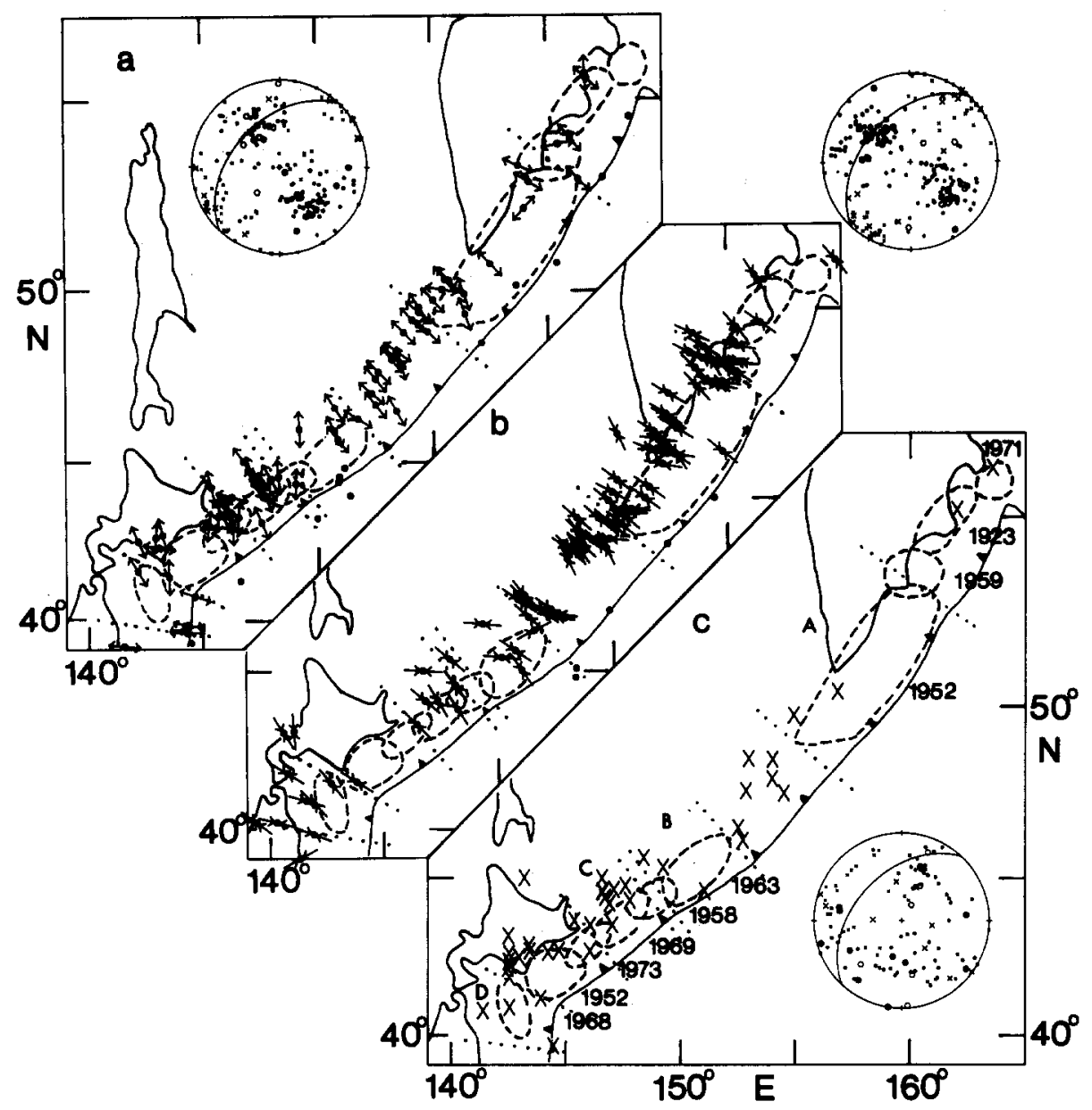

Fig. 19. Intraplate earthquakes within the subducting Pacific plate along the Kamchatka-Kurile Islands-northern Japan zone. The conventions are the same as in Fig. 5 for (a) tensional, (b) compressional and (c) tear/oblique category events. The dotted lines and associated letters indicate the arc segments for which cross-sections are shown in Fig. 20.

pressional event, has only tensional activity at intermediate depth, consistent with the presence of a locked interface.

Compressional activity dominates at the downdip edge of the 1952 and $1959\left(M_{\mathrm{s}}=8.2\right)$ Kamchatka rupture zones. There have been several tensional events down-dip of the Kamchatka thrust during the last 25 years, indicating that a double Benioff zone may extend through this region. Tensional outer rise activity along this area followed the thrust events, although since 1978 there have been two outer rise compressional events up-dip of the 1952 rupture zone. The temporal intermixing of tensional and compressional activity in the outer rise is suggestive of bending stresses in this region (Chapple and Forsyth, 1979) or of accumulating strain due to a recoupled interplate contact (Christensen and Ruff, 1988).

The Kurile Islands region exhibits a complex mixture of tensional, compressional and tear/oblique faulting, with complicated spatial relationships to the interplate thrust events. The 1952 Hokkaido $\left(M_{\mathrm{w}}=8.1\right)$ event is distinctive in lacking activity of any type other than tear faulting directly down-dip. This may be owing to the proximity of the lateral bend in the subducting plate near Hokkaido. The focal mechanisms for many additional small events in this region have been determined by Sasatani (1976). The spatial distribution of tensional and compressional inter- 
mediate depth events along the other Kurile thrust zones is suggestive of a double Benioff zone, while only tensional events following the main thrusts have occurred in the outer rise. Down-dip of the 1968 Tokachi-Oki $\left(M_{\mathrm{w}}=8.2\right)$ event compressional activity is dominant. Several very large tear faulting events have occurred near the Hokkaido corner as well as down-dip of the $1973\left(M_{\mathrm{w}}=7.8\right)$ rupture zone.

No intraplate focal mechanisms are known for events preceding the 1952 Kamchatka thrust, so the time sequence (Fig. 20, Row A) is one-sided with respect to the thrust. While two large compressional events followed the thrust within 1 year,
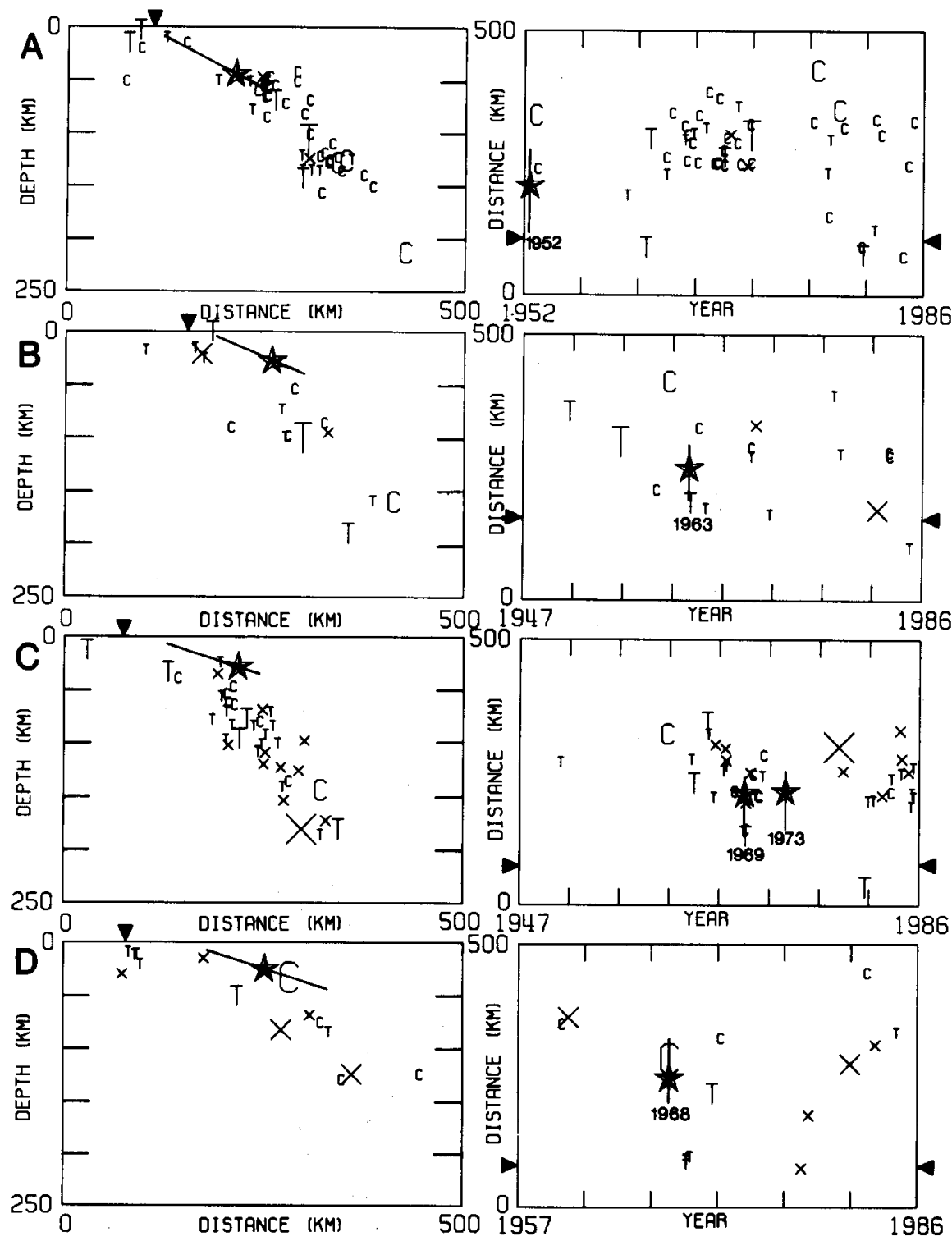

Fig. 20. Depth and time profiles of intraplate activity associated with large thrust events along the Kamchatka-Kurile Islands-northern Japan region in 1952 (Row A), 1963 (Row B), 1969/1973 (Row C) and 1968 Tokachi-Oki (Row D). The corresponding arc segments are indicated in Fig. 19. The symbol conventions are the same as in Fig. 7. 
subsequent activity has involved both large tensional and large compressional events. The outer rise also appears to exhibit a period of principally tensional activity followed by more recent mixed behavior. This suggests that intraplate stresses are nearly in equilibrium, producing double seismic zones in both intermediate depth and outer rise regions, following the model of Fujita and Kanamori (1981).

The 1963 Kurile Island event $\left(M_{\mathrm{w}}=8.5\right)$ was preceded by several large tensional events at the down-dip edge of the interplate contact (Fig. 20, Row B), as well as a deeper compressional event. A small compressional event that is perhaps too far inland to be called an outer rise event also preceded the thrust, and tensional activity in the outer rise followed the mainshock. The region of large down-dip tensional events prior to the thrust has had a mixture of small compressional and tensional events since the 1963 rupture, consistent with the temporal variation of the dynamic model.

Intraplate activity near the overlapping 1969 $\left(M_{\mathrm{w}}=8.2\right)$ and $1973\left(M_{\mathrm{w}}=7.8\right)$ rupture zones (Fig. 20, Row C) is mixed, but has a general pattern similar to that in the 1963 zone. Relatively large tensional events occurred down-dip of the thrust zones prior to the events, along with a deeper compressional shock. Following the events, smaller tensional and compressional activity has continued in the vicinity of the earlier tensional events. Two tensional events seaward of the 1969 rupture zone followed the mainshock, with the event in the outer rise actually located up-dip of where the 1969 and $1958\left(M_{\mathrm{w}}=8.3\right)$ rupture zones overlap (Fig. 19). A small compressional event occurred seaward of the 1969 rupture as well, 3 days after the thrust.

The 1968 Tokachi-Oki event (Fig. 20, Row D) is located in a region of strong distortion of the subducting slab, and presents a rather complex intraplate stress distribution. Outer rise tensional events followed the mainshock, while at intermediate depths the activity shows no simple relation to the thrust event. The large $1968\left(M_{\mathrm{s}}=7.5\right)$ normal faulting aftershock of the thrust event (Kanamori, 1971) does have down-dip compression consistent with a transient increase in the intraplate compressional stress. Kanamori (1971) has argued that the geometric complexity of the distorted slab played a role in concentrating the shallow compressional stresses following the interplate thrust, which is consistent with the general dynamic model concept in Fig. 2b. On August 2, 1971, a large tensional event $\left(M_{\mathrm{s}}=7.0\right)$ occurred just to the northeast of the 1968 rupture zone (Fig. 19), which suggests that slip in the 1968 event induced lateral loading of the adjacent arc segment south of the 1952 rupture zone.

\section{New Britain-Solomon Islands}

The Solomon Islands region has very active seismicity in both the interplate and intraplate environments. The Solomon plate is subducting toward the north along the New Britain trench and toward the northeast along the Solomon trench (Fig. 21). A fairly large number of events in the NOAA catalog with $5.5 \leq m_{\mathrm{b}}<6.0$ lack reliable focal mechanisms in this region, and the steep dip of the subducting slab presents some difficulty in distinguishing intraplate tensional events from interplate thrusts. This is compounded by a general tendency for the catalog source depths of large interplate events in this region to be greater than in other zones. Thus, given the caveat that a few tensional events may have been omitted or misidentified, the general characteristics of the activity in this region can be considered.

Numerous tensional events have occurred in the outer rise following the 1971 and 1975 interplate doublets (see Lay and Kanamori, 1980, for a discussion of the thrusts). Tensional events with steeply dipping tension axes are located at intermediate depth near the leading edge of the coupled zone throughout the region. Similarly, compressional events, with much more variable stress axis orientations, are distributed along the entire arc. Numerous tear faults and oblique mechanisms are also found in the region, suggesting complexity of the intraplate stress regime owing to the lateral bending of the Solomon plate. Two compressional events near the outer rise have occurred in the southwestern New Britain trench (Christensen and Ruff, 1988), one of which is in close proximity to a tensional outer rise event. 


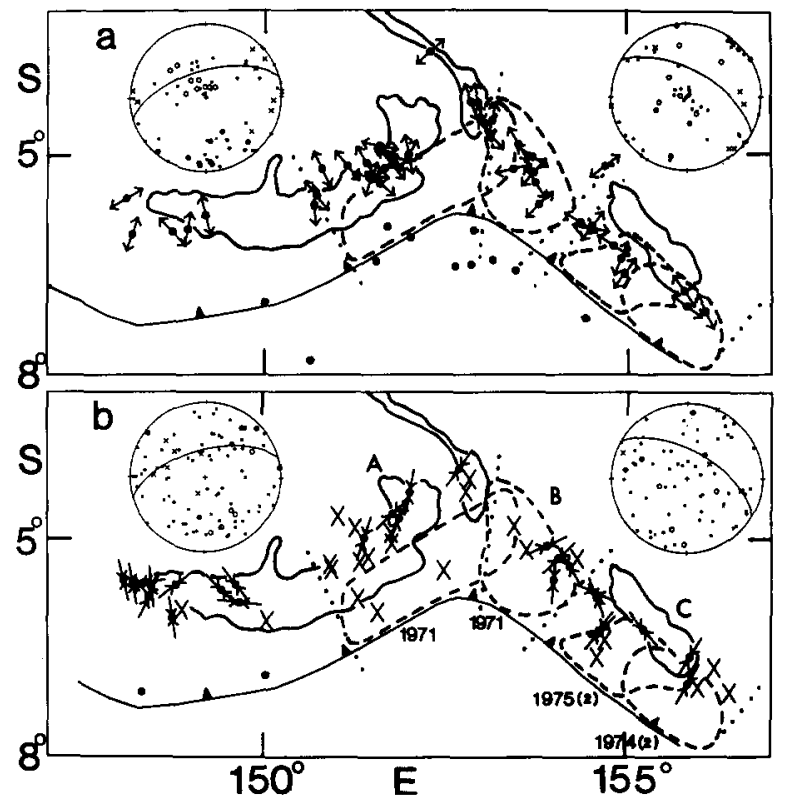

Fig. 21. Intraplate earthquakes within the subducting Solomon plate. The symbol conventions are the same as in Fig. 5 for (a) tensional and (b) compressional or tear/oblique events. The pressure, tension and intermediate axes are plotted in separate focal spheres for events in the New Britain trench (left) and Solomon trench (right) in both figures. The dotted lines and associated letters indicate the arc segments for which cross-sections are shown in Fig. 22.

This area is considered to be a seismic gap with some potential for a large thrust event (McCann et al., 1979), although the exact nature of the previous large events in the region in 1945 and 1946 is not well understood. Both tensional and compressional activity at intermediate depths is observed in this region, indicative of double Benioff zone stresses; however, the largest event was a tensional event $\left(M_{\mathrm{w}}=6.6\right.$, February 24,1981$)$. The northward convergence of New Guinea appears to complicate the intraplate stress regime in this region, making it difficult to go further in appraising the interplate seismic potential.

The July 26, $1971\left(M_{\mathrm{w}}=8.1\right)$ earthquake was accompanied by temporal variation in intraplate activity (Fig. 22, Row A). Prior to the thrust, several tensional events occurred down-dip of the thrust contact, while somewhat deeper compressional activity took place for 10 years following the thrust. After 1980, tensional activity resumed in the shallower region. The outer rise had several large tensional events after the thrust, and no compressional events have occurred in the region.

The July 14, $1971\left(M_{\mathrm{w}}=8.0\right)$ Solomon Island event ruptured the northwest portion of the trench, with a rather oblique mechanism (Lay and Kanamori, 1980). This thrust may involve a change in mechanism during the rupture, but is probably an interplate event (Schwartz et al., 1989). There was mixed tensional and compressional activity at intermediate depth prior to the thrust (Fig. 22, Row B), with a large tensional event near the epicenter on July $19,1971\left(M_{\mathrm{s}}=7.1\right)$, and a large compressional event on September 28, 1971 ( $d=$ $107 \mathrm{~km}, M_{\mathrm{s}}=6.6$ ) down-dip of the event. The latter event is consistent with enhanced compressional stress down-dip following the thrust, while the tensional outer rise event following the mainshock is also consistent with the dynamic stress model. However, the July 19 event occurred in the 12-day interval between the two 1971 thrust events, and it is unclear what relation it may have to the doublet. Large intermediate depth tensional events in 1983 occurred in the northwestern region of the rupture zone. It appears that lateral contortion of the slab near this bend dominates the stress regime.

The two pairs of large interplate earthquakes in $1974\left(M_{\mathrm{w}}=7.3,7.4\right)$ and $1975\left(M_{\mathrm{w}}=7.7,7.4\right)$ are associated with little temporal variation of intraplate activity (Fig. 22, Row C) other than the occurrence of an outer rise tensional event in 1977 seaward of the 1975 ruptures. These events are all relatively small, so little temporal variation in the intraplate environment is to be expected.

\section{New Hebrides}

The New Hebrides is a region of moderate to weak seismic coupling, similar to the Solomon Islands in demonstrating a tendency for temporal clustering of large thrust events (Lay et al., 1982). The steep dip of the subducting plate again complicates the segregation of interplate thrusts from shallow tensional intraplate events. Figure 23 indicates the high level of activity in this arc, with the region around $18^{\circ} \mathrm{S}$ also having diminished activ- 


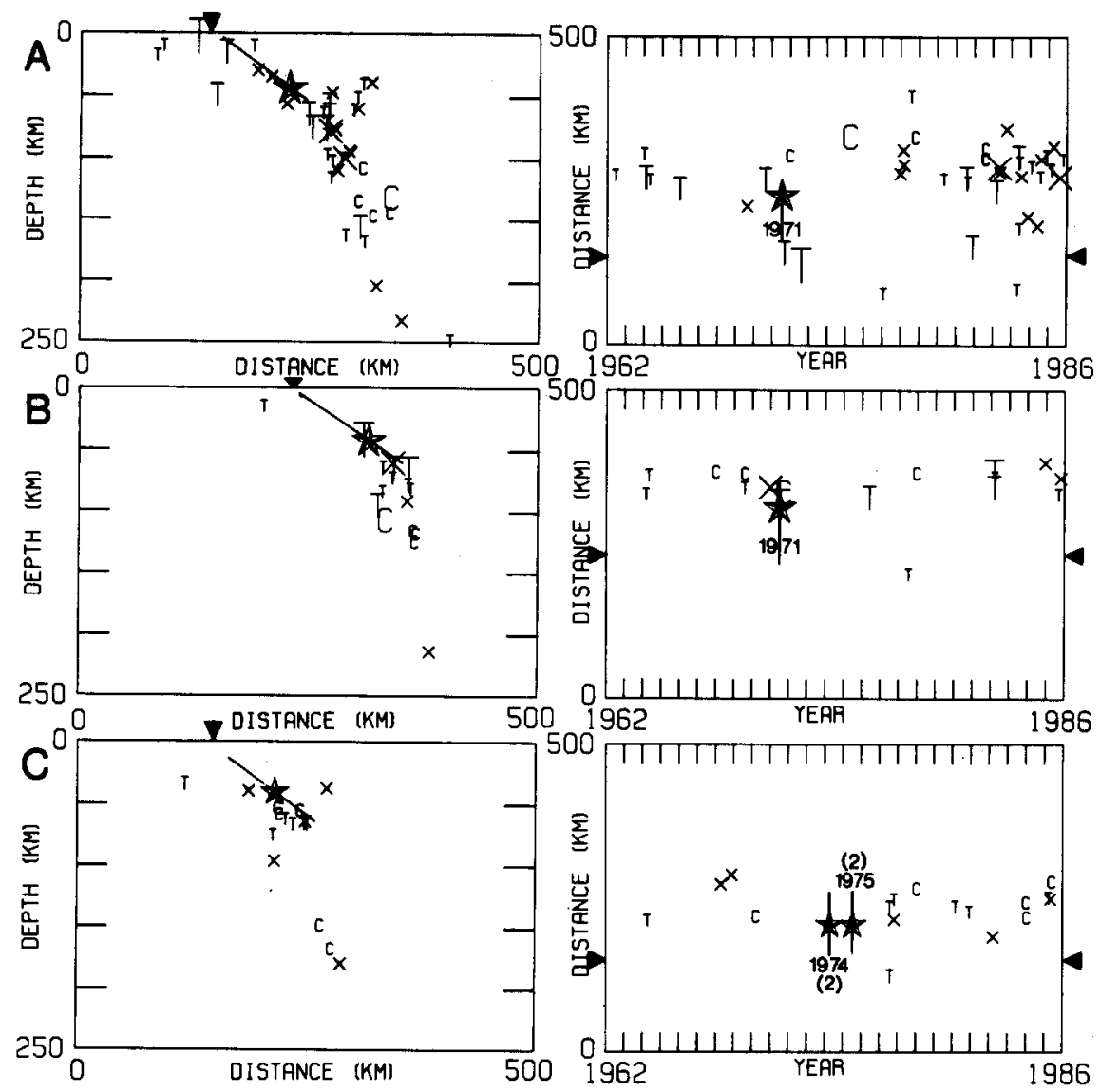

Fig. 22. Depth and time profiles of intraplate activity associated with large thrust events in the New Britain-Solomon Islands region in 1971 (Row A: New Britain), 1971 (Row B: Solomon Islands), and 1974/1975 (Row C: Solomon Islands). The corresponding arc segments are indicated in Fig. 21. The symbol conventions are the same as in Fig. 7.

ity in the NOAA catalog. Many tensional and compressional events are located down-dip from the 1980 Santa Cruz $\left(M_{w}=7.5,7.8\right)$ events in the north, and the $1973\left(M_{\mathrm{s}}=7.9\right)$ event. Tensional activity dominates along the $1965\left(M_{\mathrm{w}}=7.6\right)$ region and near $19^{\circ} \mathrm{S}$, while compressional activity is common north of the $1980\left(M_{\mathrm{w}}=7.2,7.5\right)$ Loyalty Islands (near $22^{\circ} \mathrm{S}$ ) events. Numerous tear fault mechanisms are located along the Loyalty Islands region, associated with the curve at the southern end of the arc.

Outer rise activity along the New Hebrides has principally involved tensional events following the ruptures in 1972, 1980 and 1965 (Christensen and Ruff, 1988). A complex sequence of events, involving both tensional and oblique mechanisms oc- curred in 1985, seaward of and preceding the December 21, $1985\left(M_{w}=7.1\right)$ thrust event. These events are located north of the intersection of the D'Entrecasteaux fracture zone and the trench. Just to the north of this region both tensional and compressional outer rise events have occurred in a seismic gap (Christensen and Ruff, 1988), which also has both tensional and compressional intermediate depth activity. No other compressional outer rise events are known to have occurred in the region.

The temporal and depth distributions of intraplate events along the larger interplate rupture zones in the northern New Hebrides are shown in Fig. 24. The 1980 Santa Cruz event (Row A) has both tensional and compressional (notably in 1978) 


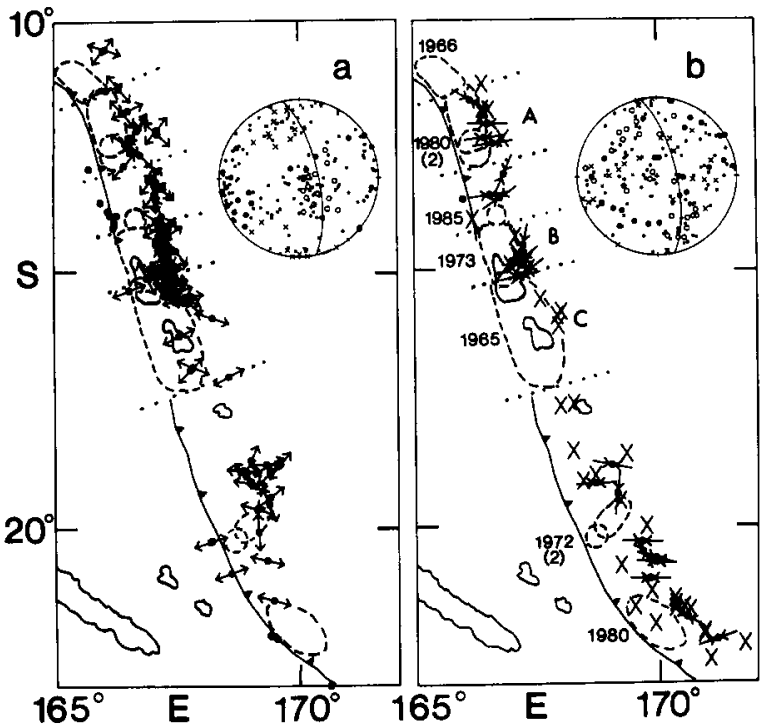

Fig. 23. Intraplate earthquakes within the subducting plate along the New Hebrides. The symbol conventions are the same as in Fig. 5 for (a) tensional and (b) compressional or tear/oblique events. The dotted lines and associated letters indicate the arc segments for which cross-sections are shown in Fig. 24.

activity at the down-dip edge of the rupture zone prior to the thrust, with mixed behavior afterward as well, along with a solitary outer rise event. Note that there is some depth separation of the compressional and tensional events in this region, as well as along the 1973 zone (Row B). Some of the larger events in the region involve oblique faulting suggestive of lateral segmentation of the subducting slab.

The 1973 thrust was preceded by some tensional and tear faulting events below $100 \mathrm{~km}$ depth, and was followed on the day after the mainshock by the December 29, $1973\left(M_{\mathrm{s}}=7.2\right)$ tensional event at $47 \mathrm{~km}$ depth. Eleven months later a slightly deeper compressional event occurred, with deeper tear faulting taking place over the next 3 years. Subsequently, deep tensional and shallower compressional activity has occurred.

The 1965 thrust event (Row C) was preceded by two large tensional events in 1963 and 1964 at depths around $130 \mathrm{~km}$. After the event, numerous tensional and tear faulting ruptures have taken place, with two events in the outer rise and one large event within the rupture zone. The only compressional event in the region occurred in
1974 at the northern end of the rupture area (see Fig. 22) where the 1973 and 1965 aftershock zones overlap.

The events along the New Hebrides do not suggest a simple temporal relation between intraplate and interplate regimes, possibly owing to the moderate size of the largest thrusts, the steep dip of the subducting slab (which appears to induce a mixed stress regime), and the abundance of tear faults that appear to reflect lateral contortion and segmentation of the slab.

\section{Tonga-Kermadec}

The intraplate activity along Tonga has been extensively studied (e.g., Isacks et al., 1969; Richter, 1979; Billington, 1980; Kawakatsu, 1986; Giardini and Woodhouse, 1984), and the intraplate mechanism catalog is probably complete for $m_{\mathrm{b}} \geq 5.5$. Figure 25 clearly demonstrates that there are numerous tensional events at intermediate depths in the Tonga portion of the arc, while the region is often characterized as being in compression at all depths. Kawakatsu (1986) has considered the occurrence of nearby tensional and compressional events as evidence for a double Benioff zone. In the northern portion of the arc the outer rise also has tensional and compressional events in close proximity. While some of this complexity may be attributed to the tear faulting deformation at the northern end of the arc, it appears that along much of the Tonga region the intraplate stresses are in a near-equilibrium state that favors the development of double seismic zones with mixed stresses (Fujita and Kanamori, 1981). From $20^{\circ} \mathrm{S}$ to $23^{\circ} \mathrm{S}$ only compressional activity is observed at intermediate depths. The seismic potential for large interplate thrust events along the Tonga arc north of $25^{\circ} \mathrm{S}$ is uncertain (McCann et al., 1979).

The Louisville Ridge intersects the arc near the jog in the trench at $25^{\circ} \mathrm{S}$, which is also the location of the $1982\left(M_{\mathrm{w}}=7.5\right)$ underthrusting event. Southward of this junction, the Kermadec arc is predominantly in tension at intermediate depths, although both compressional and tear faulting events are scattered along the region. The 

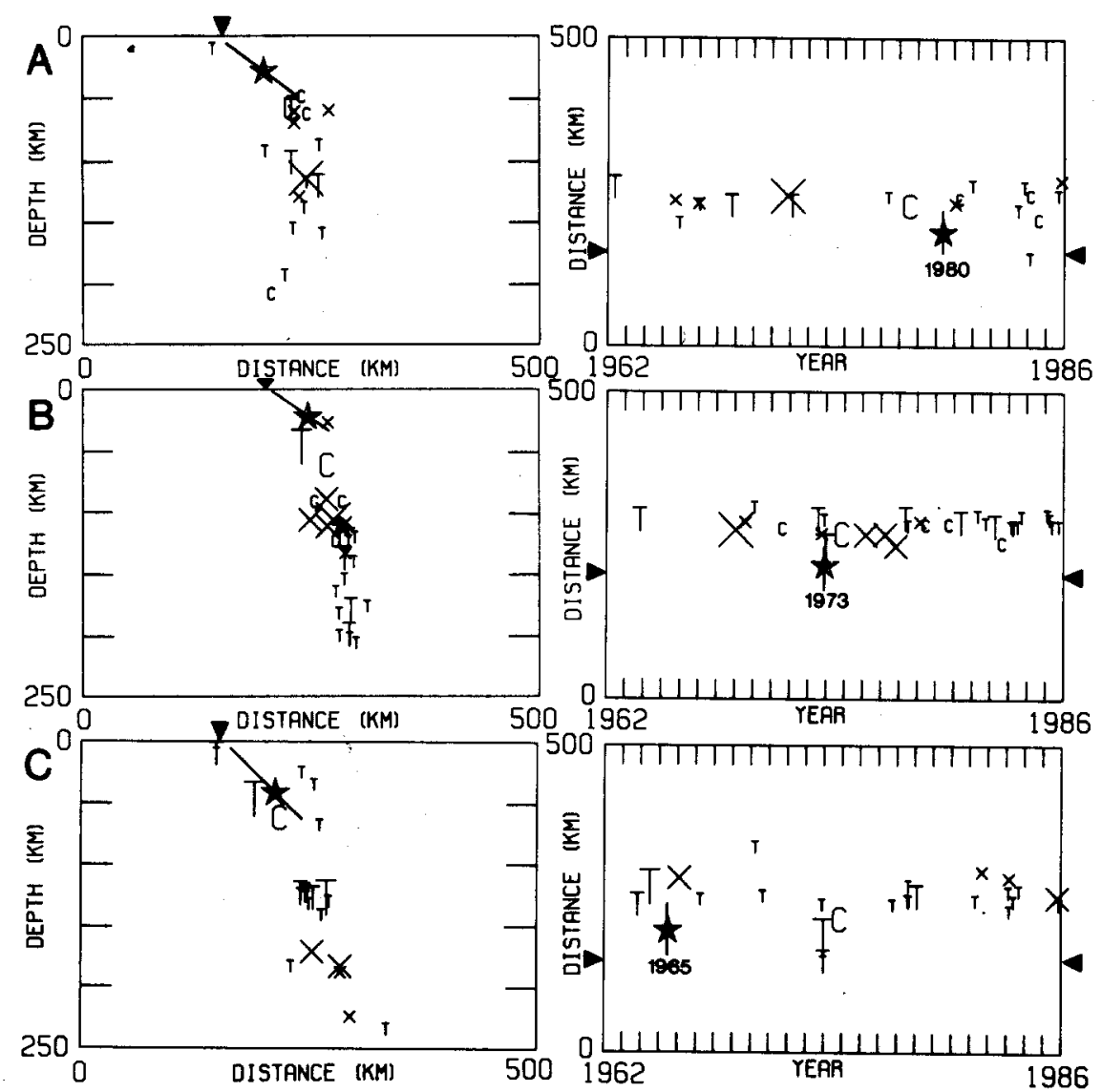

Fig. 24. Depth and time profiles of intraplate activity associated with large thrust events in the New Hebrides in 1980 (Row A), 1973 (Row B) and 1965 (Row C). The corresponding arc segments are indicated in Fig. 23. The symbol conventions are the same as in Fig. 7.

Kermadec zone appears to be moderately to strongly coupled in the region of the $1976\left(M_{\mathrm{s}}=\right.$ 7.7, 8.0), $1978\left(M_{\mathrm{w}}=7.0\right), 1968\left(M_{\mathrm{s}}=7.0\right)$ and $1986\left(M_{\mathrm{w}}=7.7\right)$ events. The mechanisms of these events have not been extensively studied, and there is some possibility that they are not all simple interplate thrusts, but we will consider them all to be thrusts for the present discussion.

The Louisville Ridge is believed to play a major role in affecting the stress regime in the Tonga arc (e.g., Isacks et al., 1969; Giardini and Woodhouse, 1984); however, this role is not exactly clear. Figure 26 shows the remarkable complexity of seismic activity above $300 \mathrm{~km}$ depth in the region where the Ridge impinges on the arc. A great diversity of large earthquake stress orientations is observed in the region. The outer rise has experienced two large events, a tensional event in 1977 studied by Eissler and Kanamori (1982), and a compressional event in 1975 studied by Christensen and Ruff (1988). The 1982 thrust event is the only large thrust event definitely known to involve interplate thrusting along the entire Tonga arc. All three of these events lie along the intersection of the Louisville Ridge with the arc. Along the down-dip projection of the Ridge, the great June 22, 1977 $\left(M_{\mathrm{w}}=8.0\right)$ normal faulting event occurred with a down-dip tension axis and a centroid depth near $70 \mathrm{~km}$. The next largest event in the region is the down-dip compressional event of April 13, 1980 $\left(M_{\mathrm{w}}=7.6\right)$ with a source depth of $165 \mathrm{~km}$. The detailed source processes of these five diverse events have been studied by Christensen and Lay (1988). 


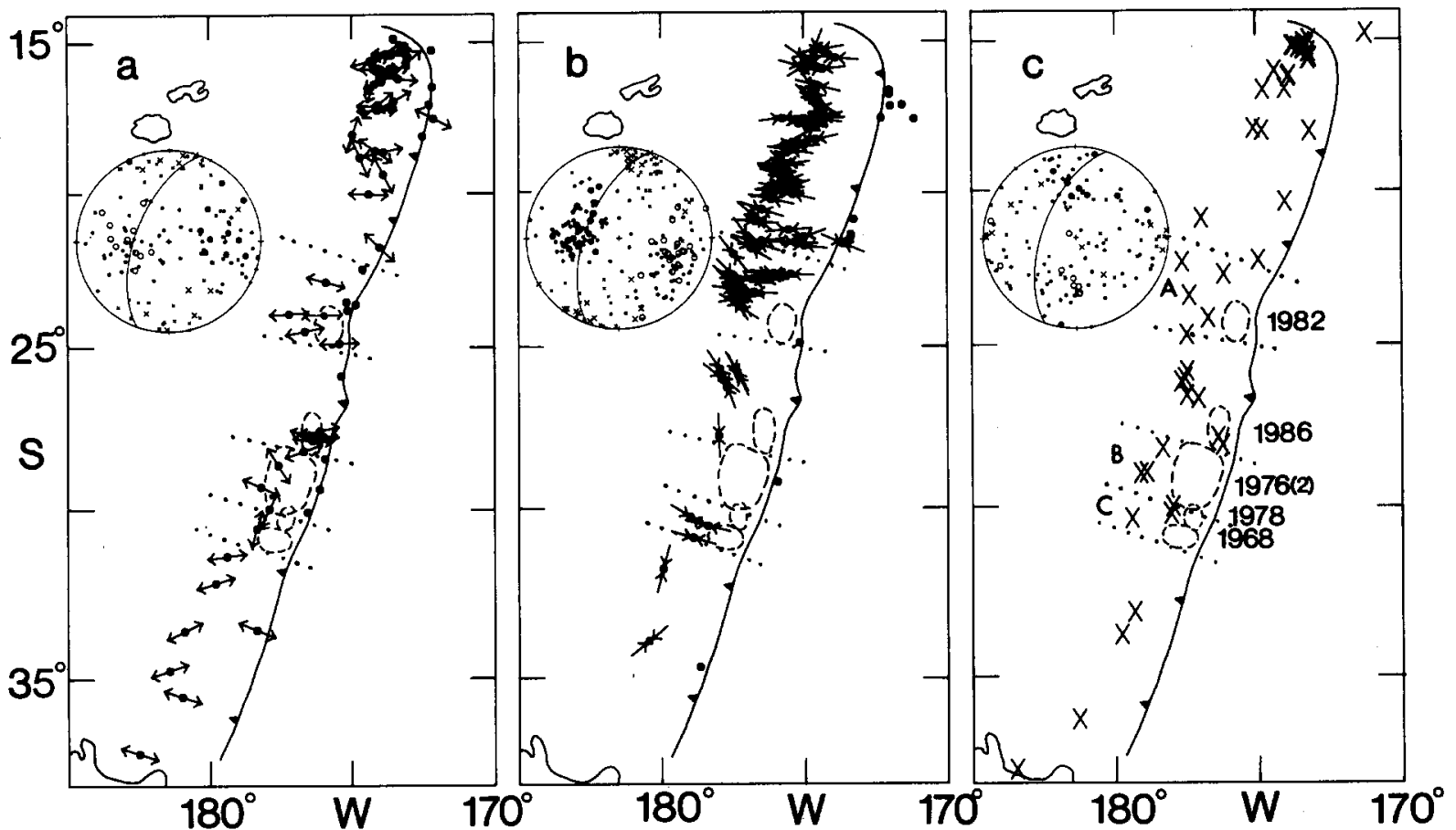

Fig. 25. Intraplate earthquakes within the subducting plate along the Tonga-Kermadec zone. The symbol conventions are the same as in Fig. 5 for (a) tensional, (b) compressional, and (c) tear/oblique events. The dip of the subducting slab at intermediate depths along Tonga is shown in the focal spheres. The dotted lines and associated numbers indicate the arc segments for which cross-sections are shown in Fig. 27.

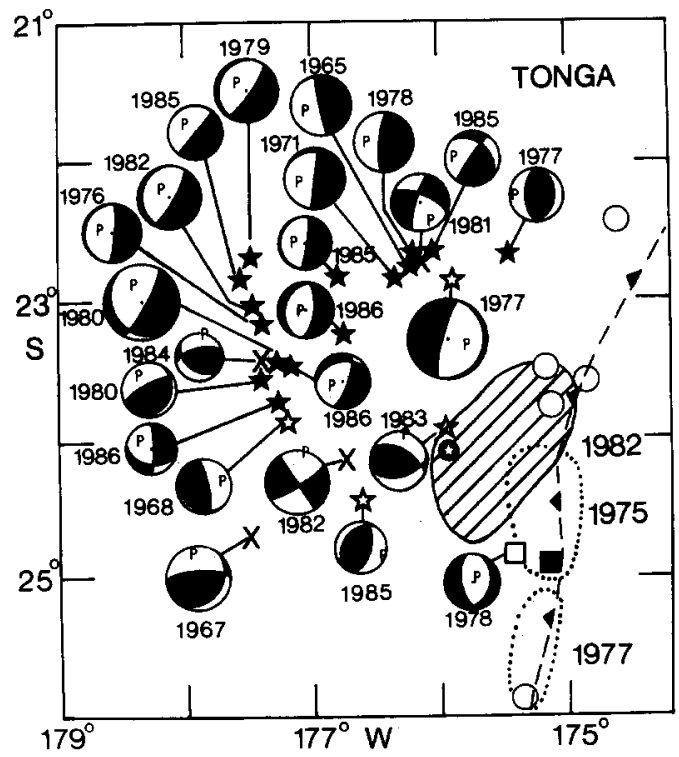

Fig. 26. Intraplate activity associated with the 1982 thrust event in Tonga. The symbol conventions are the same as in Figs. 1 and 6. The dotted aftershock zones are for the outer rise events in 1975 and 1977.
While any examination of the temporal relation between large intraplate activity and the 1982 thrust must be considered in the context of the perturbation of the stress regime caused by the Louisville Ridge, there are some interesting temporal features in Fig. 26. While the large 1975 outer rise compressional event did precede the thrust, there was also shallow outer rise tensional activity at both ends of the 1982 thrust zone prior to the mainshock. The northern activity involved two events in 1967 as well as two events following the 1977 intermediate depth event (Christensen and Ruff, 1988). On the southern end of the rupture zone, the large 1977 tensional event occurred as well as a smaller event in 1978. The rapid variation along-strike of the outer rise stress regime is suggestive of localized strong interplate coupling in the 1982 zone. The deeper activity is comparably complex, with both tensional and compressional activity preceding the thrust. Christensen and Lay (1988) suggest that the Louisville Ridge is a buoyant zone which produces 

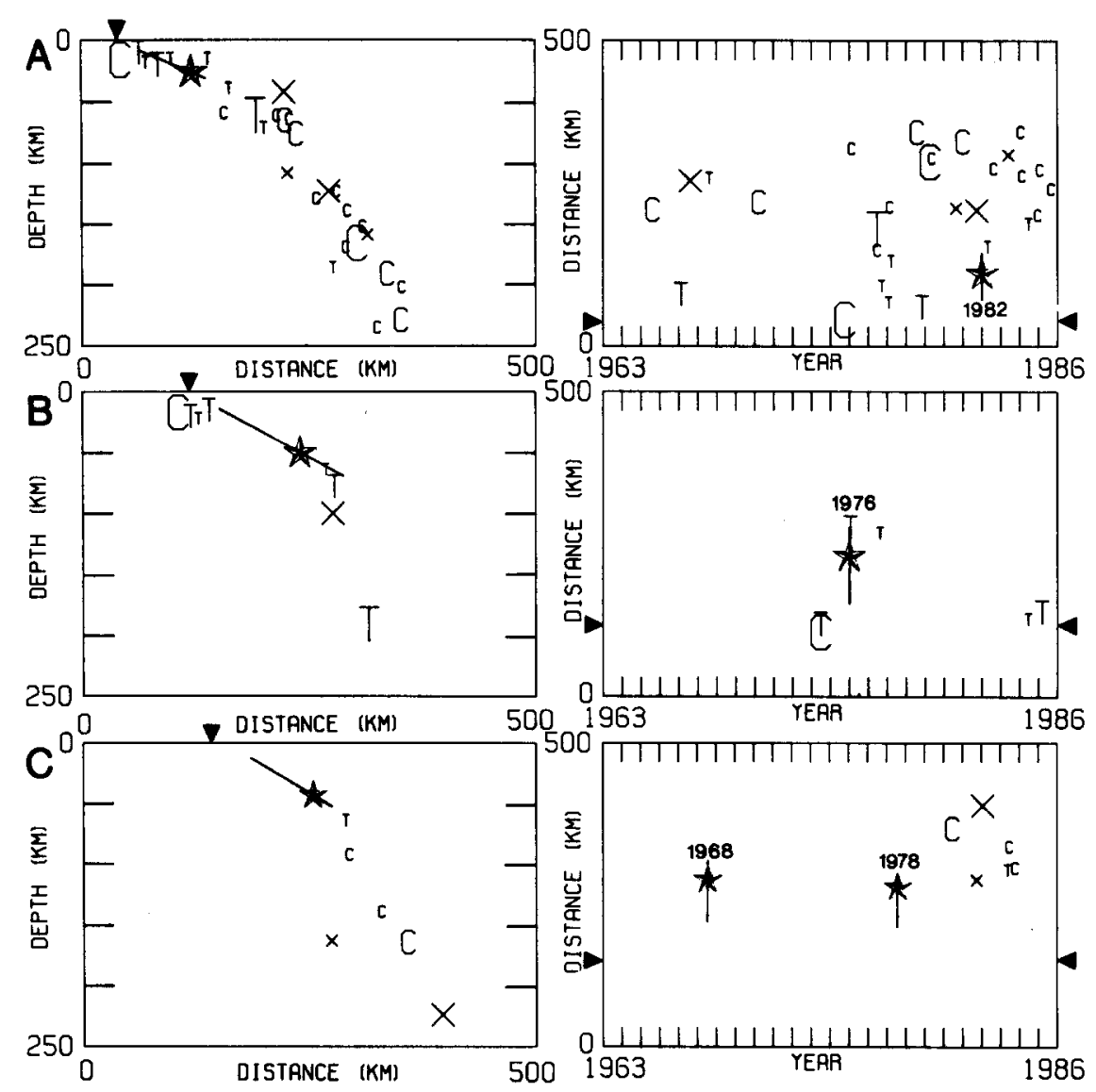

Fig. 27. Depth and time profiles of intraplate activity associated with large thrust events in Tonga-Kermadec in 1982 (Row A), 1976 (Row B) and 1968/1978 (Row C). The corresponding arc segments are indicated in Fig. 25. The symbol conventions are the same as in Fig. 7.

locally strong coupling in the wedge of the plate north of its intersection with the trench, thereby allowing tension to accumulate to a sufficient degree to result in the great 1977 event, and also building up strain on the interplate contact which failed in the 1982 thrust. The 1977 earthquake, like the 1970 Peru normal event, was followed by predominantly down-dip compressional events, which are located both near the 1977 hypocenter and at depths near $180 \mathrm{~km}$.

The complex time distribution of all of these events is displayed in Fig. 27 (Row A). While the depth profile can be interpreted as evidence for a double Benioff zone (e.g., Kawakatsu, 1986), the oblique intersection of the Louisville Ridge with these events argues for caution in interpreting this activity.
The seismic activity along the Kermadec zone is somewhat simpler to inspect. Row B of Fig. 27 shows the intraplate activity near the 1976 doublet. This event was preceded by a large outer rise compressional event as well as a smaller tensional event on the next day (Christensen and Ruff, 1988 ), and only tensional activity has followed the thrusts. At intermediate depth, several tensional events followed the thrusts. The deepest tensional event $\left(M_{\mathrm{s}}=7.3\right)$ shown in the depth profile occurred in 1949, while the tear fault $\left(M_{\mathrm{s}}=7.0\right)$ took place in 1957.

The 1968 and 1978 Kermadec events have been followed mainly by compressional activity (Fig. 27, Row C), which is interesting because tensional activity at the same depth is dominant to the south of this region (Fig. 25). There are numerous 
earlier events in this region with $5.5 \leq m_{\mathrm{b}}<6.0$ listed in the NOAA catalog, for which the mechanisms are not known and the depths are given at the default of $33 \mathrm{~km}$. Future efforts are needed to improve understanding of both the interplate and intraplate activity along Kermadec.

\section{Discussion and conclusions}

Intraplate seismic activity in the vicinity of large interplate thrust events clearly exhibits substantial regional diversity of spatial and temporal patterns. On the basis of the existing record, there are insufficient data from which to establish quantitatively the existence of temporal patterns or even to characterize precursory activity. However, some qualitative characteristics can be defined, and the composite diagrams in Fig. 3 can be considered. The outer rise region exhibits the least ambiguous behavior (Christensen and Ruff, 1988), with compressional activity only being observed prior to major thrusts (four cases: 1985 Chile, 1983 Chile, 1982 Tonga, 1976 Kermadec) or in seismic gaps of either known or uncertain seismic potential. However, the time interval between the compressional events and subsequent thrusts varies substantially, from 2 to 19 years, and the very largest thrust events have not had precursory compressional activity documented. It may be that previous thrusting or tensional activity in adjacent regions plays a role in loading the outer rise (as in three of the four cases: 1985 Chile, 1983 Chile, 1982 Tonga) prior to a moderate-sized thrust. Bending stresses may complicate the outer rise scenario as well (Chapple and Forsyth, 1979; Ward, 1983; Christensen and Ruff, 1988), for tensional and compressional events occur in close proximity prior to two of the thrusts, as well as in several of the seismic gaps (Peru, Kamchatka, Solomon Islands, and Tonga).

The intermediate depth intraplate activity shows the most dramatic temporal changes (from downdip tensional events prior to a thrust to down-dip compressional events afterward) for the 1960 Chile, 1966 Chile, 1974 Peru, 1957 Aleutians, 1963 Kurile, 1968 Tokachi-Oki, and 1971 New Britain events. Thrusts associated with merely a decrease in the tensional activity rather than a complete conversion to compressional behavior include the 1983 Chile, 1985 Chile, 1970 Chiapas, 1969 and 1973 Kurile Islands, and 1965 New Hebrides events. The thrust events of the second group tend to be smaller than those of the first group, consistent with the idea that large displacements are needed to induce a substantial transient compressional stress in the plate. The moderate size thrust events along Middle America are often preceded by tensional activity, but the record is unclear as to whether there is a decrease in this activity following the events. The 1964 Alaska, 1979 Colombia, and 1965 Rat Islands events lack any temporal pattern in the down-dip activity despite their large size, while they were all followed by at least one tensional outer rise event. The events with $M_{\mathrm{w}}<$ 8.0 in the moderately coupled Solomon Islands and New Hebrides regions do not show any clear temporal patterns other than tensional outer rise activity following the thrust events. The composite behavior is shown in Fig. 3. Note that for the first year after the thrust events, there is a more frequent occurrence of compressional events than tensional events for the entire range of thrust event size.

It is of interest to consider the intermediate depth activity near seismic gaps that have compressional outer rise events identified by Christensen and Ruff (1988). The compressional event just north of the 1966 Peru thrust is up-dip of the 1970 tensional rupture, consistent with a locked interface. However, the compressional aftershock activity of the 1970 event may indicate that the interface slipped during the 1970 rupture, which is believed to have a complex source process (Beck and Ruff, 1984). Intermediate depth tensional activity dominates in the region down-dip from the outer rise compressional events in the Ecuador region, but there is also tensional activity offshore in the area. While the general activity is consistent with a locked interface, the evidence for complexity of the intraplate stress regime due to curvature of the subducting slab is quite good (e.g., Stauder, 1975; Pennington, 1981). The outer rise compressional event along the 1950 Guatemala rupture zone is up-dip of very active tensional activity below the interface, consistent with a locked con- 
tact zone. Outer rise compressional activity near the Kurile gap of uncertain seismic potential occurs up-dip of both tensional and compressional intermediate depth events, but the region directly down-dip of the largest outer rise compressional event has only tensional events below the plate contact. This is suggestive of a localized region of strong coupling in the central part of the gap, which causes a disruption of the double Benioff zone activity. Thus, one might anticipate only a moderate-sized thrust event in this gap, comparable to the previous event in 1915 .

Several compressional outer rise events in the southwestern New Britain trench, as well as a shallow tensional event, occur near a seismic gap. Both tensional and compressional intermediate depth events are found in this region, but the largest events are tensional. The same is true for the region north of the 1985 New Hebrides thrust, where another outer rise compressional event is located seaward of a seismic gap. Compressional outer rise activity in Tonga occurs in two clusters, one in the northern part of the arc, up-dip of a region with mixed compressional and tensional intermediate depth activity, and the other in central Tonga (near $21^{\circ} \mathrm{S}$ ), up-dip of a region with compressional intraplate activity that extends right up to the trench. The first of these two regions has numerous tensional outer rise events as well. A final compressional outer rise event, located in southern Kermadec (near $35^{\circ} \mathrm{S}$ ) is up-dip of a region with tensional and compressional intermediate depth events, and there is also a nearby tensional outer rise event.

While it is very difficult to appraise confidently the seismic potential of these regions with outer rise compression, the intermediate depth behavior suggests that the 1950 Guatemala and the central Kurile gap appear to present the simplest cases of activity associated with a locked interface. Both regions have had adjacent thrusting events as well. The other regions all exhibit mixed stress regimes in both the outer rise and at intermediate depths, which can be attributed to 'static' stresses due to bending and unbending or lateral distortion of the slab; however, it is known that large thrusts have occurred in such areas (1982 Tonga, 1976 Kermadec).
There are several regions that lack any outer rise activity or have only tensional events, but do have active intermediate depth seismicity. The seismic gaps along the 1928 and 1939 rupture zones in Chile show intermediate depth tensional activity very similar to that preceding the $\mathbf{1 9 8 5}$ Valparaiso thrust event. Similarly, the central portion of the 1922 Chile rupture zone has intermediate depth tension, as well as an oblique outer rise event (the latter event was categorized as compressional by Chapple and Forsyth, 1979, and Christensen and Ruff, 1989). The southern portion of the 1922 zone has compressional intermediate depth activity. The 1877 and 1868 rupture zones in northern Chile have active tensional faulting at intermediate depths, and no outer rise activity. The same is true along Nicaragua, El Salvador and Acapulco, while the Tehuantepec region has tensional activity all the way to shallow depths. The 1938 Alaska and the Shumagin gap regions have only tensional activity at intermediate depths, while there is mixed tension and compression in the 1923 Kamchatka zone and in the southern New Hebrides gaps. Southern Kermadec has a long stretch of tensional activity with scattered compressional and tear faulting in regions with no outer rise events. Although we have not discussed the subduction zone off the northwestern U.S.A. because it is not known to be a strongly coupled zone, the large intraplate activity in this region is tensional as well (Astiz et al., 1988). With the exception of the Tehuantepec region and the southern portion of the 1922 Chile event, the intraplate activity in all of these regions is consistent with that observed prior to large thrust events elsewhere. However, we do not at present have a quantitative model upon which to base any precursory time-scale or even to confidently gauge the seismic potential of the interplate contact in these regions.

This regional analysis of intraplate earthquake mechanisms generally supports the dynamic stress model presented in Fig. 2, with allowance for the fact that regional stresses will always simply be superimposed on the large-scale deformation stress regime. Numerous examples of both outer rise and intermediate depth temporal variations associated with large interplate thrust events have been docu- 
mented for several coupled subduction zones. As the earthquake mechanism catalog is extended to lower magnitude thresholds and longer time intervals, it should be possible to extract information about the viscoelastic response of the subducting lithosphere from the temporal behavior of the seismicity (Spence, 1977, 1987; Dmowska et al., 1988). Of course, for the intermediate depth events this analysis must be performed cautiously, given the complexity of the three-dimensional intraplate stress environment and the many additional factors influencing the seismicity. It will also be of interest to analyze the seismically uncoupled regions to establish whether there is any stress migration from the outer rise to the intermediate depth regions. The temporal connection between activity in the upper plate and thrusting in seismically coupled regions may also provide stress indicators of accumulating strain on locked interplate contacts (e.g., Seno, 1979).

\section{Acknowledgments}

We thank Susan Beck and Susan Schwartz for discussions during this analysis. We thank $D$. Giardini for providing a tape with the CMT solutions. This research was supported by NSF Grant EAR-8451715. Acknowledgment is made to the donors of the Petroleum Research Fund, administered by the American Chemical Society, for the partial support of this research. Contribution No. 4536, Division of Geological and Planetary Sciences, California Institute of Technology, Pasadena, CA.

\section{Appendix A}

The detailed analysis of intraplate seismicity requires accurate source mechanisms and source

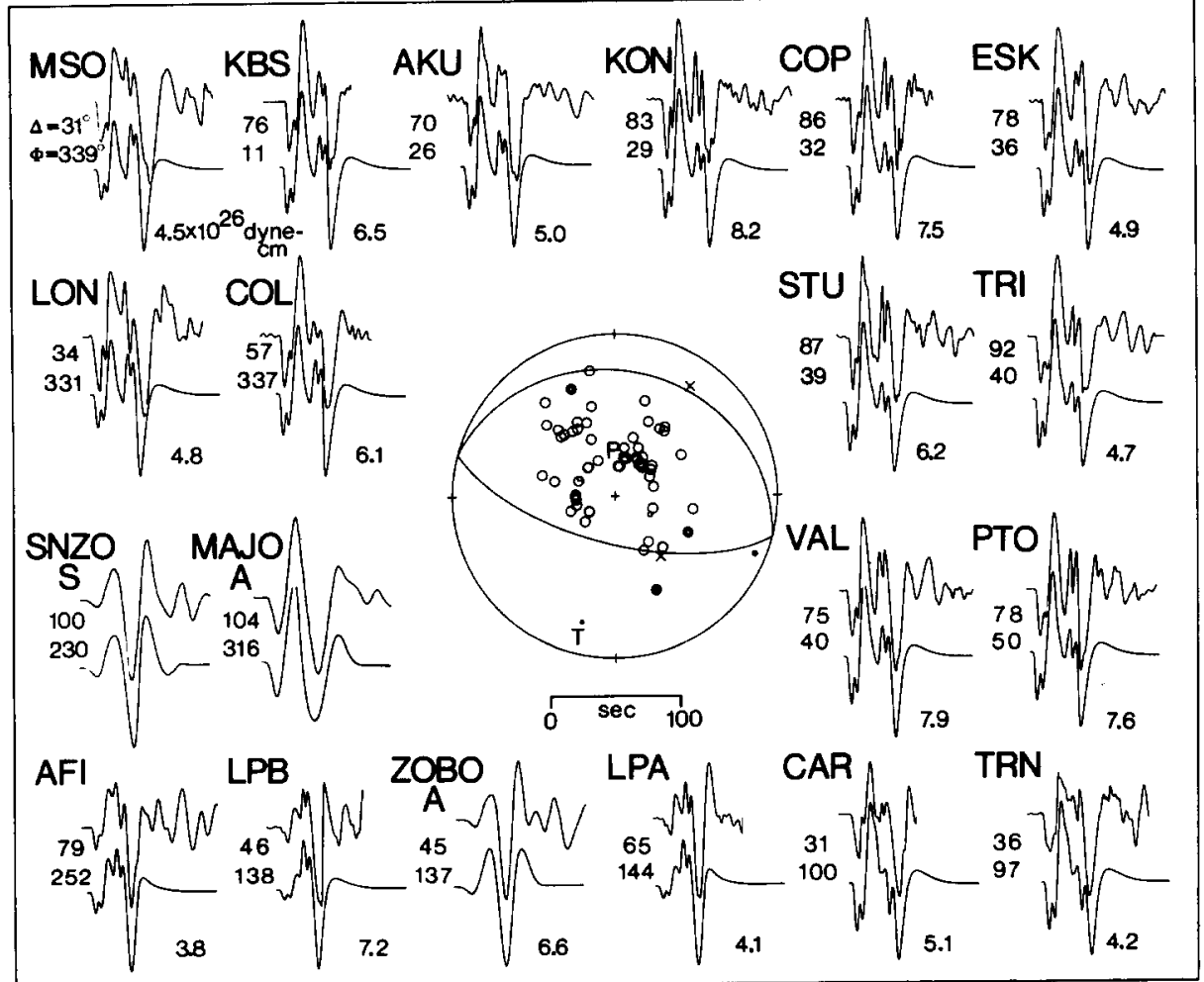

Fig. A1. Long-period P wave observations (upper traces) and synthetics (lower traces) for the October 24, 1980, Huajuapan event. The first-motion polarities (open circles are dilatations and filled circles are compressions) are shown in the lower hemisphere of an equal area projection. 
depths. Body wave and surface wave analyses of two important intermediate depth events are presented here. Figure Al shows long-period $P$ wave observations and synthetics for the October 24, 1980 , Huajuapan event $\left(18.2^{\circ} \mathrm{N}, 98.2^{\circ} \mathrm{W}\right)$. The first motions from teleseismic $P$ wave recordings are shown in the lower hemisphere equal area projection. The synthetics are for a double source at a depth of $65 \mathrm{~km}$ in a three-layer source velocity model. In this structure there are two crustal layers, the upper one being $10 \mathrm{~km}$ thick with a $P$ velocity of $6 \mathrm{~km} \mathrm{~s}^{-1}$, and the lower one being 30 $\mathrm{km}$ thick with a $P$ velocity of $7 \mathrm{~km} \mathrm{~s}^{-1}$. The mantle $P$ velocity and density are $8.0 \mathrm{~km} \mathrm{~s}^{-1}$ and $3.3 \mathrm{~g} \mathrm{~cm}^{-3}$ respectively. A Poisson ratio of 0.25 is assumed for all layers and the receiver structure has the same velocities as the shallow crustal layer at the source. A $t^{*}$ of $1.0 \mathrm{~s}$ is used for all phases. The strike, $\phi=285^{\circ}$, dip $\delta=24^{\circ}$ and rake $\lambda=$ $-90^{\circ}$ are the same for both subevents, with the second source delayed by $5 \mathrm{~s}$. The two trapezoidal source functions have rise times, flat times and fall times of $(2.0,2.0,2.0)$ and $(1.5,1.5,4.0) \mathrm{s}$ respectively, with the moment of the second source being 1.7 times that of the first. The average body wave moment from 20 non-nodal observations is $M_{0}=5.8 \times 10^{26} \mathrm{dyn} \mathrm{cm}$.

Analysis of 256-s period Rayleigh and Love wave spectra from the GDSN and IDA recordings of the Huajuapan event is shown in Fig. A2. The solid curves show the fit of the major double couple for an unconstrained moment tensor inversion of the complex spectra. For this inversion the relative size of the minor double couple was $6 \%$. Excitation functions for a distributed source from 50 to $80 \mathrm{~km}$ depth were used, along with an assumed source process time of $20 \mathrm{~s}$. The major double couple has parameters $\phi=300^{\circ}, \delta=33^{\circ}$, $\lambda=-88^{\circ}$ and $M_{0}=7.1 \times 10^{26}$ dyn cm. A nonlinear inversion for the moment using just the amplitude data and keeping the body wave mechanism fixed, gives $M_{0}=8.5 \times 10^{26} \mathrm{dyn} \mathrm{cm}$. The dashed curve is the result of inversion of amplitude spectra alone for both the moment and mechanism, with the body wave mechanism used as a starting model. The result for this case was $\phi=309^{\circ}, \delta=19^{\circ}, \lambda=-66^{\circ}, M_{0}=10.1 \times 10^{26}$ dyn cm.

A similar analysis of the June $19,1982, \mathrm{El}$ Salvador event $\left(13.2^{\circ} \mathrm{N}, 89.4^{\circ} \mathrm{W}\right)$ is shown in
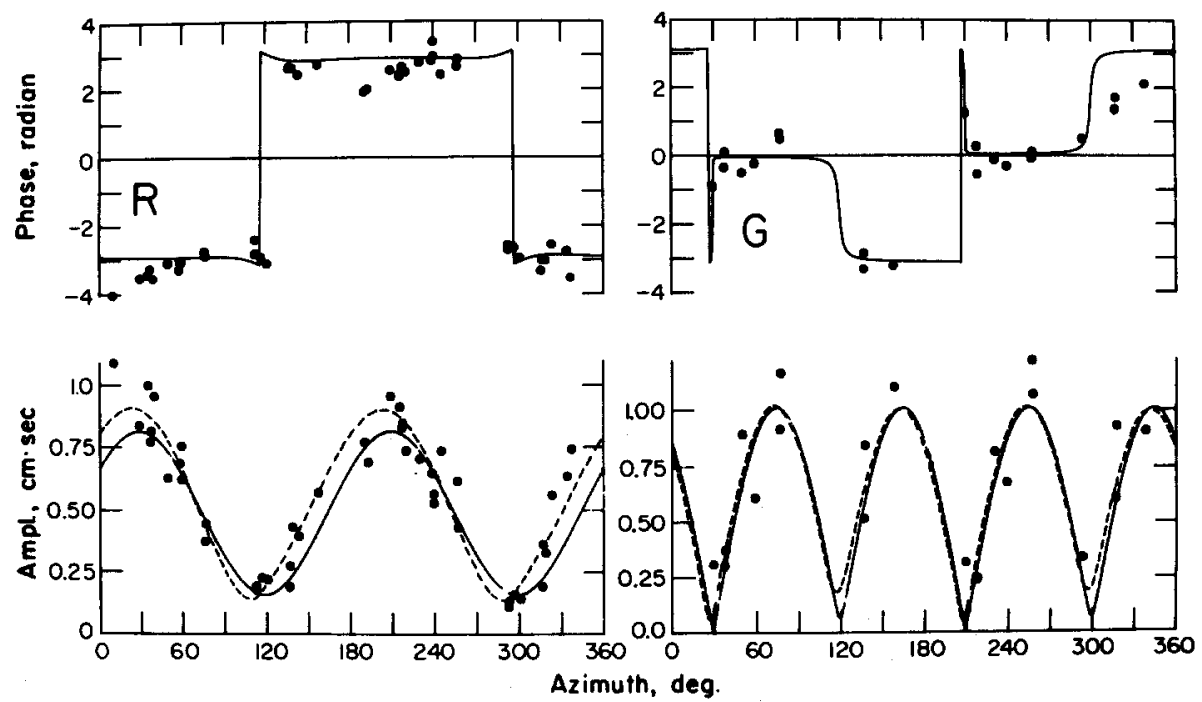

Fig. A2. Inversions of 256-s period Rayleigh wave (left) and Love wave (right) spectra for the Huajuapan earthquake recorded by GDSN and IDA stations. The solid curves show the fit of the major double couple of an unconstrained moment tensor inversion, while the dashed curves are for an amplitude inversion with unconstrained orientation. The parameters for each model are given in the text. 


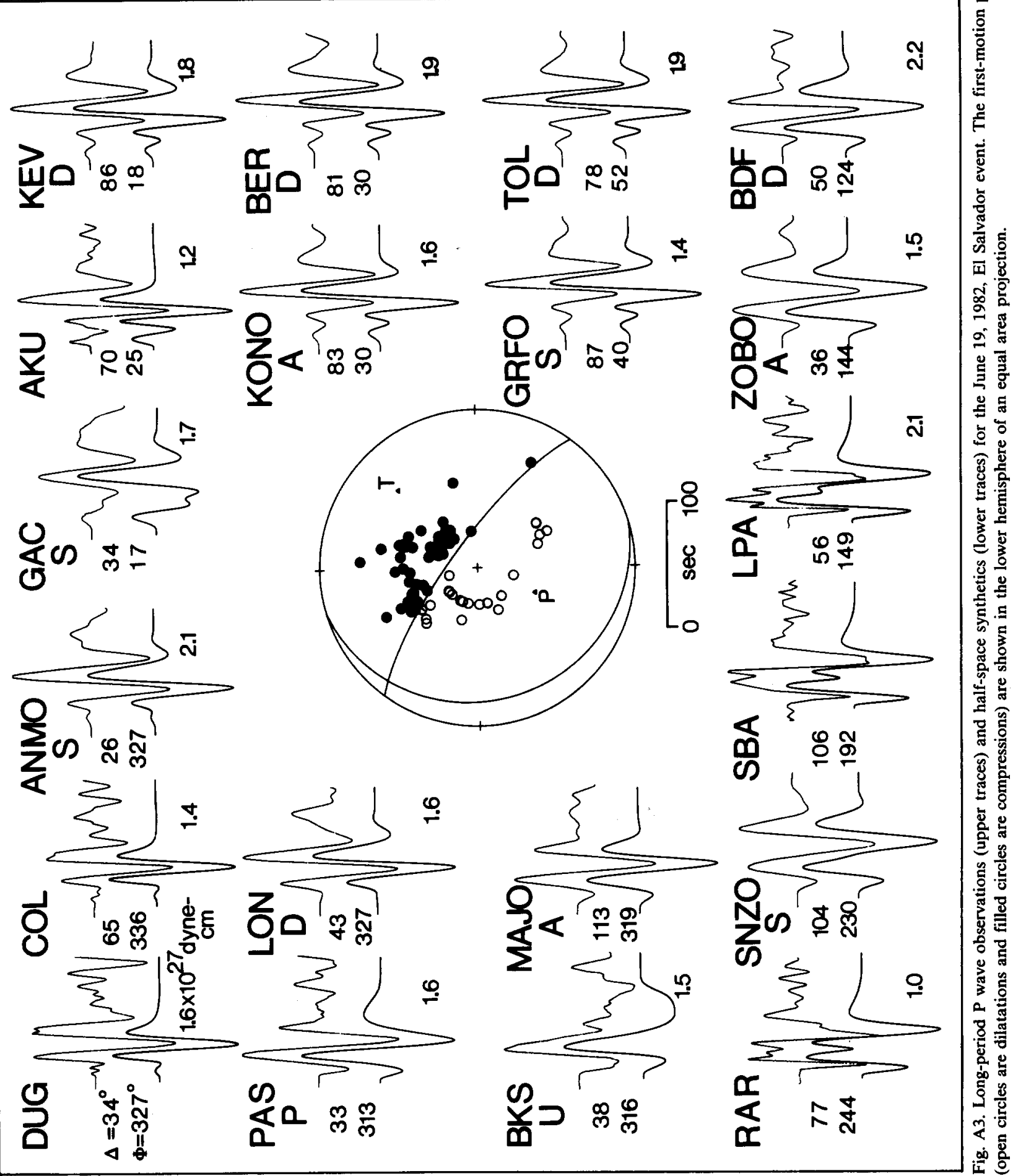


Figs. A3 and A4. The body wave mechanism in Fig. A3 has $\phi=307^{\circ}, \delta=76.5^{\circ}, \lambda=-100^{\circ}$, and an average moment of $M_{0}=1.6 \times 10^{27}$ dyn cm from 28 observations. The source trapezoid is given by $(6.0,3.0,8.0) \mathrm{s}$, with a source depth of 52 $\mathrm{km}$ using the same source velocity structure described above. The major double couple of an unconstrained moment tensor inversion, using 256-s period spectra and excitation functions for a source distributed from 30 to $80 \mathrm{~km}$ in depth and a source process time of $30 \mathrm{~s}$, is shown in Fig. A4. This solution has only a $3 \%$ minor double couple. The major double couple is given by $\phi=306^{\circ}$, $\delta=72^{\circ}, \lambda=-80^{\circ}, M_{0}=1.9 \times 10^{27} \mathrm{dyn} \mathrm{cm}$.
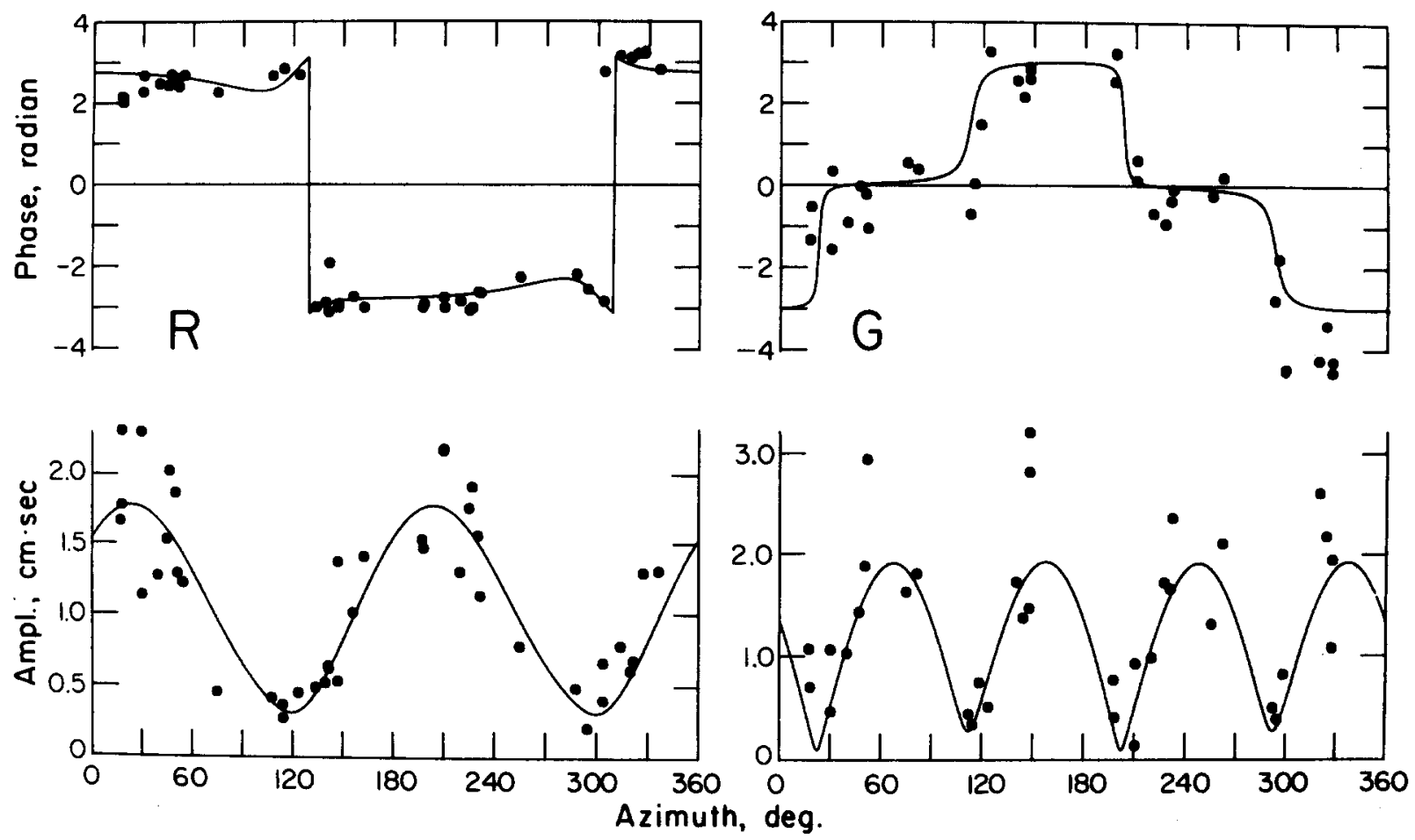

Fig. A4. Inversion of 256-s period Rayleigh wave (left) and Love wave (right) spectra for the El Salvador earthquake recorded by GDSN and IDA stations. The solid curves show the fit of the major double couple of an unconstrained moment tensor inversion. The parameters for this model are given in the text. 


\section{Appendix B}

Source parameters for intraplate subduction zone earthquakes for events with mb $>5.0$. The hypocentral parameters are those given by the references cited for each focal mechanism or are the NEIS locations (as for all of the CMT solutions). The magnitudes are those listed by Astiz et al. (1988) for the larger events and are mb (NEIS) for the smaller events. The symbols are: $H=$ depth in $\mathrm{km}$; PAZ = trend of the pressure axis; PPL: plunge of the pressure axis; TAZ: trend of the tension axis; TPL: plunge of the tension axis; BAZ: trend of the null axis; BPL: plunge of the null axis; ST: strike; M: mechanism type, $T=$ tensional, $C=$ compressional, $X=$ oblique/tear.

REG \# MO DA YR LAT

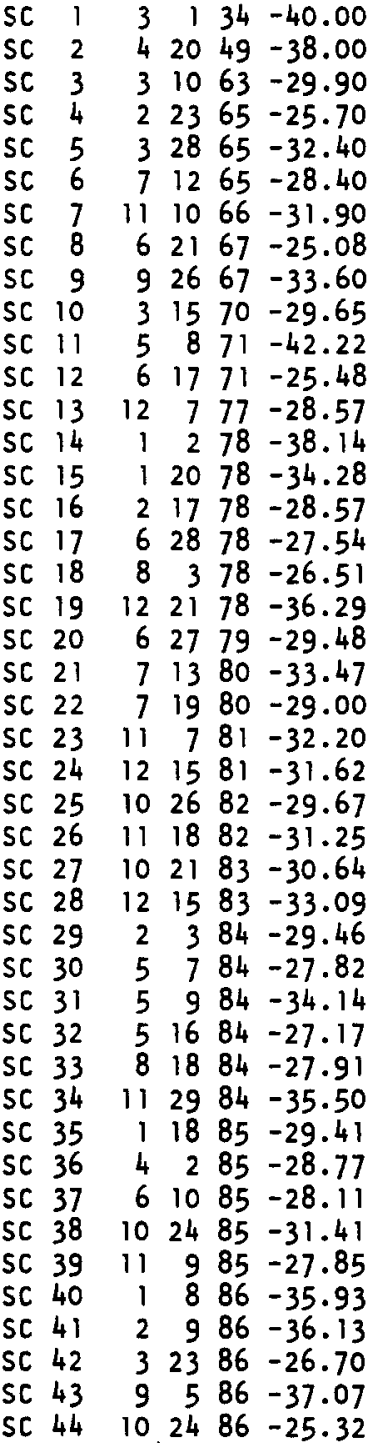

LON SOUTHERN CHILE

$-73.00120 .7 .1 \quad 313.47 .78 .29 .187 .30 .119 .31 .-160$. AK T $\begin{array}{llllll}-73.50 & 70.7 .3 & 216.49 .108 .15 . & 8.37 .237 .44 . & -30 . \text { AK T }\end{array}$ $\begin{array}{lllll}-71.20 & 70.6 .3 & 250.48 .51 .40 .149 .99 .82 .11 .-159.573 \mathrm{~T}\end{array}$ $-70.5080 .7 .3 \quad 291.51 .93 .37 .193 .10 .139 .13 .-145.573 \mathrm{~T}$

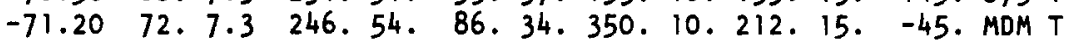
-68.30118 .5 .7 259.84. 53. 5. 143. 2. 140.40. $-94.573 \mathrm{~T}$ $-68.40113 .6 .0 \quad 28.52 .284 .11 .186 .36 .50 .46 .-36.573 \mathrm{c}$ $\begin{array}{llllllll}-70.45 & 45.5 .7 & 313 . & 5.99 .84 .223 .4 .47 .40 . & 95.573 \mathrm{C}\end{array}$ $-70.50 \quad 84.5 .8 \quad 315.47 .116 .42 .215 .10 .140 .8 .-162.573 \mathrm{~T}$ -69.50119 .6 .0 90.70.252.20.344. 6. 332.25. $-103.573 \mathrm{C}$ $-71.69150 .6 .8 \quad 93.34 .294 .54 .190 .10 .146 .15 .94$ 4. ALK C $\begin{array}{lllll}-69.15 & 93.7 .2 & 250.62 .103 .24 .7 .13 .219 .24 . \quad-55 . \text { ALK T }\end{array}$ $-67.39144 .5 .5 \quad 171.84 .53 .3 .322 .5 .149 .42 . \quad-82$. CMT T $-71.10144 .5 .5 \quad 58.31 .315 .20 .198 .52 .93 .53 . \quad-9$. CMT C

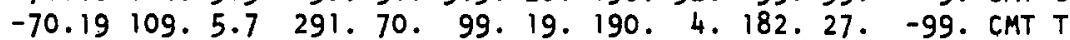
$\begin{array}{lllll}-71.02 & 66.5 .7 & 93.30 .311 .54 .194 .18 .141 .23 . & 35 . \text { CMT C }\end{array}$ $-70.10120 .5 .3 \quad 310.58 .80 .22 .179 .22 .134 .30 .-139$. СMT T $-70.5469 .6 .8 \quad 267.61 .115 .26 .12 .19 .231 .22 . \quad-57$. СМТ T $\begin{array}{lllll}-72.46 & 50.5 .7 & 38.16 .271 .64 .134 .20 .101 .34 . \quad 52 . \text { CMT C }\end{array}$ $-68.28141 .5 .6287 .59 .161 .20 .62 .23 .284 .32 .-43$. CMT $X$ $-70.15113 .5 .6 \quad 299.43 .91 .44 .195 .14 .103 .13 . \quad 178$. CMT T $-69.68129 .5 .9 \quad 9.70 .206 .19 .114 .6 .305 .27 .-78$. CMT $X$

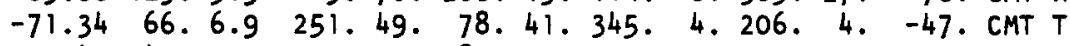

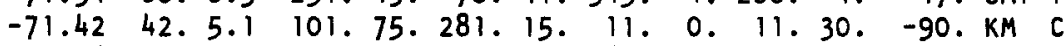
$\begin{array}{lllll}-71.26 & 56.5 .6 & 270.50 .63 .37 .164 .13 .101 .15 .-153 . \text { CMT T }\end{array}$ $-66.86166 .6 .0 \quad 263.65 .67 .22 .151 .10 .129 .24 .-114$. CMT T $-69.11132 .5 .5 \quad 142.56 .271 .24 .12 .23 .323 .29 .-142$. CMT C $-70.28104 .6 .0 \quad 271.65 .103 .24 .11 .4 .203 .22 . \quad-77$. CMT T

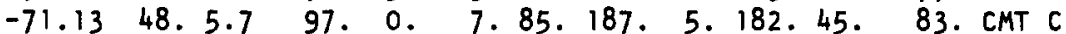
$-66.64147 .5 .6 \quad 158.51 .60 .6 .325 .38 .184 .51 . \quad-37$. CMT T -70.27108 .5 .6 309. 75. 119. 15. 209. 3. 205. 30. -95. СMT T -67.04156 .5 .4 132. 19. 38. 11.280.67.174.69. -6. СMT $x$ $-66.81182 .5 .2 \quad 167.69 .48 .10 .315 .18 .159 .38 . \quad-60$. СMT T $-71.12102 .5 .4 \quad 326.50 .112 .35 .214 .17 .151 .19 .-154$. CMT T $-70.7175 .6 .3 \quad 276.8 .182 .25 .22 .64 .322 .67 . \quad 13$. CMT C $\begin{array}{llllll}-68.97 & 83.5 .1 & 346.48 . & 77 . & 0.167 .42 .133 .58 . & -142 . \text { CMT T }\end{array}$ -67.19170 .6 .3 185.70. 52.14.318.14.161.33. -64. CMT T -68.64124 .5 .7 244.80.344. 2. 74. 10.64.44. -104. CMT $X$ -66.64165 .5 .0 170.60. 51. 6. 314. 25. 172.47. -45 . CMT T $-71.2496 .5 .4288 .43 .138 .43 .33 .16 .303 .16 . \quad 0$. CMT T $-71.27125 .5 .0 \quad 282.31 .101 .59 .192 .1 .14 .14 . \quad 92$. CMT T $-70.7899 .5 .3 \quad 313.66 .133 .24 .43 .0 .223 .21 . \quad-90$. CMT T $-71.81 \quad 81.5 .6 \quad 336.38 .111 .42 .226 .24 .129 .24 .174$. CMT T $-70.1850 .5 .6 \quad 91.34 .215 .39 .336 .32 .239 .32 .174$. CMT C 


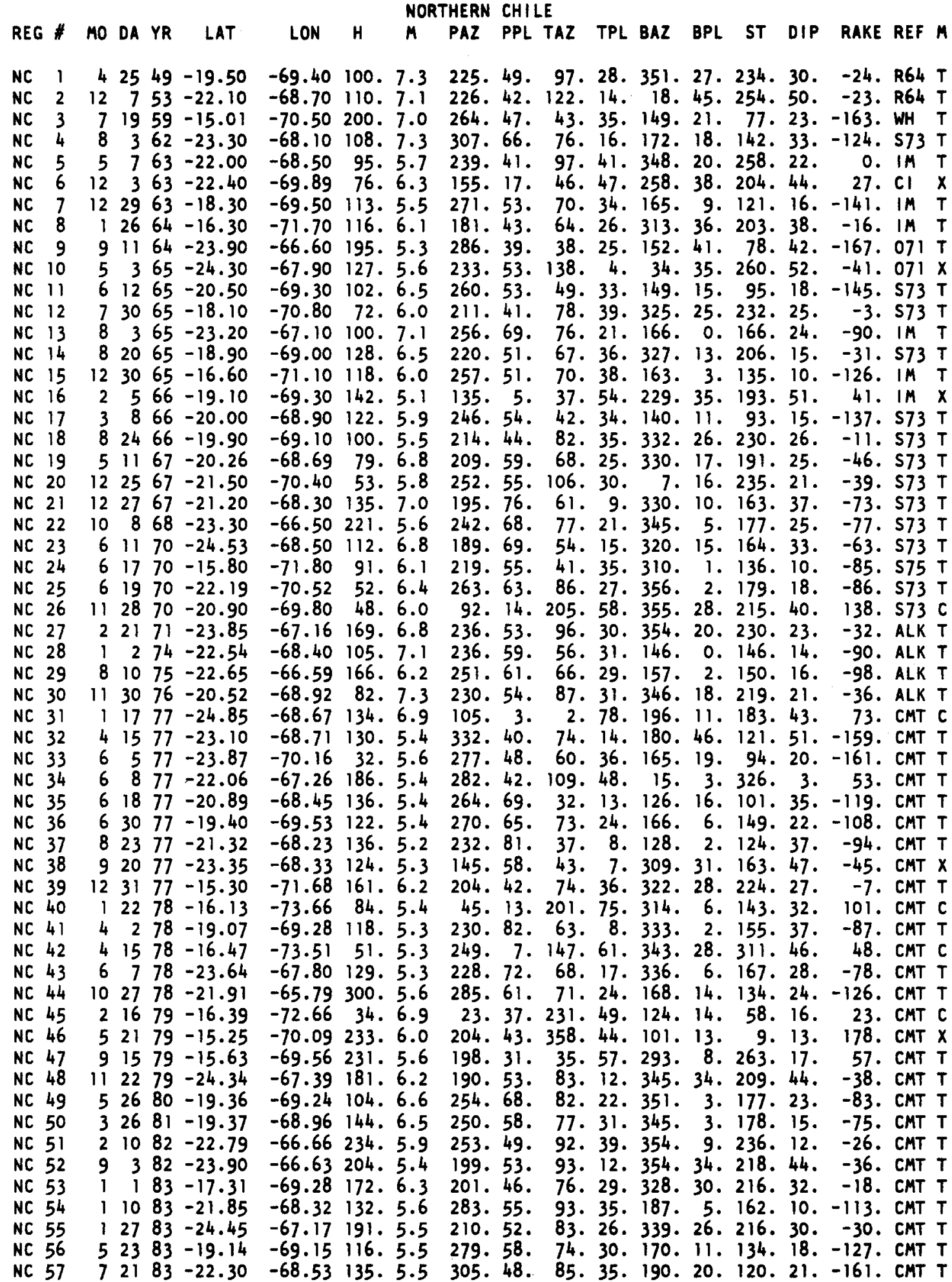




$\begin{array}{lrrrrr}\text { NC } & 58 & 9 & 1 & 83 & -17.58 \\ \text { NC } & 59 & 10 & 16 & 83 & -23.84 \\ \text { NC } & 60 & 1 & 1 & 84 & -22.61 \\ \text { NC } & 61 & 1 & 6 & 84 & -23.92 \\ \text { NC } & 62 & 2 & 26 & 84 & -17.32 \\ \text { NC } & 63 & 4 & 24 & 84 & -24.36 \\ \text { NC } & 64 & 6 & 18 & 84 & -15.73 \\ \text { NC } & 65 & 6 & 20 & 84 & -23.98 \\ \text { NC } & 66 & 8 & 12 & 84 & -24.36 \\ \text { NC } & 67 & 8 & 26 & 84 & -16.19 \\ \text { NC } & 68 & 9 & 12 & 84 & -15.77 \\ \text { NC } & 69 & 9 & 20 & 84 & -15.06 \\ \text { NC } & 70 & 10 & 20 & 84 & -24.07 \\ \text { NC } & 71 & 12 & 11 & 84 & -22.84 \\ \text { NC } & 72 & 12 & 31 & 84 & -23.06 \\ \text { NC } & 73 & 2 & 14 & 85 & -23.85 \\ \text { NC } & 74 & 3 & 26 & 85 & -15.16 \\ \text { NC } & 75 & 5 & 18 & 85 & -19.20 \\ \text { NC } & 76 & 6 & 23 & 85 & -24.06 \\ \text { NC } & 77 & 8 & 27 & 85 & -21.46 \\ \text { NC } & 78 & 10 & 8 & 85 & -23.05 \\ \text { NC } & 79 & 2 & 20 & 86 & -21.15 \\ \text { NC } & 80 & 3 & 12 & 86 & -24.13 \\ \text { NC } & 81 & 3 & 15 & 86 & -19.16 \\ \text { NC } & 82 & 4 & 9 & 86 & -23.01 \\ \text { NC } & 83 & 4 & 30 & 86 & -18.36 \\ \text { NC } & 84 & 5 & 10 & 86 & -23.56 \\ \text { NC } & 85 & 9 & 12 & 86 & -22.51\end{array}$

-69.98105 .5 .9228 .58 .50 .32 .319 .1 1. 143. 13. -86 . CMT T

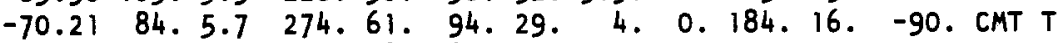
-66.02275 .5 .4 246. 48. 89. 40.349.12. 239. 11. -21 . CMT T $-68.65108 .5 .4 \quad 240.49 .119 .23 .14 .31 .253 .36 . \quad-26$. CMT T $-70.53 .115 .6 .1 \quad 224.64 .63 .25 .329 .7 .169 .21 . \quad-69$. CMT T $-66.95178 .5 .2 \quad 178.35 .69 .25 .312 .45 .209 .45 . \quad-9$. CMT T $-72.48131 .5 .8 \quad 156.46 .251 .4 .345 .44 .305 .56 .-147$. CMT T $-66.97187 .5 .4 \quad 213.49 .74 .33 .329 .21 .215 .23 . \quad-22$. CMT T $-69.25118 .5 .6 \quad 167.66 .66 .6 .334 .24 .180 .44 .656$. CMT T $-69.55210 .5 .2 \quad 226.59 .63 .30 .329 .7 .175 .16 . \quad-63$. CMT T $-71.89150 .5 .1 \quad 149.85 .47 .4 .317 .5 .142 .44 . \quad-83$. CMT T -73.50118 .5 .2 303.71. 92. 16. 185. 9. 168. 30. -109. CMT T $-66.83192 .6 .2 \quad 263.68 .113 .20 .19 .10 .220 .26 . \quad-68$. CMT T -68.80128 .5 .6 270.56. 103. 33. 9. 6. $216.14 . \quad-61$. CMT T $-66.91202 .5 .5 \quad 240.54 .75 .35 .340 .7 .196 .12 . \quad-53$. CMT T $-67.75144 .5 .6 \quad 329.29 .65 .12 .176 .58 .111 .61 .-167$. CMT T $-71.68144 .5 .1 \quad 171.8 .80 .6 .316 .80 .215 .80 . \quad-1$. CMT $X$ $-69.12126 .5 .4 \quad 231.53 .92 .30 .350 .20 .226 .23 . \quad-32$. CMT T $-67.10197 .5 .5233 .52 .74 .36 .336 .10 .207 .13 .-38$. СMT T -67.45218 .5 .2 248. 59. 5. 15. 103. 26. 63. 38. -136. CMT $x$ $-66.43244 .5 .5260 .46 .78 .44 .169 .1 .130 .2 .-130$. CMT T $-70.1192 .5 .7 \quad 301.71 .80 .15 .174 .12 .154 .32 .-113$. CMT T -66.82211 .5 .2 274. $60.91 .30 .182 .2 .177 .15 . \quad-95$. CMT T $-67.46241 .5 .6235 .55 .137 .5 .43 .35 .259 .50 . \quad-42$. CMT $x$ $-66.75218 .5 .2 \quad 243.47 .68 .43 .336 .3 .197 .22 .48$. CMT T -69.45118 .5 .5 200. 51. 83. 21. 339. $32.214 .37 . \quad-30$. CMT T $-68.88171 .5 .2 \quad 322.33 .70 .25 .190 .46 .109 .47 .-173$. CMT T -70.16 109. 5.1 264. 69. 105. 20. 13. 7.207. 26. -74. CMT T

REG \# MO DA YR LAT

$\begin{array}{lrrrrr}P E & 1 & 6 & 7 & 50 & -4.50 \\ P E & 2 & 4 & 13 & 63 & -6.30 \\ P E & 3 & 9 & 17 & 63 & -10.80 \\ P E & 4 & 9 & 24 & 63 & -10.60 \\ P E & 5 & 11 & 2 & 64 & -4.10 \\ P E & 6 & 9 & 17 & 65 & -1.50 \\ P E & 7 & 5 & 1 & 66 & -8.40 \\ P E & 8 & 3 & 2 & 67 & -0.30 \\ P E & 9 & 9 & 9 & 68 & -8.73 \\ P E & 10 & 9 & 28 & 68 & -13.16 \\ P E & 11 & 5 & 28 & 69 & -2.10 \\ P E & 12 & 5 & 31 & 70 & -9.18 \\ P E & 13 & 6 & 2 & 70 & -9.30 \\ P E & 14 & 6 & 4 & 70 & -9.80 \\ P E & 15 & 7 & 2 & 70 & -10.10 \\ P E & 16 & 5 & 17 & 71 & -1.60 \\ P E & 17 & 7 & 27 & 71 & -2.75 \\ P E & 18 & 4 & 3 & 73 & 4.69 \\ P E & 19 & 4 & 24 & 73 & 4.96 \\ P E & 20 & 5 & 30 & 73 & -2.30 \\ P E & 21 & 1 & 5 & 74 & -12.30 \\ P E & 22 & 3 & 18 & 75 & -4.23 \\ P E & 23 & 5 & 19 & 76 & 4.50 \\ P E & 24 & 3 & 13 & 77 & -8.04 \\ P E & 25 & 5 & 1 & 77 & -6.12 \\ P E & 26 & 10 & 8 & 77 & -9.52 \\ P E & 27 & 5 & 20 & 78 & -10.23 \\ P E & 28 & 10 & 5 & 79 & -3.55\end{array}$
LON H M PAZ PPL TAZ TPL BAZ BPL ST DIP RAKE REF $M$

-77.00100 .6 .8 110.40.209. 9. 309. 48. 258.56. -156. FK C $-76.70125 .6 .1 \quad 49.69 .271 .16 .177 .13 .20 .31 .04 .6 B \quad C$ $\begin{array}{llllll}-78.20 & 61.6 .7 & 180.69 .76 .5 .344 .20 .187 .44 . & -60.575 T\end{array}$ $-78.0080 .6 .0 \quad 261.56 .39 .27 .139 .20 .91 .25 .-141.575 \mathrm{~T}$

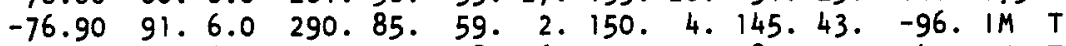
$-77.70191 .6 .5 \quad 242.52 .38 .36 .137 .12 .83 .13 .-143.1 M T$ -74.30154 .6 .8 251. 54. 117. 27. 15. 22. 248. 27. $-34.575 \mathrm{~T}$ $-78.70121 .5 .8 \quad 40.49 .181 .34 .286 .20 .219 .22 .-158.1 M \quad X$ $-74.52120 .6 .0 \quad 265.51 .57 .36 .157 .14 .98 .15 .-149.575 \mathrm{~T}$ $\begin{array}{llll}-76.38 & 70.6 .0 & 257.57 . & 59.32 .154 .8 .122 .15 .-122.575 T\end{array}$ $\begin{array}{llllll}-76.90 & 163.5 .5 & 213.55 .33 .35 .303 . & 0.123 .10 . & -90 . P E T\end{array}$ $\begin{array}{lllllllll}-78.82 & 48.7 .8 & 250.85 & 70 . & 5.160 .0 .160 .40 . & -90.575 T\end{array}$ $-79.00 \quad 49.5 .7 \quad 33.17 .267 .63 .130 .21 .95 .33 .51 .575 \mathrm{C}$ $-78.6057 .5 .8 \quad 70.28 .223 .59 .334 .12 .189 .20 .127 .575 \mathrm{C}$ $-78.6062 .5 .8 \quad 79.48 .239 .40 .337 .10 .270 .11 .-159.575 \mathrm{C}$ -77.70176 .6 .5 209. 63. 45. 26. 312. 6. 150.20. $-71.575 \mathrm{~T}$ $-77.43135 .7 .5194 .65 .94 .4 .24 .24 .208 .46 . \quad-55.575 T$ -75.63158 .6 .7 293. 59. 108. 31. 197.6. 191. 14. -99. PE T

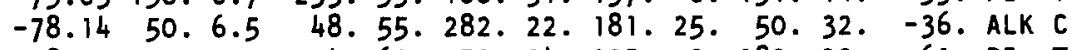

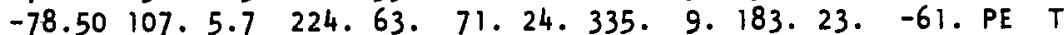

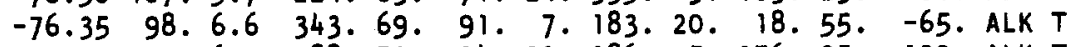
-77.0275 .6 .5 288. 70. 94. 20. 186. 5. 176. 25. -100. ALK T -75.80166 .5 .9 352. 50. 110.17. 207. 37. 159. 42. $-150 . \mathrm{PE} T$ -74.41 153. 5.1 285. 34. 75. 52. 184. 15. 61. 18. 148. CMT T -77.13 130. 4.9 153. $79.45 .3 .314 .11 .146 .43 . \quad-74$. CMT T $-74.66137 .5 .5 \quad 317.70 .104 .17 .197 .10 .178 .29 .-111$. CMT T $-78.5250 .5 .6 \quad 67.30 .244 .60 .336 .2 .162 .15 . \quad 96$. CMT C $-76.27 \cdot 132.5 .5347 .77 .82 .1 .172 .12 .159 .45 .-108$. CMT T 


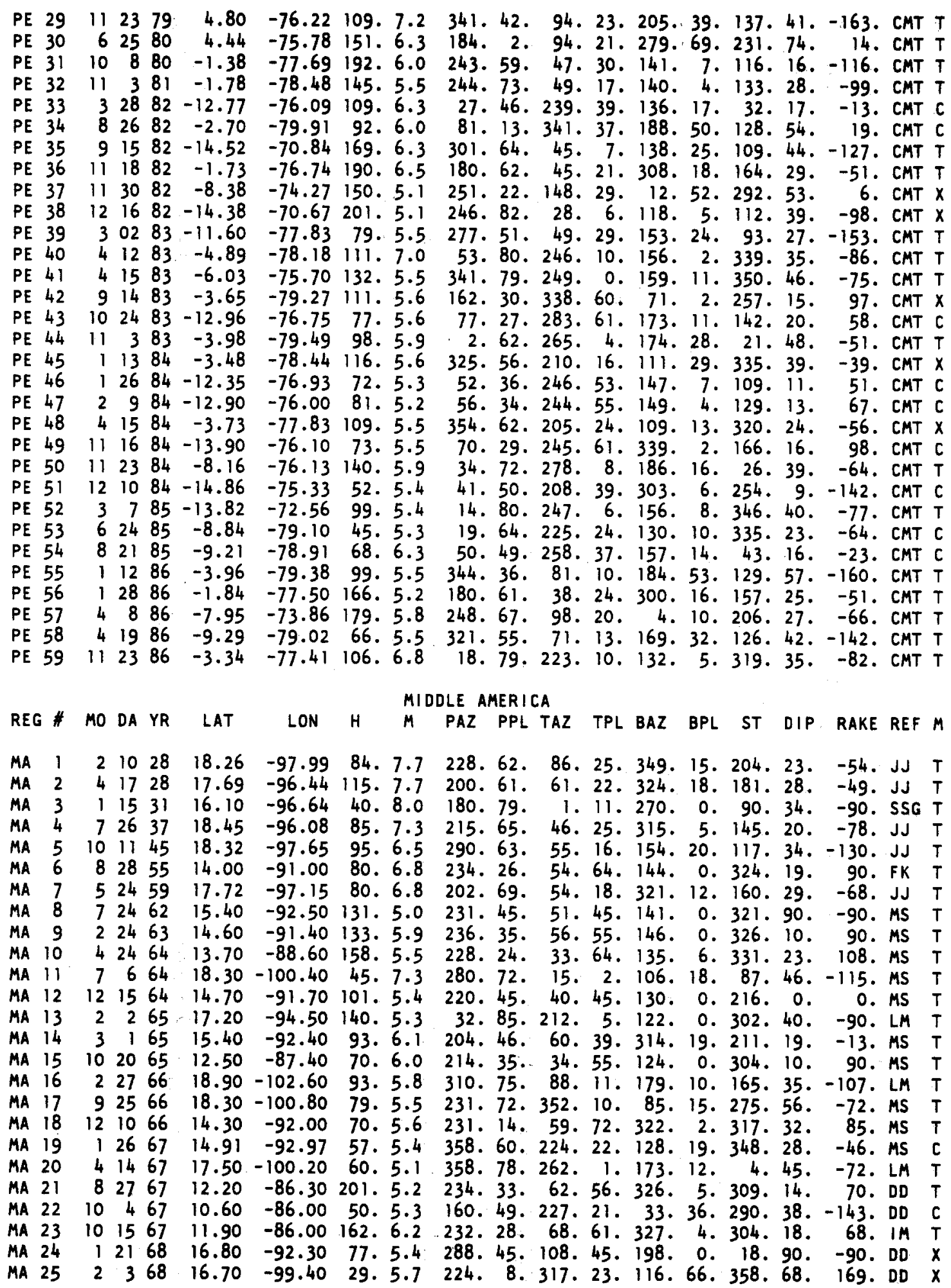









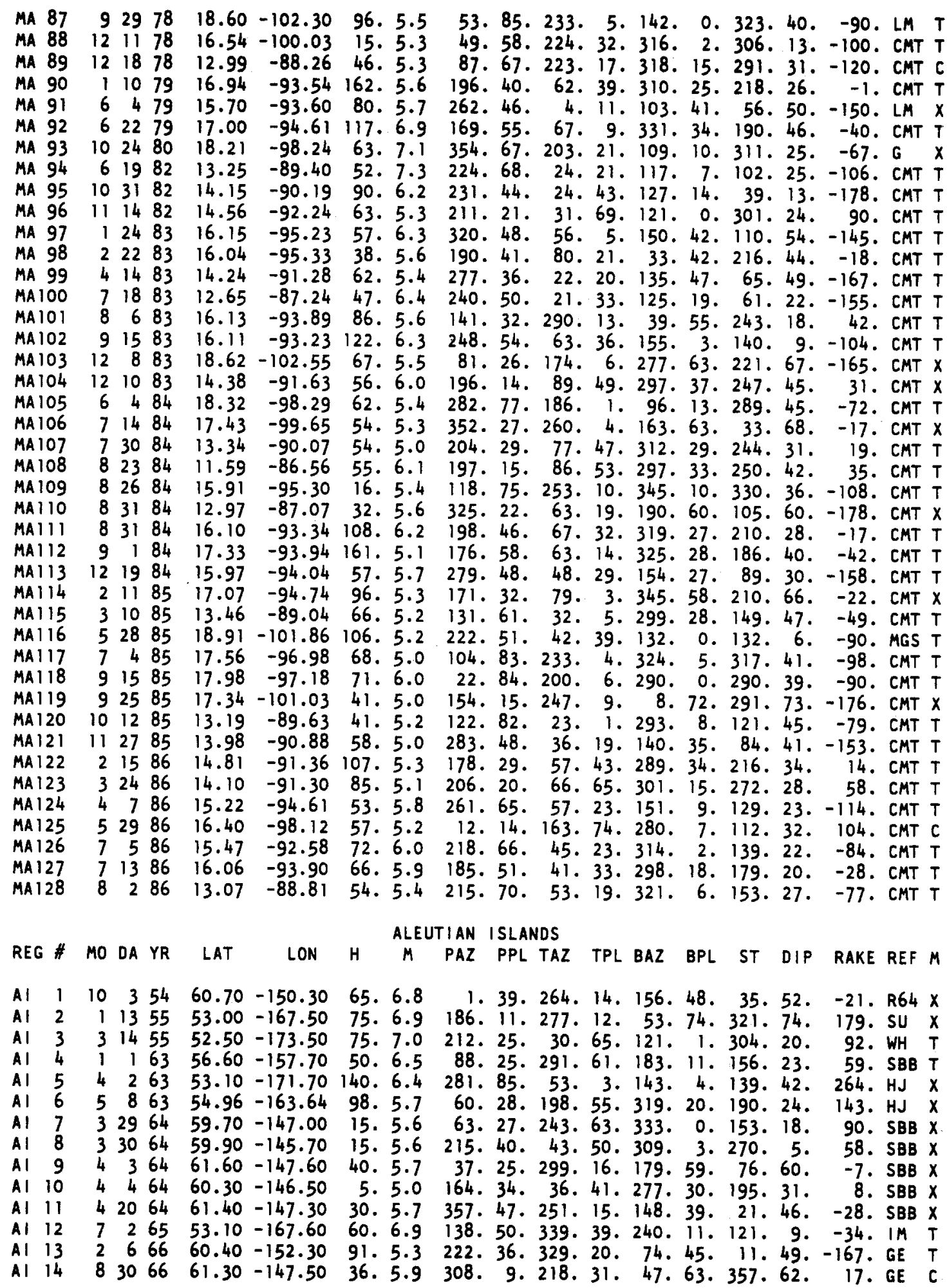


A) $15 \quad 10766661.60-150.10 \quad 56.5 .7 \quad 199.50 .99 .5 .15 .47 .225 .53 . \quad-36$. GE T

A) $16 \quad 12 \quad 2466 \quad 59.90-153.40113 .5 .1 \quad 16.30 .196 .60 .106 .0 .106 .15$.

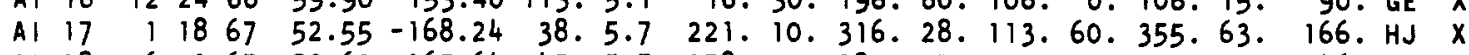

Al $18 \quad 6 \quad 167 \quad 53.60-165.64 \quad 45.5 .7 \quad 278.26185 .57 . \quad 9.33 .339 .52 .46$. HJ C

$\begin{array}{llllllllllllll}\text { Al } & 19 & 6 & 3 & 67 & 58.40 & -151.20 & 32.5 .5 & 129.27 .214 .19 . & 33.77 .263 .57 . & -173 . \text { GE C }\end{array}$

A) $20 \quad 7 \quad 167 \quad 54.44-157.94 \quad 12.6 .1 \quad 51.16 .318 .9 .200 .72 .94 .72 .9-5 . H J T$

Al $21 \quad 11 \quad 1067 \quad 62.30 \quad-151.40 \quad 90.4 .9 \quad 65.3 .155 .3 .290 .83 .200 .86 .180$. GE $X$

Al $22 \quad 122767 \quad 58.40-153.00 \quad 50.6 .5 \quad 158.37 .300 .46 .52 .50 .308 .21 .167$. SBB T

A) $23 \quad 42368 \quad 58.70-150.00 \quad 23.6 .3 \quad 116.74 .205 .14 .296 .16 .279 .32 .-111$. GE $X$

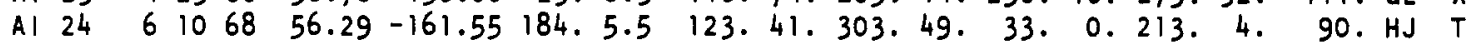

Al $25 \quad 121768 \quad 60.20-152.80 \quad 90.6 .5 \quad 91.18 .222 .64 .355 .18 .208 .31 .127$. ALK X

Al $26 \quad 62069 \quad 56.30-161.60191 .5 .5 \quad 123.41 .303 .49 .33 .0 .213 .4 .90$. $4 J$ T

Al $27 \quad 22870 \quad 52.70-175.10 \quad 159.6 .1 \quad 313.67 .102 .20 .195 .12 .174 .27 .-115.572$ C

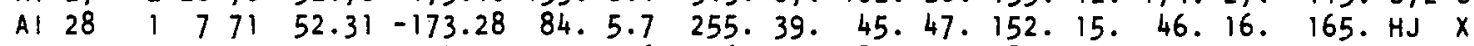

Al $2932771 \quad 52.52-174.55133 .5 .6 \quad 316.50 .80 .25 .185 .29 .126 .33 .-153$. HJ C

A) $30 \quad 4 \quad 571153.30-170.50140 .5 .8 \quad 310.70 .148 .19 .66 .6 .248 .27 .077$. HJ C

A) $31 \quad 9 \quad 471 \quad 54.90-163.40134 .5 .7 \quad 154.45 .334 .45 .64 .0064 .0 .90$. HJ T

Al $32 \quad 32472 \quad 56.14-157.18 \quad 71.6 .0 \quad 222.8 .342 .75 .130 .13 .327 .39 .111$. HJ $X$

A) $33 \quad 42172 \quad 54.00-166.80104 .5 .8 \quad 356.49 .176 .41 .86 .0 .266 .4 .40 .9 J$ C

$\begin{array}{llllllllllllllll}\text { A) } 34 & 3 & 19 & 73 & 52.80 & 173.80 & 81.5 .8 & 355.32 . & 175.53 . & 85 . & 0.85 .20 . & 90 . \text { WT } C\end{array}$

A) $3552673 \quad 60.20-154.00171 .4 .4 \quad 274.32 .113 .60 .610 .10 .341 .9 .972$. BB $x$

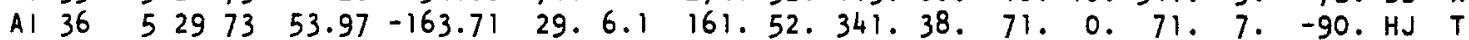

A) $37 \quad 1 \quad 175 \quad 61.90-149.70 \quad 66.5 .9 \quad 126.55 .316 .35 .223 .4 .67 .10 .67$. WT T

A) $38 \quad 12775 \quad 52.20-175.90 \quad 151.4 .9 \quad 294.44 .194 .10 .93 .44 .323 .52 .332$. T78 C

A) $39 \quad 113075 \quad 51.90-176.00 \quad 99.4 .8 \quad 9.15 .274 .15 .141 .70 .51 .69 . \quad 0 . T 78 \times$

A) $40 \quad 82876 \quad 52.20-175.00138 .5 .1 \quad 343.63 .163 .28 .253 .0 .253 .16 .090$. F 79 C

A) $41 \quad 72077 \quad 54.61-161.60 \quad 54.5 .3 \quad 93.63 .334 .14 .238 .23 .92 .37 . \quad-50$. CMT T

A) $42 \quad 1127 \quad 77 \quad 58.56-155.38 \quad 134.4 .9 \quad 353 . \quad 3.261 .33 .88 .57 .42 .65 . \quad 23$. CMT X

A) $43 \quad 1227 \quad 77 \quad 60.39-153.70184 .5 .1 \quad 34.14 .270 .66 .129 .19 .100 .35 . \quad 55$. CMT X

A) $44 \quad 33178 \quad 61.77-151.41 \quad 98.5 .1 \quad 162.45 .311 .41 .55 .16 .334 .16 .-172$. CMT T

A) $45 \quad 51278 \quad 62.25-149.4067 .5 .1 \quad 215.41 .319 .15 .64 .45 .6060 .50 .158$. CMT T

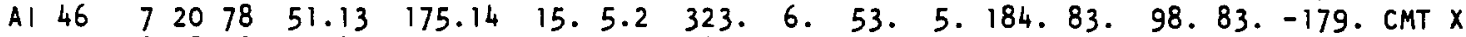

A) $47 \quad 81878 \quad 59.89-153.53 \quad 127.6 .1 \quad 183.5 .278 .43 .88 .47 .312 .57 . \quad 150$. CMT T

A) $48 \quad 10 \quad 478 \quad 50.93 \quad 173.53 \quad 15.5 .3 \quad 113.78 .211 .2 .301 .12 .289 .45 .-108$. CMT T

A) $49 \quad 1257960.13-153.12124 .5 .5 \quad 11.4 .277 .46 .105 .44 .65 .56 . \quad 34$. CMT X

Al $50 \quad 52079 \quad 56.65-156.73 \quad 71.6 .5 \quad 78.25 .314 .50 .183 .29 .124 .33 .27$. HJ T

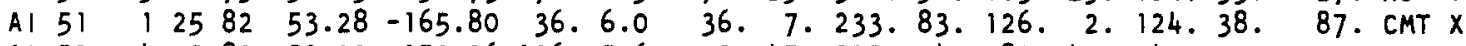

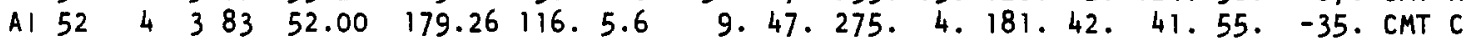

Al $53 \quad 7 \quad 1283 \quad 61.03-147.38 \quad 41.6 .4 \quad 180.66 .308 .15 .43 .18 .14 .34 .-124$. CMT T

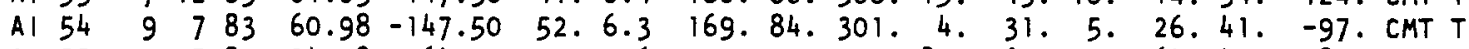

Al $55 \quad 122783 \quad 54.18 \quad-164.09 \quad 70.5 .6 \quad 335.60 .239 .89 .65 .61 .64 .45 . \quad 89$. CMT C

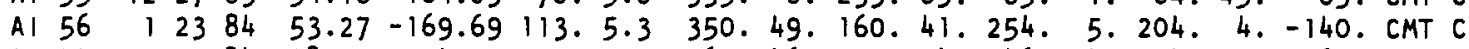

Al $57 \quad 32384 \quad 58.99-154.17 \quad 119.5 .2 \quad 165.46 .299 .34 .46 .24 .334 .25 .-165$. CMT T

Al $\begin{array}{lllllllllllllll}58 & 6 & 5 & 84 & 56.89 & -157.29 & 104.5 .2 & 44.50 .304 .96 .207 .39 .70 .50 . & -35 . \text { CMT T }\end{array}$

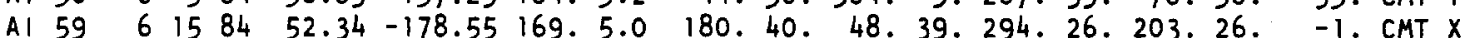

A) $60 \quad 32385 \quad 52.62-178.79241 .4 .9 \quad 191.22 .79 .42 .301 .40 .234 .42 . \quad 18$. CMT X

A1 $61 \quad 102785 \quad 58.49-154.35106 .5 .4 \quad 181.20 .286 .35 .67 .48 .318 .50 .168$. CMT T

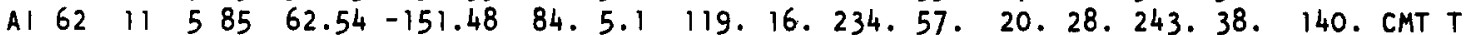

Al $63 \quad 11886 \quad 51.57-173.12 \quad 36.5 .7 \quad 279.2$ 2. 17.77. 189. 13. 22. 44. 108. CMT X

Al $64 \quad 4 \quad 986 \quad 51.05 \quad 172.93 \quad 15.5 .4 \quad 203.71 .57 .16 .324 .10 .163 .30 . \quad-69$. CMT T

A) $6552386 \quad 58.88-153.20 \quad 88.5 .1 \quad 44.11 .308 .26 .154 .61 .89 .64 . \quad 11$. CMT X

Al $66 \quad 79986 \quad 51.68-176.87 \quad 62.4 .9 \quad 137.10 .239 .47 .38 .41 .265 .50 . \quad 149$. CMT T

A) $67 \quad 7 \quad 1986 \quad 53.35-165.88 \quad 57 \cdot 5.5 \quad 4.4 .260 .73 .96 .17 .77 .43 . \quad 66$. CMT C

A) $68 \quad 71986 \quad 53.34-165.86 \quad 66.5 .1 \quad 352 . \quad 2.255 .76 .62 .14 .68 .45 . \quad 70$. CMT C

REG \# MO DA YR LAT LON H M PAZ PPL TAZ TPL BAZ BPL ST DIP RAKE REF M

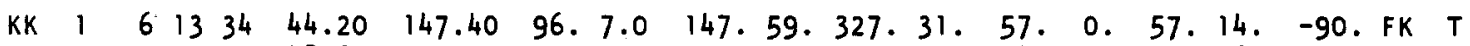

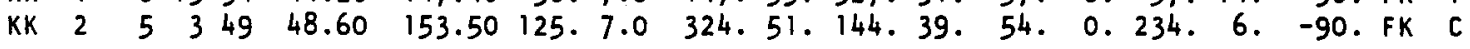




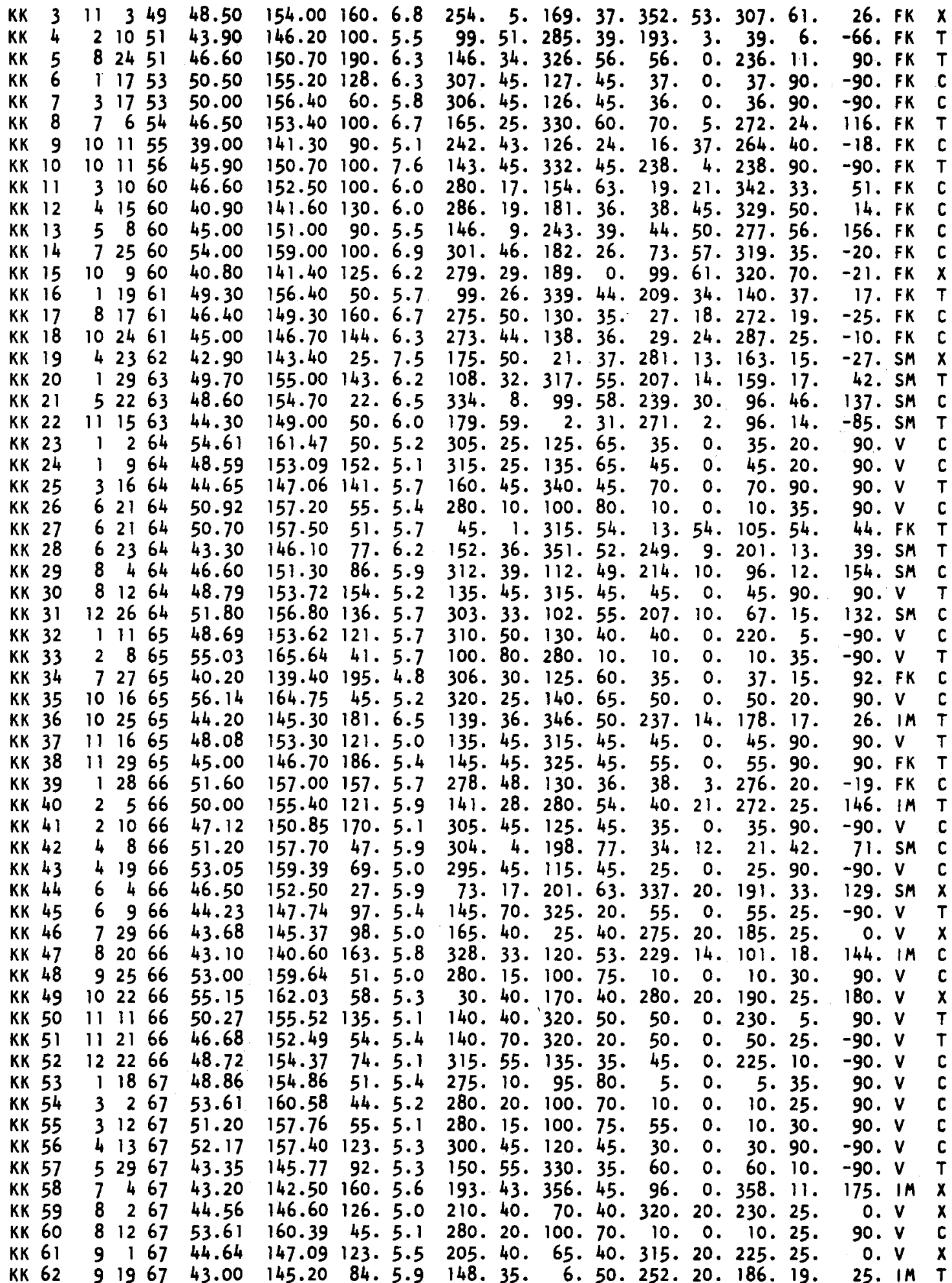




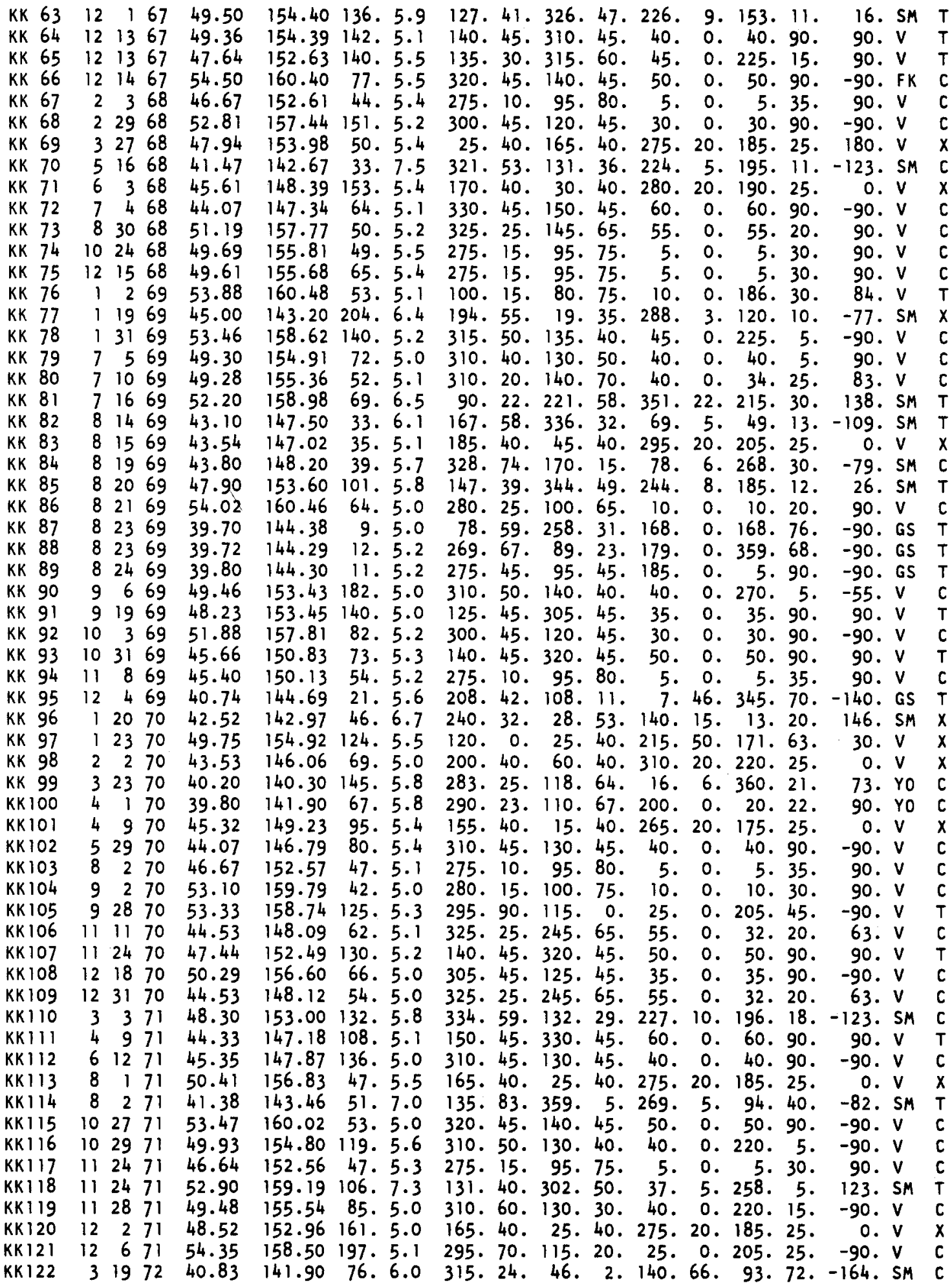




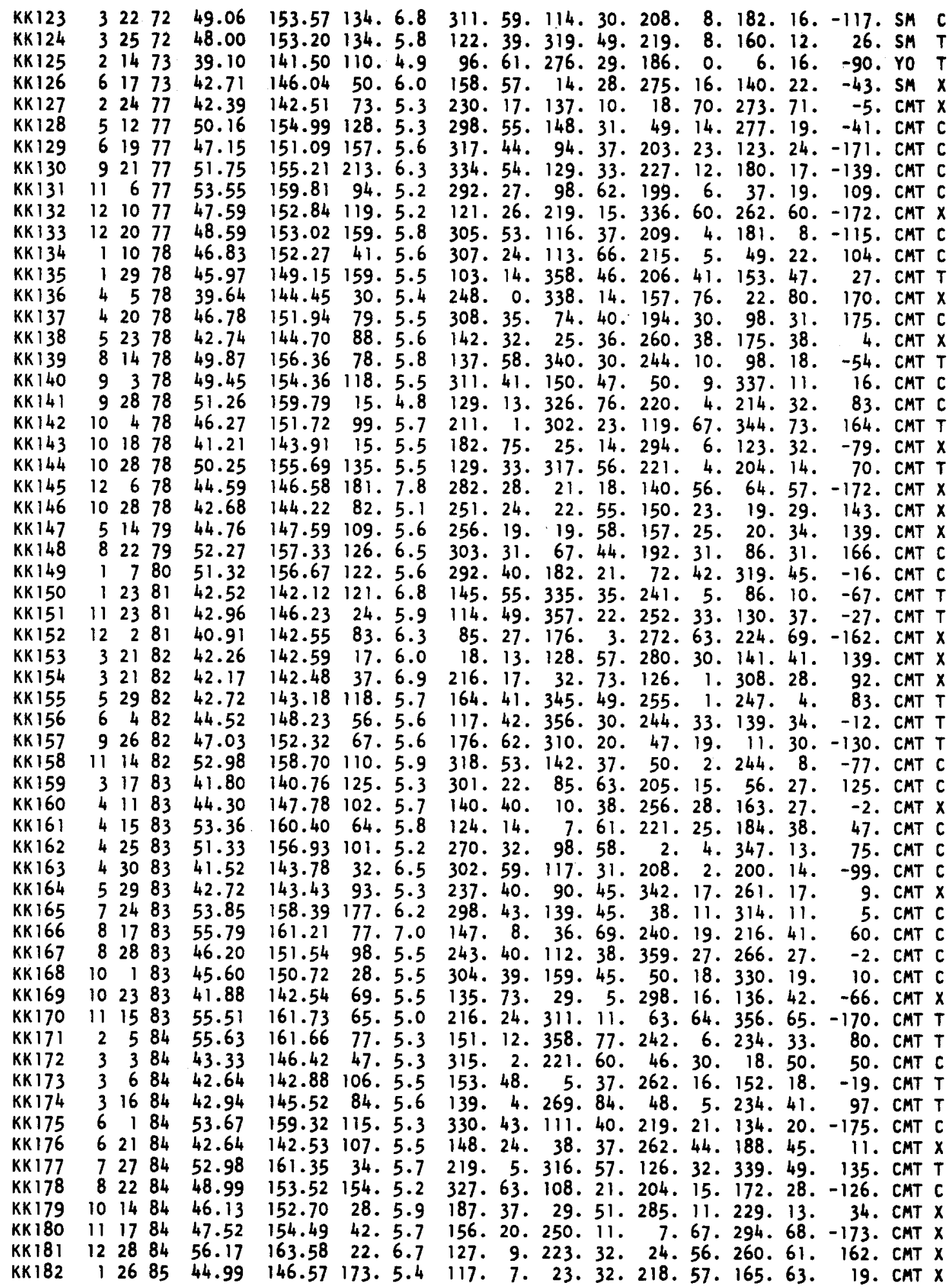




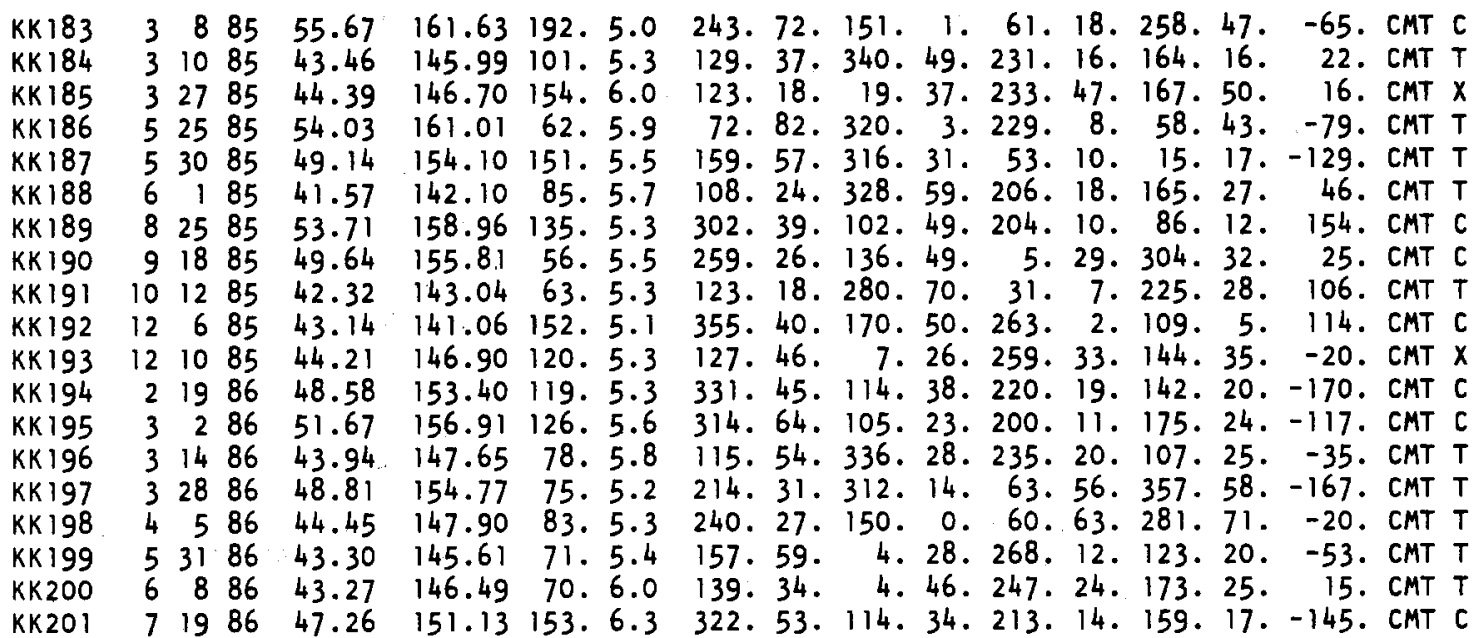

REG \# MO DA YR LAT LON H SOLOMON ISLANOS

\begin{tabular}{|c|c|c|c|c|c|c|c|c|c|c|c|c|c|c|c|c|c|}
\hline & $\begin{array}{r}2 \\
2 \\
3 \\
4 \\
5 \\
6 \\
7 \\
8 \\
9 \\
10 \\
11 \\
12 \\
13 \\
14 \\
15 \\
16 \\
17 \\
18 \\
19 \\
20 \\
21 \\
22 \\
23 \\
24 \\
25 \\
26 \\
27 \\
28 \\
29 \\
30\end{array}$ & $\begin{array}{r}12 \\
12 \\
4 \\
6 \\
4 \\
7 \\
8 \\
10 \\
11 \\
12\end{array}$ & $\begin{array}{r}28 \\
4 \\
30 \\
9 \\
3 \\
20 \\
8 \\
6 \\
29 \\
7 \\
30 \\
20\end{array}$ & $\begin{array}{l}64 \\
64\end{array}$ & $\begin{array}{l}-5 . \\
-5 . \\
-5 . \\
-4 . \\
-4 . \\
-5 . \\
-5 . \\
-5 . \\
-7 . \\
-6 . \\
-7 . \\
-5 . \\
-0\end{array}$ & & $\begin{array}{c}58 . \\
84 . \\
76 . \\
82 . \\
65 . \\
76 . \\
213 . \\
118 . \\
13 . \\
38 . \\
180 . \\
71 . \\
66 . \\
73 . \\
116 . \\
57 . \\
76 . \\
59 . \\
69 . \\
76 . \\
61 . \\
42 . \\
107 . \\
79 . \\
109 . \\
133 . \\
95 . \\
161 .\end{array}$ & $\begin{array}{l}5 \\
6 \\
5 \\
5\end{array}$ & 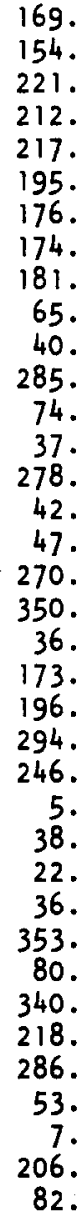 & $\begin{array}{r}35 . \\
4 . \\
0 . \\
0 . \\
12 . \\
13 . \\
40 . \\
24 . \\
03 . \\
4 . \\
30 . \\
75 . \\
58 . \\
19 . \\
5 . \\
21 . \\
5 . \\
13 . \\
15 . \\
60 . \\
17 . \\
35 . \\
54 . \\
13 . \\
5 . \\
42 . \\
20 . \\
2 . \\
49 . \\
7 .\end{array}$ & $\begin{array}{r}320 . \\
122 . \\
37 . \\
12 . \\
356 . \\
308 . \\
59 . \\
328 . \\
308 . \\
163 . \\
326 . \\
196 . \\
182 . \\
222 . \\
185 . \\
11 . \\
170 . \\
238 . \\
353 . \\
339 . \\
114 . \\
45 . \\
255 . \\
218 . \\
112 . \\
141 . \\
259 .\end{array}$ & $\begin{array}{l}5 . \\
5 . \\
5 . \\
1 . \\
5 . \\
9 . \\
8 . \\
0 . \\
0 .\end{array}$ & $\begin{array}{r}64 . \\
128 . \\
302 . \\
127 . \\
104 . \\
86 . \\
60 . \\
286 . \\
157 . \\
143 . \\
38 . \\
235 . \\
292 . \\
57 . \\
132 . \\
314 . \\
178 . \\
80 . \\
134 . \\
263 . \\
103 . \\
24 . \\
142 . \\
103 .\end{array}$ & $\begin{array}{r}0 . \\
24 . \\
9 . \\
0 . \\
0 . \\
0 . \\
25 . \\
30 . \\
18 . \\
66 . \\
34 . \\
15 . \\
10 . \\
61 . \\
0 . \\
21 . \\
24 . \\
0 . \\
9 . \\
0 . \\
12 . \\
0 . \\
10 . \\
28 . \\
0 . \\
50 . \\
47 . \\
29 . \\
33 . \\
11 . \\
20 . \\
11 .\end{array}$ & $\begin{array}{r}24 \\
98 \\
64 \\
128 \\
165 \\
173 \\
56 \\
244 \\
315\end{array}$ & & $\begin{aligned} & 90 . \mathrm{IM} \\
& 125 . \mathrm{MOM} \\
& 77 . \mathrm{JM} \\
& 90 . \mathrm{JM} \\
& 91 . \mathrm{JM} \\
& 90 . \mathrm{IM} \\
& 180 . \mathrm{IM} \\
& 27 . \mathrm{IM} \\
& 63 . \mathrm{IM} \\
& 15 . \mathrm{JM} \\
& 11 . \mathrm{R} 74\end{aligned}$ \\
\hline
\end{tabular}


S1 $38 \quad 22578 \quad-4.19 \quad 152.83 \quad 40.5 .4 \quad 214.28 .323 .31 .90 .46 .357 .46 . \quad 178$. CMT $X$

$\begin{array}{lllllllllll}51 & 39 & 3 & 6 & 78 & -4.93 & 151.76 & 95.5 .5 & 23.18 .136 .49 .280 .35 .155 .41 . & 152 . \text { CMT X }\end{array}$ S1 $40 \quad 7 \quad 1878 \quad-6.44 \quad 153.16 \quad 15.5 .7 \quad 279.76 .36 .7 .127 .12 .112 .40 .-109$. CMT T $\begin{array}{lllllllllllllll}51 & 41 & 8 & 5 & 78 & -3.58 & 152.29 & 249.5 .7 & 256.58 . & 48.29 .145 .12 .107 .20 . & -130 . \text { CMT T }\end{array}$ S1 $42 \quad 10 \quad 1578 \quad-5.58 \quad 148.06 \quad 162.5 .8 \quad 347.62 .215 .19 .118 .19 .334 .31 . \quad-50$. CMT C 51 $43 \quad 10 \quad 2078 \quad-4.37 \quad 152.01 \quad 146.5 .3 \quad 11.41 .128 .27 .240 .37 .168 .38 .-166$. CHT $\begin{array}{llllllllllllll}51 & 44 & 12 & 28 & 78 & -5.38 & 154.21 & 125.5 .4 & 330.55 .203 .23 .102 .25 .332 .32 . & -35 . & \text { CMT C }\end{array}$ S1 $45 \quad 12479 \quad-6.24 \quad 155.23 \quad 149.5 .5 \quad 320.50 .223 .6 .128 .39 .348 .52 . \quad-36$. CMT

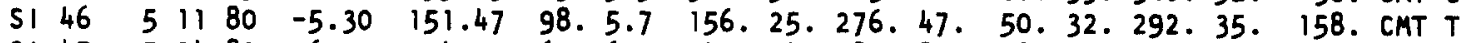

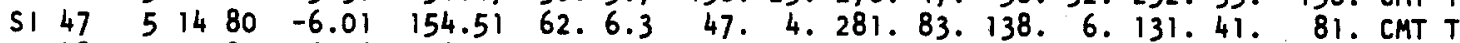
S1 $48 \quad 2 \quad 2481 \quad-6.06 \quad 148.74 \quad 78.6 .6 \quad 185.99 .315 .76 .93 .11 .288 .37 .108$. CMT T

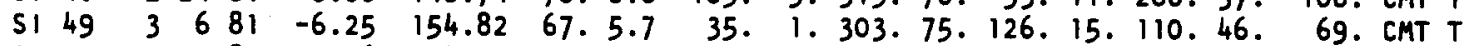

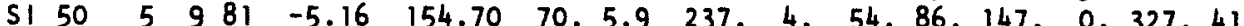

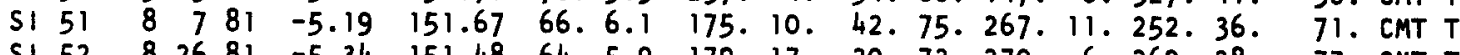

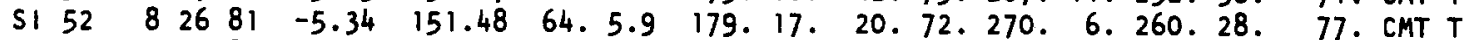

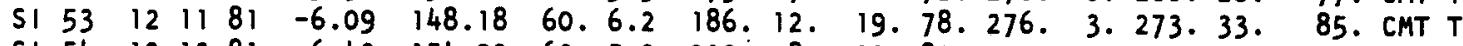
SI $\begin{array}{lllllllllllllll}54 & 12 & 13 & 81 & -6.43 & 154.92 & 63.5 .9 & 219 . & 8 . & 22.82 .129 . & 2.312 .37 . & 94 . \text { CMT T }\end{array}$ SI $55 \quad 8 \quad 8 \quad 820-4.66 \quad 151.78148 .5 .6 \quad 46.45 .144 .7 .241 .44 .196 .54 .-149$. CMT C S1 $56 \quad 8 \quad 9882 \quad-5.00 \quad 151.39136 .5 .5 \quad 19.70 .159 .16 .252 .13 .231 .31 .-115$. CMT C $323.67 .230 .1 .139 .23 .342 .48 .-58$. CMT $C$ $150.0557 .6 .2 \quad 307.4 .38 .18 .204 .71 .81 .74$. 170. CMT $x$ 153.5170 .7 .7 59. 0.150 .68 .329 .22 .170 .49 .120$. CMT T $153.1365 .6 .3 \quad 195.18 .319 .61 .97 .23 .316 .33 .133$. CMT T $153.7078 .5 .5 \quad 231.10 .123 .62 .326 .26 .293 .42 .49$. CMT T 154.5940 .5 .6 269. 18. 157.50. 12. 34. 319. 41. 30. CMT $X$ 150.92101 .6 .4 38. 43.161 .30 .272 .32 . 198. 33. -166. CMT $x$ $150.94111 .5 .6 \quad 50.35 .163 .30 .283 .41 .199 .41 .-175$. CMT $x$

230. $45.18 .41 .123 .16 .40 .15 .-172$. CMT $x$ $148.30170 .6 .1 \quad 187.45 .61 .30 .312 .30 .203 .31 .-16$. CMT $X$ $\begin{array}{llllll}530 & 84 & -4.88 & 151.60 & 157.6 .2\end{array}$ $\begin{array}{llll}6 & 21 & 84 & -5.16\end{array}$ $151.45 \quad 48.5 .3$ 138. 18. 282. 68. 44. 12. 247. 29. 116. CMT T 50. 0.320 .85 .140 .5 .135 .45 .83$. CMT T 53. 3. 145. 28. 318.62. 185. 68. 162. CMT $X$ 350. 62. 97. 9. 191.26. 159.43. -131. CMT $C$ 148.45135 .5 .8 $\begin{array}{llll}11 & 29 & 84 & -5.44\end{array}$ $\begin{array}{llll}12 & 8 & 84 \\ 12 & -1\end{array}$

S) 74

S1 75

SI 76

1985

$-5.71$

154.56 89. 5.1 $354.54 .204 .32 .105 .14 .335 .19 .-38$. CMT C $152.48 \quad 35.5 .6$ 149.42108 .5 .7 294. 49. 31. 5. 125. 40. 86. 53. -144 . CMT C 148. 67. 261. 9. 354. 21. 328, 40, -124 . CMT $x$ 155.84 56. 5.4 315. 49. 161. 38. 61. 13. 307. 14. -23. CMT C $\begin{array}{lll}154.63 & 54.5 .4 \\ 148.79 & 171.5 & 5.2\end{array}$ 158.27168 .5 .2 149.20112 .5 .4

SI 81

SI 82

$\begin{array}{lll}6 & 3 & 85\end{array}$ $-6.01$ 151.5730 .5 .5 $\begin{array}{lllllll}6 & 24 & 85 & -5.81 & 148.41 & 118.5 & 5.4\end{array}$ $\begin{array}{lll}728 & 85\end{array}$ SI $84 \quad 8 \quad 13 \quad 85 \quad-4.36$ $-5.02$ 151.99117 .5 .2 31.7 .137 .66 .298 .23 .145 .43 .125$. CMT C 43. 22. 249.65. 137. 10.114. 25. 65. CMT C 52. 38. 157. 17. 266, 47, 202. 50. -163 . CMT C 144. 12. 327. 78. 234. 1. 233. 33. 89. CMT T 105. 22. 197. 5. 299. 68. 243. 71. -168. CMT $X$ 178. 41. 346. 48, 83. 6. 322. 8. 154. CMT T 46. 56. 188. 28. 288. 17. 240.23. -140 . CMT $X$ 26. 56. $201.33 .293 .2 .281,14 .-103$. CMT $C$ 120. 0. 30.80. 210. 0. 200. 46. 76. CMT T 152.7861 .5 .3 $152.86 \quad 41.5 .4$ 154.32214 .5 .2 123085 3786 $-5.57$

S। 88

S। 89

SI 90

SI 91

S। 92

S1 93

S1 94

SI 95

SI 96 32886 4586 41486 5586 $\begin{array}{lll}5 & 28 & 86\end{array}$ $\begin{array}{lll}6 & 2386\end{array}$ $\begin{array}{lll}7 & 286\end{array}$ 91286 151.76101 .5 .8 270. 9. 8. 41. 169. 48. 40.55. 154. CMT $x$ 228. 18. 339. 48. 124. 36. 359. 42. 153. CMT T 121. 9. 214.16 . 3. 71. 257.72. 175. CMT $X$ 155. 47. 319. 42. 57. 8. 344. 8. -162 . CMT T $-6.87 \quad 155.7967 .5 .3 \quad 40.5 .144 .70 .309 .19 .150 .43 .119$. CMT T $-4.86 \quad 151.27205 .5 .4 \quad 148.22 .44 .31 .268 .50 .189 .51$. 7. CMT $X$ $-7.05$ 155.9865 .5 .6 256. 24.149 .33 .15 .47 .296 .48 . $155.87168 .5 .2 \quad 33.74 .299 .1 .209 .16 .45 .46$.

8. CMT $X$ $-6.02$ 148.95100 .5 .6 $267.12,10,45,166,42,37,50$. $\begin{array}{llllllll}-7.81 & 150.64 & 29.5 .5 & 180.90 .138 . & 1.48 . & 0.228 .45 .\end{array}$ 153.7464 .5 .2 232. 1. 326. 79. 42. 11. 333. 45. -68. CMT C 153. CMT T -90. CMT T 106. CMT T

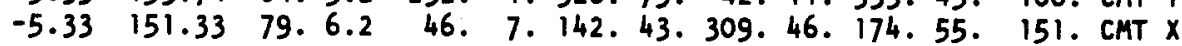


SI $98 \quad 102086 \quad-4.83 \quad 153.45 \quad 92.5 .5 \quad 245.40 .110 .41 .357 .24 .269 .23 . \quad 1$. CMT X 51 $99 \quad 102786 \quad-4.28 \quad 152.96 \quad 52.5 .0 \quad 249.5 .346 .54 .155 .36 .11 .51 .139$. CMT T

REG \# MO DA YR LAT LON H M PAZ PPL TAZ TPL BAZ BPL ST DIP RAKE REF M

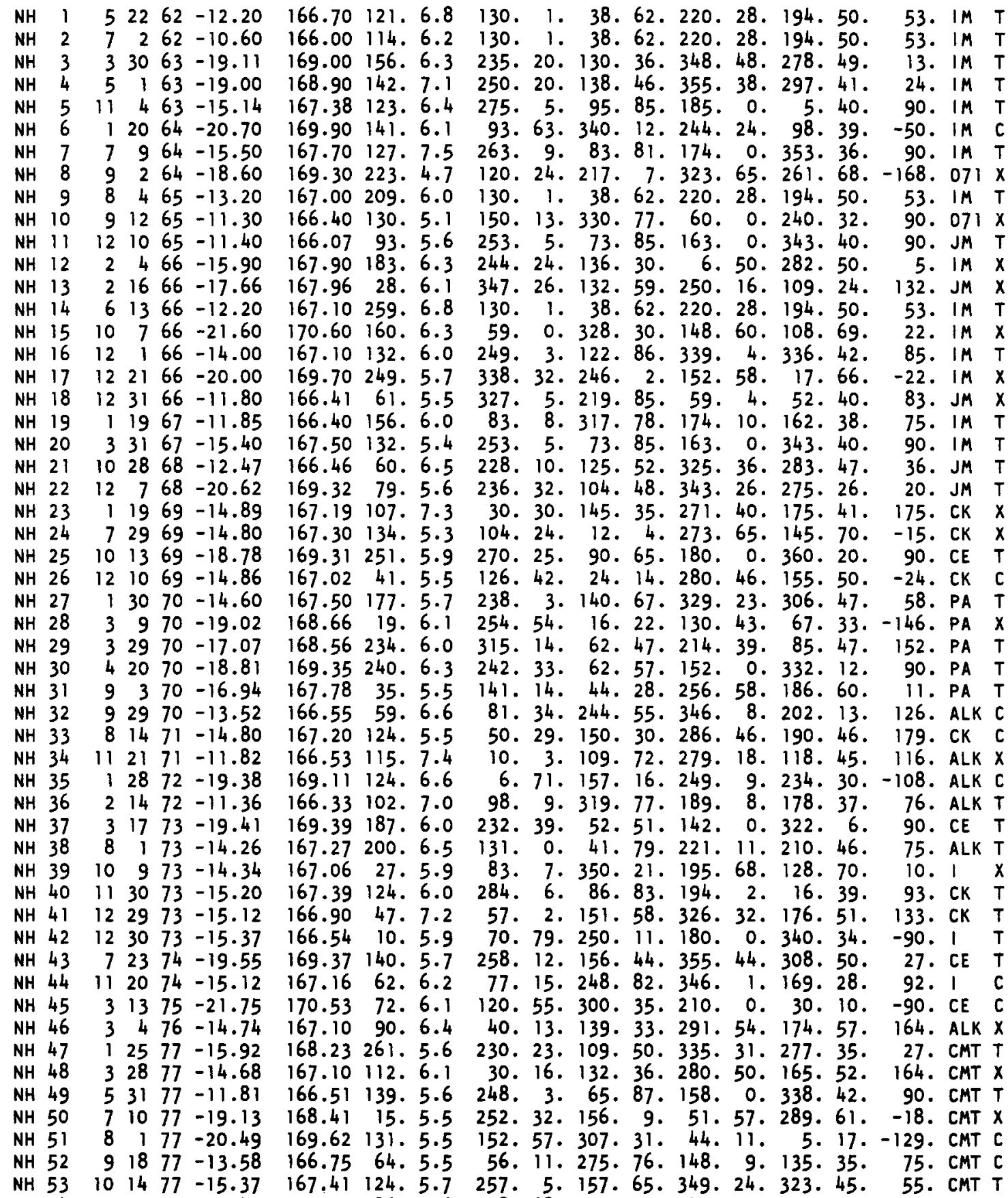

NH $54 \quad 1023 \quad 77 \quad-21.49 \quad 170.30 \quad 86.5 .6 \quad 198.68 .315 .10 .49 .19 .23 .39 .-122$. CMT X 
NH $55 \quad 10 \quad 30 \quad 77 \quad-14.89$ NH $56 \quad 3 \quad 2978=19.64$ $\begin{array}{llllll}\text { NH } & 57 & 5 & 13 & 78 & -14.52\end{array}$ $\begin{array}{llllll}\text { NH } & 58 & 5 & 18 & 78 & -20.07\end{array}$ NH $59 \quad 5 \quad 26 \quad 78-20.86$ NH $60 \quad 6 \quad 24 \quad 78-15.00$ $\begin{array}{llllll}\text { NH } & 61 & 6 & 29 & 78 & -20.26\end{array}$ NH $\begin{array}{lllll}62 & 7 & 28 & 78 & -18.82\end{array}$

NH 63

NH 64

NH 65

NH 66

NH 67

NH 68

NH 69

$\mathrm{NH} 70$

NH 71

$\mathrm{NH} 72$

$\mathrm{NH} 73$

$\mathrm{NH} 74$

NH 75

NH 76

$\mathrm{NH} 77$

NH 78

NH 79

NH 80

NH 81

NH 82

NH 83

NH 84

NH 85

NH 86

NH 87

NH 88

NH 89

NH 90

NH 91

$\mathrm{NH} 92$

NH 93

NH 94

NH 95

NH 96

NH 97

NH 98

$\mathrm{NH} 99$

NHIOO

NH101

$\mathrm{NH} 102$

$\mathrm{NH} 103$

$\mathrm{NH} 104$

NH105

NH106

NH107

NH108

NHIOS

NHI 10

NHIII

$\mathrm{NH} 112$

$\mathrm{NH} 113$

NHI 14 $\begin{array}{llll}8 & 3 & 78 & -15.37\end{array}$ $\begin{array}{llll}8 & 8 & 78 & -12.38\end{array}$ $\begin{array}{lllll}8 & 24 & 78 & -15.62\end{array}$ $\begin{array}{llll}8 & 30 & 78 & -15.47\end{array}$ $\begin{array}{llll}9 & 6 & 78 & -13.32\end{array}$ $92378-13.92$ $92678-13.31$ $\begin{array}{llll}10 & 19 & 78 & -13.49\end{array}$ $12779-18.54$ $\begin{array}{llll}2 & 14 & 79 & -15.56\end{array}$ $\begin{array}{llll}2 & 27 & 79 & -14.97\end{array}$ $\begin{array}{llll}5 & 1 & 79 & -21.24\end{array}$ $\begin{array}{llll}6 & 19 & 79 & -14.51\end{array}$ $\begin{array}{llll}7 & 22 & 80 & -20.30\end{array}$ $92680-15.03$ $13181-11.90$ $\begin{array}{lllll}2 & 19 & 81 & -21.54\end{array}$ $\begin{array}{llll}424 & 81 & -12.10\end{array}$ $52881-14.69$ $\begin{array}{lllll}6 & 20 & 81 & -21.38\end{array}$ $\begin{array}{lllll}7 & 6 & 81 & -22.26\end{array}$ $\begin{array}{lllll}8 & 23 & 81 & -22.08\end{array}$ $\begin{array}{llll}17 & 82 & -12.15\end{array}$ $\begin{array}{llll}4 & 25 & 82 & -15.10\end{array}$ $\begin{array}{lllll}9 & 5 & 82 & -15.82\end{array}$ $\begin{array}{lllll}10 & 2 & 82 & -14.74\end{array}$ $\begin{array}{lllll}2 & 3 & 82 & -13.35\end{array}$ $\begin{array}{llll}4 & 4 & 83 & -15.02\end{array}$ $\begin{array}{llll}4 & 17 & 83 & -20.75\end{array}$ $\begin{array}{lllll}7 & 5 & 83 & -22.55\end{array}$ $\begin{array}{lllll}8 & 22 & 83 & -14.83\end{array}$ $\begin{array}{lllll}9 & 4 & 83 & -21.01\end{array}$ $\begin{array}{llll}12 & 28 & 83 & -13.11\end{array}$ $\begin{array}{lllll}2 & 17 & 84 & -16.88\end{array}$ $22784-15.12$ $22784-16.10$ $4384-14.32$ $\begin{array}{lllll}4 & 6 & 84 & -18.90\end{array}$ $\begin{array}{llll}4 & 10 & 84 & -17.62\end{array}$ $\begin{array}{lllll}5 & 20 & 84 & -15.41\end{array}$ $7384-14.15$ $7484-12.91$

$91184-15.54$ $\begin{array}{llll}921 & 84 & -14.90\end{array}$ $111184-12.69$ $\begin{array}{llll}11 & 15 & 84 & -22.02\end{array}$ $2185-18.70$ $\begin{array}{llll}2 & 28 & 85 & -19.18\end{array}$ $\begin{array}{lllll}3 & 6 & 85 & -12.49\end{array}$ $\begin{array}{llll}6 & 9 & 85 & -21.55\end{array}$ $\begin{array}{llll}8 & 7 & 85 & -20.62\end{array}$
166.95107 .6 .2

169.1298 .6 .0 167.32180 .6 .8 $169.15 \quad 54.5 .3$ 168.59 15. 5.5 167.27119 .5 .5 $168.17 \quad 15.5 .6$ 169.00 200. 5.3 $167.48 \quad 120.5 .7$ $\begin{array}{lllll}9 & 28 & 78 & -19.14\end{array}$
166.45 58. 6.2

167.74130 .5 .3 167.48126 .5 .2 167.14202 .6 .7 167.21207 .6 .7 167.07208 .5 .6 168.98144 .5 .6 $167.07200 \cdot 5.2$ $168.21 \quad 25.5 .8$ 167.57127 .6 .1 167.33 109. 5.6 $169.80 \quad 73.7 .4$ 167.22112 .5 .6 169.61133 .6 .3 $167.30 \quad 92.5 .9$ 166.4270 .5 .8 $169.46 \quad 35.6 .0$ $166.52 \quad 49.5 .7$ 167.28 138. 6.2 169.45 15. 5.8 $171.73 \quad 58.7 .5$ 170.89125 .5 .8 166.73160 .5 .8 167.44121 .5 .5 167.99224 .5 .3 167.28155 .6 .0 167.21229 .6 .5 167.27 120. 6.1 169.18 29. 6.3 171.02 19. 6.5 166.99 92. 5.5 169.77 104. 5.4 166.83 98. 5.5 167.83 68. 5.4 167.28183 .5 .1 167.93188 .5 .6 167.14165 .5 .4 $168.85 \quad 175.6 .8$ 168.2375 .5 .4 $167.47125 \cdot 5.5$ 167.15201 .5 .2 166.44194 .5 .2 $167.65141 \cdot 5.5$ 167.40141 .5 .3 166.7788 .5 .7 170.9099 .7 .0 169.00222 .5 .1 168.6761 .5 .5 166.6263 .5 .7 170.47138 .5 .4 169.9078 .5 .5
58. 6. 151.25 .316 .64 .192 .68$. 242. 45. 107. 35. 359. 24. 254. 25 . 67. 1. 160.68. 337. 22. 178. 48. 49. 7. 177. 78. 318. 9. 150. 39. 252. 75. 71. 15. 161. 0. 160. 30 . 30. 2. 125. 73. 299. 16. 137. 46. 274. 74. 73. 15. 165. 5. 155. 30. -101. CMT T $101.35 .341 .35 .220 .35 .131 .35 . \quad 1$. CMT C 258. 12. 150. 57. 355. 30. 315. 42. 42. CMT T 83. 4. 312.84. 173. 5. 168.41. 83. CMT C 286. 15. 127. 74. 17. 5. 8. 31. 79. CMT T 284. 24. 113.66. 16. 3. 7.21. 81. CMT T 242. 9. $131.65 .336 .23 .307 .41 . \quad 53$. CMT T 260. 2. 162. 76. 350.14. 336. 45. 70. CMT T 85. 4. 180. 53. 352. 36. 207. 52. 139. CMT T 253. 40. 100. 47. 355. 14. 280. 14. 15. CMT T 266. 7. 41.80.175. 7. 4. 39. 101. CMT T 131. 51. 311. 39. 221. 0. 41. 6. $-90.1 \times$ 271. 17. 77. 73. 180. 4. 7. 29. 98. CMT T 335. 7. 243. 17. 86.71. 20.73. 7. CMT $X$ 226. 38. 340. 27. 95. 40. 18. 41. -170 . CMT $x$ $12.61,161,25,257,13,224,23,-126$. CMT C 91. 68. 266. 22. 357. 2. 353. 23. -94. CMT C 52. 17. 300.51. 154.34. 103. 41. 32. CMT C 172. 1. 265. 56. 82. 34. 292. 53. 135. CMT $X$ 173. 6. 270.51 .78 .39 .297 .51$. 142. CMT $X$ 90. 17. 234. 70. 356. 11. 196. 29. 112. CMT C 57. 3. 150. 41.324 .49 .185 .60 .151 . CMT T 211. 52. 106. 12. 7. 37. 232. 45. -35 . CMT T 191. 38. 318. 37. 74. 30. 345. 31. -179 . CMT $x$ 193. 23. 302. 38. 79. 43. 331. 45. 167. CMT $x$ 267. 7. 30. 77. 176. 11. 9. 39. 107. CMT T 271. 11. 139. 73. 3. 12. 346. 36. 68. CMT T 9. 29. 132. 45.260 .31 .149 .33 .163$. CMT $x$ 63. 8. 163.48 .326 .41 .190 .51 .147 . CMT T 249. 5. 134. 77. 340.11. 326. 41. 72. CMT T 51. 21.173 .54 .309 .28 .180 .34 .146$. CMT T 289. 31. 161. 45. 38. 28. 326. 30. 16. CMT $X$ 178. 40. 277. 11. 19. 48. 326. 54. -157 . CMT $X$ 40.42. 159.29.271. 35. 197. 35. -167. CMT $C$ 90. 52. 277. 38. 184. 4. 33. 8. -62 . CMT C 24. 67. 263. 13. 169. 19. 16. 36. -57 . CMT C 222. $41.113 .21 .3 .42 .249 .44 .-18$. CMT T 223. 58. 110. 14. 12. 28. 233. 40. -42. CMT T 317. 52. 151. 38. 56. 7. 280. 10. -45. CMT $X$ 77. 4. 175. 63. 344. 26. 193. 47. 128. CMT T 254. 35. 95. 53. 351. 10. 304. 14. 41. CMT T 274. 22. 172. 29. 36. 53. 315.53. 6. CMT $X$ 236. 4. 123. 80. 327. 9. 316. 42. 76. CMT T 101. 10. 242.77 .10 .8 .201 .36 .104$. CMT T 273. 6. 40.80 .183 .8 .13 .40 .103$. CMT T 281. $20.111 .70 .12 .3 .3 .25 . \quad 83$. CMT T 216. 42. 78. 39. 328. 23. 234. 23. -4. CMT T 298. 22. 134.67. 31. 6. 17. 24. 75. CMT T 207. 36. 338. 42. 95. 27. 357. 27. 173. CMT $X$ 162. 21. 23. 64. 258. 16. 226. 27. 56. CMT T 86. 1. 186.82. 356.8 .184 .45 .101 . CMT C 81. 12. 258.78 .350 .0 .172 .33 .91 . CMT C $227.47,341,21,87,35.27,40,-156$. CMT $x$ 106. 36. 331.44 .215 .24 .137 .25$. 10. CMT C 
NH1 $15 \quad 8 \quad 1985-11.62 \quad 166.15209 .5 .1 \quad 301.78 .68 .7 .159 .9 .147 .39 .-105$. CMT C NH116 $8 \begin{array}{llll} & 28 & 85 & -22.18\end{array}$ NHI17 $10 \quad 6 \quad 85-18.93$ NH118 $11586-21.38$ NH119 $21086 \quad-21.58$ $\mathrm{NH} 120 \quad 2 \quad 1386-14.29$ NH121 $21486-13.47$ NH122 $21686-12.28$ NH123 $3 \quad 586-18.80$ NH1 $124 \quad 3 \quad 2686-14.32$ $\begin{array}{lllll}\text { NH1 } 125 & 5 & 1 & 86 & -21.87\end{array}$ $\begin{array}{llllll}\text { NH1 } 126 & 5 & 14 & 86 & -14.88\end{array}$ $\begin{array}{lllll}\mathrm{NH} 127 & 7 & 16 & 86 & -19.51\end{array}$ NHI $28 \quad 9 \quad 16 \quad 86-12.35$ NH129 $92986-14.93$ NH130 $10 \quad 22 \quad 86-10.57$ $\begin{array}{lllll}\text { NHI } 131 & 10 & 23 & 86 & -15.57\end{array}$ $\begin{array}{llllll}\mathrm{NH} 132 & 11 & 12 & 86 & -12.40\end{array}$ NH133 $112086-16.27$

171.16116 .5 .2 169.39266 .6 .1 170.28121 .7 .1 170.29110 .5 .6 167.34207 .5 .7 167.07185 .5 .0 167.12256 .5 .1 169.58292 .5 .7 167.28203 .4 .9 169.8844 .6 .1 167.25121 .5 .2 169.17118 .6 .6 166.60118 .5 .5 167.26111 .5 .5 $166.04 \quad 183.6 .0$ 167.56171 .6 .2 166.8360 .5 .3 167.5525 .5 .7
71. 24. 305. 52. 174. 27. 119. 32 . 296. 14. 43. 50. 195. 36. 64. 45. 234. 32. 4. 46. 125. 27 . 17. 28.

37.0 .307 .49 .127 .41 .94 .58$. 68. 12. 238.78 .338 .2 .161 .33$. 99. 2. 357. 78. 189. 12. 177. 44. 243.11 .132 .62 .339 .26 .305 .41$. 306. 3. 38. 42. 212.48 .73 .59$.

56. 8. 158. 57. 321. 32. 177. 46. 217.22 .320 .28 .95 .53 .357 .53$. 265. 14. 157. 51. 6. 35.317 .44$. 353.71 .162 .19 .253 .3 .246 .26$. 84. 7. 193.68. 351. 20. 196. 42. 293. 11. 93.78. 202. 4. 28. 34. 268. 23. 109. $65 . \quad 1.8 .342 .23$. 270. 19. 171. 24.34 .59 .312 .59$. 267. 13. 2. 21.148 .65 .43 .66$. 190. 27.65 .49 .296 .29 .234 .32$.
30. CMT C 148. CMT T 163. CMT $X$ 39. CMT $X$ 94. CMT T 73. CMT T 49. CMT T 149. CMT T 137. CMT T 175. CMT $X$ 33. CMT T -98. CMT $X$ 122. CMT T 97. CMT T 69. CMT T

4. CMT $X$ 174. CMT $X$ 24. CMT T

REG \# MO DA YR LAT LON H M M PAZ PPL TAZ TPL BAZ BPL ST DIP RAKE REF M

TK $1 \quad 112249-29.30-178.20191 \cdot 7.3$ $\begin{array}{llllllllll}\text { TK } & 2 & 8 & 18 & 54 & -21.50 & -175.00 & 160.6 .9\end{array}$ $\begin{array}{llllllllllllllll}\text { TK } & 3 & 6 & 11 & 57 & -30.00 & -178.00 & 100.7 .0\end{array}$ $\begin{array}{lllllllll}\text { TK } & 4 & 3 & 27 & 60 & -39.10 & 174.90 & 228.6 .6\end{array}$ $\begin{array}{lllllllll}\text { TK } & 5 & 7 & 4 & 63 & -26.30 & -177.70 & 190.6 .5\end{array}$ $\begin{array}{llllllll}\text { TK } & 6 & 10 & 8 & 63 & -15.00 & -173.20 & 25.0 .0\end{array}$ TK $7 \quad 72164-26.00-177.90200 .6 .4$ TK $8 \begin{array}{llllllll}8 & 8 & 5 & 64 & -32.20 & -179.80 & 235 & 5.7\end{array}$ $\begin{array}{lllllllll}\text { TK } & 9 & 3 & 18 & 65 & -19.90 & -175.90 & 219.5 & 5.5\end{array}$ TK $10 \quad 32265-15.30-173.40 \quad 44.6 .0$ $\begin{array}{llllllll}T K & 11 & 3 & 23 & 65 & -15.10 & -173.40 & 153.4 .6\end{array}$ $\begin{array}{lllllllll}\text { TK } & 12 & 8 & 20 & 65 & -22.80 & -176.20 & 65.6 .1\end{array}$ $\begin{array}{lllllllll}\text { TK } & 13 & 12 & 8 & 65 & -37.10 & 177.50 & 156.6 .2\end{array}$ $\begin{array}{llllllll}\text { TK } 14 & 8 & 10 & 66 & -20.10 & -175.40 & 95.6 .5\end{array}$ TK $15 \quad 8 \quad 28 \quad 66-36.21 \quad 178.71240 .5 .5$ $\begin{array}{lllllll}\text { TK } 16,167 & -15.20 & -173.80 & 23.5 .9\end{array}$ TK $17 \quad 3 \quad 4 \quad 67-18.40-175.40 \quad 228.5 .5$ TK 18 TK 19

TK 20

TK 21

TK 22

TK 23

TK 24

TK 25

TK 26

TK 27

TK 28

TK 29

TK 30

TK 31

TK 32

TK 33

TK 34

TK 35

$\begin{array}{ll}\text { TK } & 36 \\ \text { TK } & 37\end{array}$ $81267-24.70-177.50 \quad 123.6 .5$

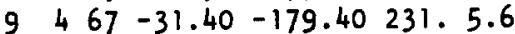
$31168-16.20-173.90112 .6 .0$ $8 \quad 168-26.60-177.50 \quad 123.5 .6$

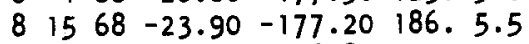
$\begin{array}{lllllll}9 & 26 & 68 & -20.86 & -176.89 & 202.5 .7\end{array}$ $\begin{array}{lllllll}4 & 28 & 69 & -22.36 & -177.66 & 288 & 5.9\end{array}$ $5 \quad 169-16.70-174.60205 .6 .0$ $\begin{array}{lllllll}10 & 26 & 69 & -16.17 & -173.95 & 127.6 .7\end{array}$

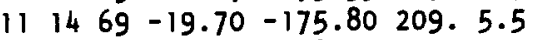
$\begin{array}{lllllll}1 & 8 & 70 & -34.74 & 178.57 & 179.7 .0\end{array}$ $12070-25.80-177.35 \quad 82.7 .2$ $\begin{array}{lllllll}2 & 18 & 70 & -20.83 & -176.71 & 240.5 .7\end{array}$ $\begin{array}{llllll}8 & 28 & 70 & -33.80 & -179.80 & 90.5 .7\end{array}$ $\begin{array}{lllllll}3 & 23 & 71 & -22.88 & -176.36 & 76.6 .1\end{array}$ $\begin{array}{llllllll}4 & 12 & 71 & -26.70 & -177.10 & 101.0 .0\end{array}$ $\begin{array}{llllllll}8 & 28 & 71 & -18.81 & -174.70 & 145.5 .4\end{array}$ $\begin{array}{llllll}9 & 12 & 71 & -26.70 & -177.10 & 101.5 .8\end{array}$

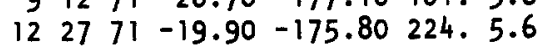
$11572-18.30-174.60135 .5 .7$
71. 60. 294. 22. 197. 18. 55. 29. -47. R64 T 250. 45. 115. 30. 10. 25. 259. 31. -16. FK C 190. 3. 303.83. 99. 6. 287. 42. 100. WH $X$ 89. 25. 243. 62. 354. 11. 202. 23. 121. FK T 339. 39. 71. 1. 164.51.122.63. -151 . ISO C $343.57 .194 .30 .97 .13 .319 .19 .-47$. I So $x$ 308, 42, 107, 47, 208, 8, 104, 8, 162, ISO C 74. 32. 254.58 .344 .0 .164 .13 .90$. I SO T 266. 38. 133. 43. 18. 25. 294. 23. 7. ISO C 339. 34.212 .40 .93 .30 .90 .32 . 6. ISO $x$ 347. 20. 156.70. 256. 3. 83.25. 98. is $x$ 263. 40. 93. 50.357. 6. 313. 5. 55. ISO C 42. 15. 288. 57. 140. 30. 98. 39. 41. IM T 282. 54. 62. 29. 163. 20. 110. 24. -145 . ISO C 91. 2. $181.37 .357 .54 .220 .63 .153 .077 x$ 354. 32. 203.54. 92. 14. 44. 19. 38. I So $x$ 258. 32. 144. 32. 21. 41. 291. 41. 0. B80 C 342. 24. 204.58. 81, 19. 38. 27. 43. CK $X$ 61. 32. 263. 56. 158. 10.119. 16. 50. IM T 339. 48. 234. 12. 137. 39. 3. 48. -31. IM $X$ 305. 3. $210,44.39 .46 .358 .58 .32 . R 79 x$ 72. 32. 268. 56. 166. 8. 136. 16. 55. B80 T 0. 72. $140,13.232 .8 .215 .34 .-111$. WM C 342. 11. 246. 24.94 .63 .26 .65$. 10. R79 $x$ 326. 69. 186.17. 91. 13. 295. 30. -65 . WM $C$ 334. 2. 239. 72. 65. 18. 46. 46. 65. B80 T 251. 54. 91. 34. 354. 9. 217. 15. -45. B80 C 101. 16. 252.59. 7. 14. 217. 37. 131. B80 T 330. 39. 150.51.240. 0. 60.6. 90. B80 C $310.52 .164 .32 .63 .16 .300 .21 .-30 . B 75 \mathrm{C}$ 248. 8. 339. 8. 114. 78. 24. 79. 180. R79 X 268. 44. 108. 44. 8. 10. 278 . 11. 0. B80 C 349. 10. 102.65. 255.23. 104. 40. 127. R79 X 109. 29. 336. 50. 214. 24. 152. 28. 25. KAW T 349. 10. 102.65. 255. 23. 104. 40. 127. R79 X 267. 32. 162. 22. 44. 50. 301.50. -8. B80 C 257. 37.123 .43 .7 .24 .286 .25$.

8. $B 80 \mathrm{C}$ 
TK $38 \quad 3 \quad 772-28.23-178.35200 .6 .7 \quad 352.39 .250 .14 .144 .48 .23 .52 . \quad-20.880 x$ TK $39 \quad 5 \quad 2272-17.70-175.20227 .6 .2 \quad 279.63 .164 .10 .68 .24 .281 .41 . \quad-50$. B80 C TK $4092272-16.50-174.50$ 186. 6.2 284. 53. 96. 37. 199. 4. 164. 8. -113. B80 C $1573-39.00 \quad 175.23150 .6 .2$ TK $42 \quad 12 \quad 1973-20.59-176.48 \quad 228.5 .8$ TK $4366474-15.85-175.10275 \cdot 6.0$ TK $44 \quad 11775-17.90-174.60140 .5 .8$ TK $45 \quad 1 \quad 2476-28.64-177.5978 .6 .2$ $\begin{array}{lllllllll}\text { TK } & 46 & 2 & 14 & 76 & -23.19 & -177.41 & 235.5 .9\end{array}$ $\begin{array}{llllllll}\text { TK } & 47 & 3 & 22 & 77 & -33.60 & 179.10 & 282.6 .0\end{array}$ $\begin{array}{lllllllll}\text { TK } 48 \quad 326 & 77 & -18.59 & -174.15 & 105.5 .6\end{array}$ $\begin{array}{lllllllll}\text { TK } & 49 & 6 & 6 & 77 & -19.24 & -175.64 & 247.5 .1\end{array}$ TK $50 \quad 6 \quad 22 \quad 77 \quad-22.88 \quad-175.90 \quad 61.8 .0$ $\begin{array}{llllllll}\text { TK } 51 & 6 & 26 & 77 & -22.70 & -175.47 & 59.5 & 5.4\end{array}$ $\begin{array}{lllllll}\text { TK } 52 & 7 & 9 & 77 & -22.30 & -175.00 & 18.5 .5\end{array}$ $\begin{array}{llllllll}\text { TK } 53 \quad 8 & 11 & 77 & -17.56 & -174.37 & 129.6 .7\end{array}$ $\begin{array}{llllllll}\text { TK } 54 & 8 & 21 & 77 & -29.97 & -177.91 & 64.5 .7\end{array}$ $\begin{array}{lllllllll}\text { TK } 55 \quad 9 & 19 & 77 & -27.80 & -177.99 & 203.5 .1\end{array}$ TK $56 \quad 1126 \quad 77 \quad-15.27 \quad-174.40 \quad 158.5 .3$

$\begin{array}{lllllll}\text { TK } 57 \quad 1 \quad 12 & 78 & -17.53 & -172.12 & 15.5 .2\end{array}$

TK $58 \quad 1 \quad 2878-25.92-177.30 \quad 98.6 .0$

$\begin{array}{lllllll}\text { TK } 59 \quad 129 & 78 & -24.85 & -175.43 & 18.5 .6\end{array}$

$\begin{array}{llllllll}\text { TK } 60 & 2 & 22 & 78 & -22.70 & -176.21 & 64.6 .0\end{array}$

$\begin{array}{lllllllll}\text { TK } 61 & 3 & 29 & 78 & -21.76 & -174.01 & 15.5 .4\end{array}$

$\begin{array}{lllllllll}\text { TK } & 62 & 6 & 25 & 78 & -17.11 & -174.43 & 164.5 .5\end{array}$

$\begin{array}{lllllllll}\text { TK } & 63 & 9 & 16 & 78 & -25.73 & -177.95 & 235.5 & 5.7\end{array}$

$\begin{array}{llllllll}\text { TK } 64 & 9 & 22 & 78 & -37.61 & 176.53 & 183.5 .4\end{array}$

$\begin{array}{llllllll}\text { TK } 65 & 11 & 14 & 78 & -15.66 & -173.23 & 76.5 .4\end{array}$

$\begin{array}{llllllll}\text { TK } & 66 & 11 & 23 & 78 & -26.18 & -177.69 & 190.5 .5\end{array}$

$\begin{array}{llllllll}\text { TK } 67 & 8 & 5 & 79 & -22.72 & -177.49 & 229 & 6.4\end{array}$

$\begin{array}{lllllllll}\text { TK } & 68 & 11 & 11 & 79 & -20.26 & -176.15 & 218.5 & 5.5\end{array}$

$\begin{array}{llllllllll}\text { TK } & 69 & 4 & 13 & 80 & -23.47 & -177.30 & 166.7 .6\end{array}$

TK 70

TK 71

TK 72

TK 73

TK 74

TK 75

TK 76

TK 77

TK 78

TK 79

TK 80

TK 81

TK 82
TK 83

$\begin{array}{ll}\text { TK } & 83 \\ \text { TK } & 84 \\ \text { TK } & 85\end{array}$

TK 85

TK 86

TK 87

TK 88

TK 89

TK 90

TK 91

TK 92

TK 93

TK 94

TK 95 $\begin{array}{lllllll}4 & 26 & 80 & -15.59 & -174.34 & 185.5 .5\end{array}$ $\begin{array}{llllllll}5 & 12 & 80 & -23.58 & -177.41 & 152.5 .5\end{array}$ $\begin{array}{lllllll}6 & 18 & 80 & -15.27 & -173.57 & 73.6 .4\end{array}$ $1130.80-19.43-175.85238 .6 .0$ $\begin{array}{lllllll}6 & 26 & 81 & -30.27 & -178.99 & 164.6 .1\end{array}$ $\begin{array}{llllllll}8 & 13 & 81 & -16.05 & -174.41 & 188.5 .4\end{array}$ $\begin{array}{llllllll}8 & 25 & 81 & -22.76 & -176.21 & 108.5 .8\end{array}$ $\begin{array}{lllllll}11 & 4 & 81 & -20.02 & -174.39 & 57.6 .5\end{array}$ $\begin{array}{llllll}12 & 23 & 81 & -15.36 & -173.80 & 120.5 .6\end{array}$ $1482-23.05-177.47 \quad 191.6 .4$ $\begin{array}{llllll}32 & 21 & 82 & -18.51 & -175.27 & 217 \\ 4 & 5.8\end{array}$ $\begin{array}{lllllll}4 & 16 & 82 & -15.68 & -173.08 & 59.6 .1\end{array}$ $\begin{array}{lllllll}6 & 11 & 82 & -17.53 & -174.46 & 113.6 .8\end{array}$ $\begin{array}{lllllll}6 & 17 & 82 & -15.20 & -173.27 & 50.5 .5\end{array}$ $\begin{array}{llllll}7 & 30 & 82 & -18.63 & -173.87 & 70.5 .5\end{array}$ $\begin{array}{llllll}9 & 28 & 82 & -24.17 & -176.75 & 42.6 .4\end{array}$ $10 \quad 582-30.23-178.06 \quad 163.5 .5$ $1883-15.32-173.40 \quad 53.6 .3$ $\begin{array}{llllll}12 & 26 & 83 & -30.36 & -179.43 & 224.7 .0\end{array}$ $\begin{array}{lllllll}3 & 21 & 83 & -21.67 & -175.32 & 52.6 .7\end{array}$ $\begin{array}{lllllll}4 & 15 & 83 & -19.10 & -175.61 & 226.5 .7\end{array}$ $\begin{array}{lllllll}4 & 24 & 83 & -23.92 & -176.01 & 39.5 .9\end{array}$ $\begin{array}{llllll}5 & 29 & 83 & -15.58 & -174.98 & 276.5 .5\end{array}$ $6183-17.00-174.71186 .6 .5$ $\begin{array}{lllllll}6 & 25 & 83 & -22.04 & -177.47 & 274 & 5.5\end{array}$ $\begin{array}{lllllll}7 & 24 & 83 & -27.90 & -176.41 & 57.5 .3\end{array}$ 69. 18. 184. 53. 328, 31. 197. 38 146. $077 \times$ 288. 42. 138. 43. 32. 16. 305. 17. 2. R79 C 285. 40. 137. 44. 30.17. 307. 19. 6. R79 C $241.67 .124 .11 .30 .20 .237 .38 . \quad-57$. R79 C 61. 8. 327. 48. 158. 42. 116.51. 34. R79 T 278. 53. 98. 37. 188. 0. 188. 8. -90. KAW C 85. 41.245 .47 .346 .10 .239 .11 .164$. CMT T 69. 28. 304. 47. 176. 30. 110. 32. 21. CMT T 320. 26. 87. 51. 215. 27. 94. 31. 152. CMT C 107. 56. 286. 34. 17. 1. 14. 11. -93. CMT T 272. 11. 71. 79. 182. 4. 7. 34. 97. CMT C 34. 82, 202. 8. 292. 2. 290. 37. -93. CMT $X$ 270. 49. 71. 39.169. 10. 107. 12. -154 . CMT $C$ 84. 10. 205. 72. 351. 15. 192. 37. 115. CMT T 358. 47. 98. 9. 196. 42. 150. 51. -149. CMT C 260. 58. 359.6 . 93. 32. 59. 48. -135 . CMT C 180. 90. 117. 0. 27. 0. 205. 45. -90. CMT T 334. 28. 106. 51. 230. 25. 109. 28. 153. CMT C 39. 73. 269. 11. 176. 13. 14. 36. -68. CMT T 276. 33. 98. $57.7 .7 . \quad 3.12 .87$. CMT C 110. 59. 313. 29. 217. 10. 70. 19. -56 . CMT T 300. 61. 175. 18. 78. 22. 296. 33. -47. CMT C 327. 27. 72. 28. 200. 50. 109. 49. 179. CMT C 136. 26. 232. 11. 343.61. 277.63. -169. CMT $x$ 51. 37. $230.53 .320 .0 .143 .8 \%$ 92. CMT $X$ 350. 38. 224. 37. 108. 31. 16. 31. -1. CMT $x$ 315. 58. 123. 32. $216.5 .195 .13 .-111$. CMT $C$ 282. 54. $118,35,22,8,241,12,-52$. CMT C 326. 51. 102. 31. 206. 22. 145. 24. -153 . CMT C 103. 58. 256. 29. 353. 12. 315. 20. -130 . CMT T 326. 27. 175. 60. 62. 12. 28. 21. 54. CMT C 45. 36. 183. 46. 298. 22. 193. 22. 166. CMT X 292. 46. 123. 43. 28. 5. $283.8 . \quad-11$. CMT C 302. 60. 102. 29. 197. 9. 169.17. -118. CMT $C$ 358. 26. 190. 64. 90. 5. 77. 19. 76. CMT $x$ 155. 27. $248.7 .351,62.295 .66 .-165$. CMT $X$ 87. 53. 273.37 .181 .3 . 19. 18. -71. CMT T 61. 41. 232. 48. 327. 5. 200. 6. 143. CMT T 313. 58. 115. 31. 210. 8. 180.15. -120. CMT C 267. 60. 115. 27. 19. 12. 233. 21. -54 . CMT C 82. 35. 229. 50. 340. 17. 223. 19. 155. CMT T 259. 53. 105. 34. 6. 13. 237. 16. -37 . CMT C 43. 29. 166. 45. 294. 31. 183. 33. 163. CMT $X$ 116. 47. 258.36 .3 3. 20. 291. 21, -164 . CMT $T$ 13. 7. 282. 7. 148.80. 57.80. 0. CMT $X$ 344. 10. 79. 27. 235.61. 118.64. 167. CMT $X$ 15. 50. 176. 39. 274. 10. 214. 11. -150 . CMT $x$ 354. 52. 177. 38. 86. 2. 278.7 .78 . CMT $x$ 272. 29. 96. 61. 3. 2. 357. 16. 84. CMT C 262. 55. 142. 19. 41. 28. 269. 36. -36. CMT C 12. 5. 271.66 .105 .23 .79 .45 .56$. CMT T 305. 72. 111. 17. 203. 4. 195. 28. -99. CMT C $315.69 .126 .21,217,3.210 .24,-97$. CMT C 322. 52. 84. 22, 187. 29. 133. 35. -149 . CMT C 125. 22. 232. 35.9 .47 .264 .48 . 169. CMT $x$ 114.13 .213 .32 .4 . 55. 249. 58. 165. CMT $x$ $\begin{array}{llllllll}\text { TK } & 97 & 8 & 15 & 83 & -17.10 & -174.59 & 181.5 .5\end{array}$ 320. 73. 117. 16. 208. 6. 198. 29. -103. CMT $c$ 
TK $98 \quad 8 \quad 2183-23.48-177.19$ 139. $5.5 \quad 260.55 .128 .25 .26 .23 .257 .29 . \quad-36$. CMT C TK $9922584-16.69-174.82269 .5 .7 \quad 195.52 .351 .36 .90 .11 .96 .13 .-143$. CMT $X$

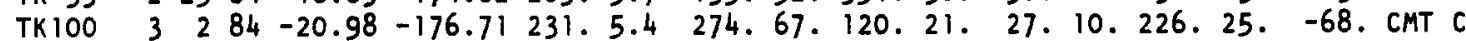

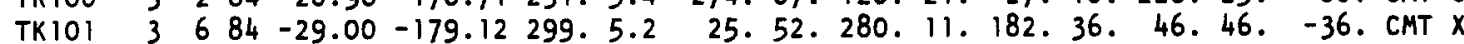
$\begin{array}{llllllll}\text { TK } 102 & 3 & 8 & 84 & -38.25 & 177.22 & 79.6 .0\end{array}$ TK103 $32384-15.19-173.74 \quad 43.6 .0$ TK104 $4 \quad 18 \quad 84-15.93-174.35158 .6 .4$ TK $105 \quad 42984-19.91-175.56230 .5 .4$ $\begin{array}{lllllllll}\text { TK } 106 & 5 & 25 & 84 & -30.57 & -178.35 & 64.5 .5\end{array}$ TK $107 \quad 5 \quad 3184-23.45-177.41 \quad 159.4 .8$ TK $108 \quad 6 \quad 1584-17.98-175.16 \quad 272.5 .1$ TK109 TK 110

TK 111

TK112

TK113

TK 114

TK 115

TK 116

TK 117
TK 118

TK 119

TK 120

$\begin{array}{llllll}6 & 15 & 84 & -15.79 & -174.87 & 270.6 .6\end{array}$ $\begin{array}{llllll}6 & 25 & 84 & -30.90 & -178.89 & 139.5 .2\end{array}$ $\begin{array}{lllllll}7 & 17 & 84 & -19.37 & -173.88 & 30.5 .2\end{array}$ $\begin{array}{llllll}728 & 84 & -17.07 & -174.07 & 144.5 .5\end{array}$ $\begin{array}{lllllll}731 & 84 & -17.59 & -175.76 & 298.5 .1\end{array}$ $\begin{array}{llllll}8 & 17 & 84 & -21.78 & -175.00 & 57.5 .6\end{array}$ $\begin{array}{lllllll}10 & 11 & 84 & -33.94 & 179.56 & 222 & 5.3\end{array}$ $\begin{array}{llllll}10 & 13 & 84 & -17.76 & -175.19 & 251.5 .2\end{array}$ $\begin{array}{lllllll}10 & 15 & 84 & -15.86 & -173.64 & 120.7 .1\end{array}$ $\begin{array}{llllll}10 & 1984 & -15.86 & -174.00 & 125.6 .0\end{array}$ $\begin{array}{lllllll}10 & 19 & 84 & -30.54 & -178.38 & 92.5 .5\end{array}$ $\begin{array}{lllllll}10 & 30 & 84 & -17.12 & -174.11 & 150.6 .5\end{array}$

$\begin{array}{lllllllll}T K 121 & 11 & 6 & 84 & -18.64 & -175.48 & 247.5 .4\end{array}$

$\begin{array}{lllllll}T K 122 & 11 & 18 & 84 & -18.72 & -175.60 & 230.5 .6\end{array}$

$\begin{array}{lllllll}\text { TK123 } 1485 & -26.07 & -177.56 & 139.5 .3\end{array}$

TK124

TK 125

TK 126

TK 127

TK128

TK 129

TK130

TK131

TK 132

TK134

TK135

TK136

TK 137

TK138

TK139

TK 140

TK 141

TK 142

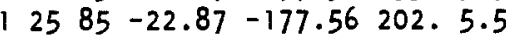

$\begin{array}{llllll}2 & 1 & 85 & -17.62 & -174.49 & 127.5 .6\end{array}$ $\begin{array}{lllllll}2 & 19 & 85 & -22.86 & -176.81 & 123.5 .3\end{array}$ $4385-33.14-179.35 \quad 65.5 .6$ $\begin{array}{llllll}4 & 11 & 85 & -35.49 & 179.02 & 97.5 .8\end{array}$

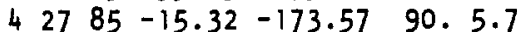
$\begin{array}{llllll}42785 & -20.93 & -176.99 & 262.5 .7\end{array}$ $\begin{array}{llllll}6 & 3 & 85 & -15.25 & -173.56 & 46.6 .6\end{array}$ $\begin{array}{llllll}6 & 29 & 85 & -24.46 & -176.64 & 71.5 .2\end{array}$ $8985-15.34-174.65221 .5 .4$ $\begin{array}{llllll}9 & 11 & 85 & -15.38 & -173.60 & 77.5 .7\end{array}$ $\begin{array}{lllllll}9 & 15 & 85 & -19.11 & -175.81 & 258.5 .7\end{array}$ $\begin{array}{llllll}9 & 15 & 85 & -16.66 & -174.05 & 67.5 .7\end{array}$ $\begin{array}{llllll}10 & 12 & 85 & -21.62 & -176.49 & 170.6 .2\end{array}$ $\begin{array}{lllllll}10 & 20 & 85 & -28.97 & -178.91 & 262.5 .3\end{array}$ $11685-16.19-173.36 \quad 50.5 .0$ $\begin{array}{llllll}11 & 30 & 85 & -16.38 & -174.20 & 179.6 .0\end{array}$ $\begin{array}{llllll}12 & 17 & 85 & -21.46 & -176.99 & 201 \\ 1 & 5.1\end{array}$ $\begin{array}{llllll}12 & 25 & 85 & -22.68 & -176.06 & 61.5\end{array}$ $12786-23.74-177.28$ 169. 5.1

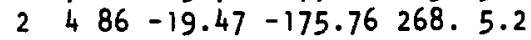
$\begin{array}{llllll}325 & 86 & -21.86 & -176.85 & 189.5 .1\end{array}$ $\begin{array}{lllllll}4 & 12 & 86 & -15.42 & -173.22 & 65.5 & 5.5\end{array}$ $\begin{array}{llllll}4 & 13 & 86 & -15.60 & -173.17 & 73.5 \\ 4 & 5.2\end{array}$ $\begin{array}{lllll}415 & 86 & -15.56 & -173.90 & 84.5 .3\end{array}$ $\begin{array}{llllll}4 & 25 & 86 & -17.25 & -174.09 & 140.5 .4\end{array}$ $\begin{array}{lllllll}6 & 28 & 86 & -20.04 & -176.05 & 222.6 .5\end{array}$ $\begin{array}{llllll}7 & 10 & 86 & -19.90 & -175.78 & 226.5 .3\end{array}$ $\begin{array}{llllll}722 & 86 & -33.57 & -178.35 & 15.5 .4\end{array}$ $\begin{array}{llllll}726 & 86 & -18.07 & -173.20 & 15.5 .2\end{array}$ $\begin{array}{lllllll}7 & 27 & 86 & -25.85 & -177.49 & 109.5 .8\end{array}$ 184. 10. 285. 50. 86. 39. 310. 48. 146. CMT T 8. 49. 180. 41. 273. 4. 226. 6. -137 . CMT $X$ 264. 65. 97. 24.5 5. 5. 198. 22. -76 . CMT C 248. 35. 144. 19. 30. 48. 281. 50. -13. CMT C 101. 2. 196. 71. 11. 19. 209. 46. 117. CMT T 8. 9. 115. 62. 273. 26. 126. 43. 131. CMT X 78. 20. 335. 30. 196.53.119.53. 8. CMT $x$ 240. 66. 105. 17. 10. 16. 218. 31. -58. CMT C 286. 52. 100. 38. 192. 3. $170.7 \cdot-111$. CMT C 235. 7. 332. 47. 138. 42. 2. 53. 147. CMT T 59. 35. 230.55 .326 .4 .169 .10 .111 . CMT T 263. 50. 68. 39. 164. 8. 111. 9. -143 . CMT C 276. 30. 119. 58. 12.11. 337. 18. 54. CMT C 231. 56. 116. 16. 17. 29. $241.39 . \quad-39$. CMT C 288. 60. 118. 30. 25. 4. 221. 15. -75. CMT C 50. 44. 265. 42. $161.15 .65 .15 . \quad-4$. CMT T 91. 39. 270.51. 1. 0. 185. 6. 95. CMT T 284. 45. 112. 45.18 .4 .292 .4 .3 . CMT C 103. 36. 273. 53. 9. 5. 219. 11. 123. CMT T 279. 53. 124. 34. 25. 12. 256. 16. -38. CMT C $245.44 .135 .19 .29 .40 .269 .44 . \quad-22$. CMT C 348. 34. 156.56.254. 6. 100.11. 114. CMT $X$ 308. 46. 134. $44.41 .3 .286 .3 . \quad-25$. CMT C $277.52 .110 .37 .15 .6 .235 .11 .-48$. CMT C 282. 52. 98. 38. 190. 2. 174. 7. -105 . CMT C 106. 15. 202. 21. 343.64. 243.64. 176. CMT $x$ 22. 4. 288. 48. 116. 46. 77. 55. 36. CMT T 136. 25. 259. 48. 30.30.272. 34. 157. CMT T

3. 14. 105. 40.258.47.136.51. 159. CMT $x$ 4. 45. 177. 45. 271.4 .179 .4 . 178. CMT $x$ 114. 14. 260.74. 22. 9. 216.32. 106. CMT T 201. 68. 60. 18. 325. 13. 170. 29. -63. CMT C 129. 26. 274.59 .32 .15 .251 .24 .132 . CMT T 272. 58. $130.27 .31 .17 .255 .23 . \quad-45$. CMT C 211.30 .79 .50 .316 .25 .253 .26 .25 . CMT $X$ 263. 54. 118. 31. 17. 17. 250. 21. -36 . CMT C 11. 36. 111. 13.218.51. 157.55. -162. CMT $X$ 62. 68. 277. 18. 183. 12. 25. 29. -65 . CMT T 81. 22. 201. 52. 338. 30. 212. 35. 149. CMT T 324. 49. 107. 34. $211.19 .145 .22 .-158$. CMT C 278. 28. 163.39. 33. 38. 316.39. 10. CMT C 303. 42. 61. 27. 172. 35. 101. 37, -166. CMT C 286. 57. 146. 26. 46. 18. 272. 25. -41 . CMT C 300. 42. 115. 48. 208. 2. 64. 4. 126. CMT C 62. 40. 190. 36. 304. 29. 220. 29. -175 . CMT $X$ 75. 32. 185. 29. 307. 44. 221. 44. -177. CMT $X$ 274.35 .113 .53 .10 .9 .326 .14 .93$. CMT C 90. 38. 269. 52. 0. 0. 184. 7. 94. CMT T 258. 44. 114. 40. 7. 19. 270. 19. -6. CMT C 283. 38. 139. 46. 28. 19. 312. 19. 13. CMT C 146. 72. 292. 15. 24. 10. 8. 31. -109. CMT T 261. 22. 171. 0. 81, 68. 304.75. -16. CMT $x$ 353. 35. 106. 29. 226. 42. 142. 42. -175. CMT $X$ 265. 71. 103. 18. 11. 5. 202. 27. -78. CMT C $\begin{array}{lllllll}\text { TK155 } & 729 & 86 & -21.26 & -175.54 & 137.5 .4\end{array}$ $\begin{array}{lllllll}\text { TK156 } 73086 & -18.05 & -174.86 & 197.5 .0\end{array}$ $\begin{array}{lllllllll}\text { TK157 } & 8 & 20 & 86 & -16.94 & -173.51 & 76.5 .6\end{array}$ 129. 36. 21. 22. 266. 46. 160. 47. -12. CMT X 90. 60. $241.27 \cdot 337 \cdot 13.303 .21,-126$. CMT T 


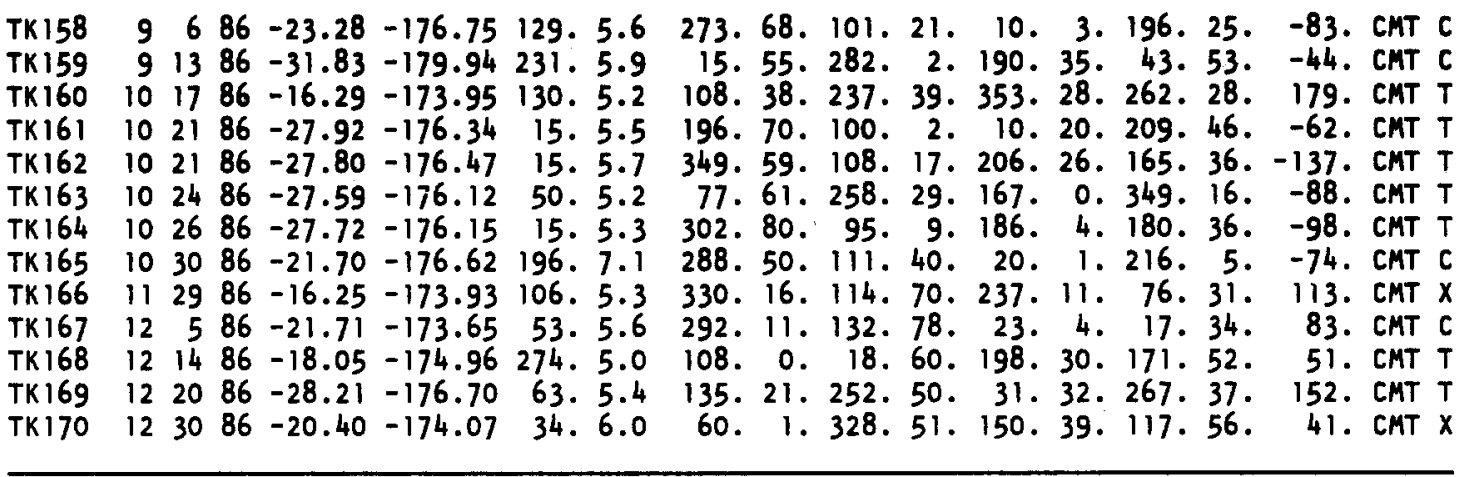

References

AK: Astiz and Kanamori (1986); ALK: Astiz et al. (1988); BB: Bhattacharya and Biswas (1979); B80: Billington (1980); Cl: Chinn and lsacks (1983); CMT: Centroid Moment Tensor [Harvard]; CK: Chung and Kanamori (1978); CE: Coudert et al. (1981); C73: Curtis (1973); DD: Dean and Drake (1978); D77: Denham (1977); F79: Fujita (1979); FK: Fujita and Kanamori (1981); GE: Gedney (1970); GS: Gonzalez and Seno (1987); G: Gonzalez-Ruiz (1986); HJ: House and Jacobs, (1983); IM: I sacks and Molnar (1971); I SO: Isacks et al. (1969); I: Isacks et al. (1979); JJ: Jimenez (1977); JM: Johnson and Molnar (1972); KAW: Kawakatsu (1986); KM: Korrat and Madariaga (1986); LM: Lefevre and MeNally (1986); MDM: Malgrange et al. (1981); MGS: MeNally et al. (1986); MOM: Mino et al. (1968); MS: Molnar and Sykes (1969); 071: 0ike (1971); P79: Pascal (1979); PA: Pascal et al. (1978); PE: Pennington (1981); R79: Richter (1979); R74: Ripper (1974); R75: Ripper (1975); R64: Ritsema (1964); SSG: Singh et al. (1985); S72: Stauder (1972); 573: Stauder (1973); S75: Stauder (1975); SB: Stauder and Bollinger (1966a); SBB: Stauder and Bollinger (1966b); SM: Stauder and Mualchin (1976); SU: Stauder and Udias (1963); T78: Topper (1978); V: Veith (1974); WH: Wickens and Hodgson (1967); WT: Wilson and Toldi (1978); WM: Wyss and Molnar (1972); Yo: Yoshii (1979)

\section{References}

Abe, K., 1972a. Lithospheric normal faulting beneath the Aleutian trench. Phys. Earth Planet. Inter., 5: 190-198.

Abe, K., 1972b. Mechanisms and tectonic implications of the 1966 and 1970 Peru earthquakes. Phys. Earth Planet. Inter., 5: $367-379$.

Astiz, L. and Kanamori, H., 1984. An earthquake doublet in Ometepec, Guerrero, Mexico. Phys. Earth Planet. Inter., 34: 24-45.

Astiz, L. and Kanamori, H., 1986. Interplate coupling and temporal variation of mechanisms of intermediate depth earthquakes in Chile. Bull. Seismol. Soc. Am., 76: 1614-1622.

Astiz, L., Lay, T. and Kanamori, H., 1988. Large intermediate depth earthquakes and the subduction process. Phys. Earth Planet. Inter., 53: 80-166.

Beck, S.L. and Ruff, L., 1984. Seismicity and subduction along the Peru trench. EOS, Trans. Am. Geophys. Union, 65: 998.
Beck, S.L., Schwartz, S.Y. and Ruff, L.J., 1986. Large precursory earthquakes associated with subduction in the Kurile and Peru trenches. Earthquake Notes, 57: 22-23.

Bhattacharya, B. and Biswas, N.N., 1979. Implications of North Pacific plate tectonics in central Alaska: focal mechanisms of earthquakes. Tectonophysics, 53: 99-130.

Billington, S., 1980. The Morphology and Tectonics of the Subducted Lithosphere in the Tonga-Fiji-Kermadec region from Seismicity and Focal Mechanism Solutions. Ph.D. Thesis, University of Cornell, $220 \mathrm{pp}$.

Chapple, W.M. and Forsyth, D.M., 1979. Earthquakes and bending of plates at trenches. J. Geophys. Res., 84: 6729-6749.

Chinn, D.S. and Isacks, B.L., 1983. Accurate source depths and focal mechanisms of shallow earthquakes in western South America and in the New Hebrides Island arc. Tectonics, 2: 529-563.

Christensen, D.H. and Ruff, L.J., 1983. Outer rise earthquakes and seismic coupling. Geophys. Res. Lett., 10: 697-700. 
Christensen, D.H. and Ruff, L.J., 1986. Rupture process of the March 5, 1985 Chilean earthquake. Geophys. Res. Lett. 13: $721-724$.

Christensen, D.H. and Lay, T., 1988. Large earthquakes associated with subduction of the Louisville Ridge. J. Geophys. Res., 93: 13367-13389.

Christensen, D.H. and Ruff, L.J., 1988. Seismic coupling and outer rise earthquakes. J. Geophys. Res., 93: 13421-13444.

Chung, W.Y. and Kanamori, H., 1978. Subduction process of a fracture zone and aseismic ridges. The focal mechanism and source characteristics of the New Hebrides earthquake of 1969, January 19 and some related events. Geophys. J. R. Astron. Soc., 54: 221-240.

Coudert, E., Isacks, B.L., Barazangi, M., Louat, R., Cardwell, R., Chen, A., Dubois, J., Latham, G. and Pontoise, B., 1981. Spatial distribution and mechanisms of earthquakes in the southern New Hebrides arc from a temporary land and ocean bottom seismic network and from worldwide observations. J. Geophys. Res., 86: 5905-5925.

Curtis, J.W., 1973. Plate tectonics and the Papua-New Guinea-Solomon Islands region. J. Geol. Soc. Aust., 20: 21-36.

Dean, B.W. and Drake, C.L., 1978. Focal mechanism solutions and tectonics of the Middle America arc. J. Geol., 86 111-128.

Denham, D., 1977. Summary of earthquake focal mechanisms for the western Pacific-Indonesia region 1929-1973. NOAA, U.S. Dept. Commerce Rep. SE-3.

Dewey, J.W. and Spence, W., 1979. Seismic gaps and source zones of recent large earthquakes in coastal Peru. Pure Appl. Geophys., 117: 1148-1171.

Dmowska, R., Rice, J.R., Lovison, L.C. and Josell, D., 1988. Stress transfer and seismic phenomena in coupled subduction zones during the earthquake cycle. J. Geophys. Res., 93: 7869-7884

Dziewonski, A.M. and Woodhouse, J.H., 1983. An experiment in the systematic study of global seismicity; centroid-moment tensor solutions for 201 moderate and large earthquakes of 1981. J. Geophys. Res., 88: 3247-3271.

Eissler, H. and Kanamori, H., 1982. A large normal-fault earthquake at the junction of the Tonga trench and the Louisville Ridge. Phys. Earth Planet. Inter., 29: 161-172.

Fujita, K., 1979. Tectonics of Divergent and Convergent Plate Margins. Ph.D. Thesis, Northwestern University, 300 pp.

Fujita, K. and Kanamori, H., 1981. Double seismic zones and stresses of intermediate depth earthquakes. Geophys. J. R. Astron. Soc., 66: 131-156.

Gedney, L., 1970. Tectonic stresses in southern Alaska in relationship to regional seismicity and the new global tectonics. Bull. Seismol. Soc. Am., 60: 1789-1802.

Giardini, D. and Woodhouse, J.H., 1984. Deep seismicity and modes of deformation in Tonga subduction zone. Nature 307: 505-509.

Gonzalez, D.G. and Seno, T., 1987. Faulting caused by earthquakes beneath the outer wall of the Japan trench, Preprint.
Gonzalez-Ruiz, J.R., 1986. Earthquake Source Mechanics and Tectonophysics of the Middle America Subduction Zone in Mexico. Ph.D. Thesis, University of California, Santa Cruz, 93 pp.

Hasegawa, A. and Umino, N., 1978. Focal mechanisms and the distribution of seismicity in northeast Japan. Progr. Abstr. Seismol. Soc. Jap., 1: 34.

Hauksson, E., Armbruster, J. and Dobbs, S., 1984. Seismicity patterns (1963-1983) as stress indicators in the Shumagin seismic gap. Bull. Seismol. Soc. Am., 74: 2541-2558.

House, L.S. and Jacob, K.H., 1983. Earthquakes, plate subduction and stress reversals in the eastern Aleutian arc. $J$. Geophys. Res., 88: 9347-9373.

Hudnut, K.W. and Taber, J.J., 1987. Transition from double to single Wadati-Benioff seismic zone in the Shumagin Islands, Alaska. Geophys. Res. Lett., 14: 143-146.

Isacks, B.L. and Molnar, P., 1969. Mantle earthquake mechanisms and the sinking of the lithosphere. Nature, 223: $1121-1124$.

Isacks, B.L. and Barazangi, M., 1977. Geometry of Benioff zones: lateral segmentation and downward bending of the subducting lithosphere. Am. Geophys. Union, Maurice Ewing Ser., 1: 99-114.

Isacks, B. and Molnar, P., 1971. Distribution of stresses in the descending lithosphere from a global survey of focal-mechanism solutions of mantle earthquakes. Rev. Geophys. Space Phys., 9: 103-174.

Isacks, B., Sykes, L.R. and Oliver, J., 1969. Focal mechanisms of deep and shallow earthquakes in the Tonga-Kermadec region and the tectonics of island arcs. Geol. Soc. Am. Bull., 80: 1443-1470.

Isacks, B.L., Cardwell, R.K., Chatelain, J.L., Barazangi, M. Marthelot, J.M., Chinn, D. and Louat, R., 1979. Seismicity and tectonics of the central New Hebrides island arc. Am. Geophys. Union, Maurice Ewing Ser., 4: 93-116.

Jimenez, Z.J., 1977. Mecanismo Focal de Siete Temblores $\left(m_{\mathrm{b}}>5.5\right.$ ) Ocurridos en la Region de Orizaba, Mexico, en el Periodo de 1928 a 1973. Tesis Profesional de Licenciatura. Facultad de Ciencias, Universidad Nacional Autonoma de Mexico, Mexico, 102 pp. (in Spanish).

Johnson, T. and Molnar, P., 1972. Focal mechanisms and plate tectonics of the southwest Pacific. J. Geophys. Res., 77: 5000-5032.

Kanamori, H., 1971. Focal mechanism of the Tokachi-Oki earthquake of May 16, 1968: contortion of the lithosphere at a junction of two trenches. Tectonophysics, 12: 1-13.

Kanamori, H., 1977. Seismic and aseismic slip along subduction zones and their tectonic implications. Am. Geophys. Union, Maurice Ewing Ser., 1: 163-174.

Kawakatsu, H., 1986. Downdip tensional earthquakes beneath the Tonga arc: a double seismic zone? J. Geophys. Res., 91: 6432-6440.

Kawakatsu, H. and Seno, T., 1983. Triple seismic zone and the regional variation of seismicity along the northern Honshu arc. J. Geophys. Res., 88: 4215-4230.

Korrat, I. and Madariaga, R., 1986. Rupture of the Valparaiso 
(Chile) gap from 1971 to 1985. In: S. Das, J. Boatwright and C.H. Scholtz (Editors), Earthquake Source Mechanics. Am. Geophys. Union, Washington, DC, pp. 247-258.

Lay, T. and Kanamori, H., 1980. Earthquake doublets in the Solomon Islands. Phys. Earth Planet. Inter., 21: 283-304.

Lay, T., Kanamori, H. and Ruff, L., 1982. The asperity model and the nature of large subduction zone earthquakes. Earthquake Prediction Res., 1: 3-72.

LeFevre, L.V. and McNally, K.C., 1985. Stress distribution and subduction of aseismic ridges in the Middle America subduction zone. J. Geophys. Res., 90: 4495-4510.

Malgrange, M. and Madariaga, R., 1983. Complex distribution of large thrust and normal fault earthquakes in the Chilean subduction zone. Geophys. J. R. Astron. Soc., 73: 489-505.

Malgrange, M., Deschamps, A. and Madariaga, R., 1981. Thrust and extensional faulting under the Chilean coast, 1965 , 1971 Aconcagua earthquakes. Geophys. J. R. Astron. Soc., 66: 313-331.

McCann, W.R., Nishenko, S.P., Sykes, L.R. and Kraus, J., 1979. Seismic gaps and plate tectonics: seismic potential for major boundaries. Pure Appl. Geophys., 117: 1087-1147.

McNally, K.C. and Gonzalez-Ruiz, J.R., 1985. Predictability of the whole earthquake cycle and source mechanics for large $\left(7.0 \leq M_{\mathrm{w}} \leq 8.1\right)$ earthquakes along the Middle America trench offshore Mexico. Earthquake Notes, 57: 22.

McNally, K.C., Gonzalez-Ruiz, J.R. and Stolte, C., 1986. Seismogenesis of the 1985 Great $\left(M_{\mathrm{s}}=8.1\right)$ Michoacan, Mexico earthquake. Geophys. Res. Lett., 13: 585-588.

Mino, K., Onoguchi, T. and Mikumo, T., 1968. Focal mechanism of earthquakes on island arcs in the Southwest Pacific region. Bull. Disaster Prev. Res. Inst. Kyoto Univ., 18, Part 2, 139: 78-96.

Mogi, K., 1973. Relationship between shallow and deep seismicity in the western Pacific region. Tectonophysics, 17: $1-22$.

Molnar, P. and Sykes, L.R., 1969. Tectonics of the Caribbean and Middle-America regions from focal mechanisms and seismicity. Geol. Soc. Am. Bull., 80: 1639-1684.

Mota, R., 1979. Contribution a l'Etude Sismo-tectonique du Mexique Meridional. Ph.D. Thesis, University of Paris VII.

Oike, K., 1971. On the nature of the occurrence of intermediate and deep earthquakes, 1 . The world-wide distribution of the earthquake generating stress. Bull. Disaster Prev. Rev. Inst., Kyoto Univ., 20: 145-182.

Pascal, G., 1979. Seismotectonics of the Papua New Guinea-Solomon Island region. Tectonophysics, 57: 7-34.

Pascal, G., Isacks, B.L., Barazangi, M. and Dubois, J., 1978. Precise relocations of earthquakes and seismotectonics of the New Hebrides island arc. J. Geophys. Res., 83: 4957-4973.

Pennington, W.D., 1981. Subduction of the eastern Panama basin and seismotectonics of northwestern South America. J. Geophys. Res., 86: 10753-10770.

Richter, F.M., 1979. Focal mechanisms and seismic energy release of deep and intermediate earthquakes in the Tonga-Kermadec region and their bearing on the depth extent of mantle flow. J. Geophys. Res., 84: 6783-6795.
Ripper, I.D., 1974. Some earthquake focal mechanisms in the New Guinea-Solomon Island region, 1963-1968. Bur. Miner. Resour. Aust., Rep. 178.

Ripper, I.D., 1975. Some earthquake focal mechanisms in the New Guinea-Solomon Islands region, 1969-1971. Bur. Miner. Resour. Aust., Rep. 192.

Ritsema, A.R., 1964. Some reliable fault plane solutions. Pure Appl. Geophys., 59: 58-74.

Sasatani, T., 1976. Mechanism of mantle earthquakes near the junction of the Kurile and the northern Honshu arcs. J. Phys. Earth, 24: 341-354.

Schwartz, S.Y., Lay, T. and Ruff, L.J., 1989. Source process of the great 1971 Solomon Islands doublet. Phys. Earth Planet. Inter. (in press).

Seno, T., 1979. Pattern of intraplate seismicity in southwest Japan before and after great interplate earthquakes. Tectonophysics, 57: 267-283.

Seno, T. and Pongswat, B., 1981. A triple-planed structure of seismicity and earthquake mechanisms at the subduction zone off Miyagi Prefecture, northern Honshu, Japan. Earth Planet. Sci. Lett., 55: 25-36.

Singh, S.K., Astiz, L. and Havskov, J., 1981. Seismic gaps and recurrence periods of large earthquakes along the Mexican subduction zone: a reexamination. Bull. Seismol. Soc. Am., 71: $827-843$.

Singh, S.K., Suarez, G. and Dominguez, T., 1985. The Oaxaca, Mexico, earthquake of 1931: lithospheric normal faulting in the subducted Cocos plate. Nature, 317: 56-58.

Spence, W., 1977. The Aleutian arc: tectonic blocks, episodic subduction, strain diffusion, and magma generation. J. Geophys. Res., 82: 213-230.

Spence, W., 1987. Slab pull and the seismotectonics of subducting lithosphere. Rev. Geophys., 25: 55-69.

Stauder, W., 1968a. Mechanism of the Rat Island earthquake sequence of February 4, 1965 with relation to island arcs and sea-floor spreading. J. Geophys. Res., 73: 3847-3858.

Stauder, W., 1968b. Tensional character of earthquake foci beneath the Aleutian trench with relation to sea-floor spreading, J. Geophys. Res., 73: 7693-7701.

Stauder, W., 1972. Fault motion and spatially bounded character of earthquakes in Amchitka Pass and the Delarof islands. J. Geophys. Res., 77: 2072-2080.

Stauder, W., 1973. Mechanism and spatial distribution of Chilean earthquakes with relation to subduction of the oceanic plate. J. Geophys. Res., 78: 5033-5061.

Stauder, W., 1975. Subduction of the Nazca plate under Peru as evidenced by focal mechanisms and by seismicity. J. Geophys. Res., 80: 1053-1064.

Stauder, W. and Udias, A., 1963. S wave studies of earthquakes of the North Pacific, Part II: Aleutian Islands. Bull. Seismol. Soc. Am., 53: 59-77.

Stauder, W. and Bollinger, G.A., 1966a. The S-wave project for focal mechanism studies: earthquakes of 1963. Bull. Seismol. Soc. Am., 56: 1363-1371.

Stauder, W. and Bollinger, G.A., 1966b. The focal mechanism of the Alaska earthquake of March 28, 1964, and its after-shock sequence. J. Geophys. Res., 71: 5283-5296. 
Stauder, W. and Mualchin, L., 1976. Fault motion in the larger earthquakes of the Kurile-Kamchatka arc and of the Kurile-Hokkaido corner. J. Geophys. Res., 81: 297-308.

Topper, R.E., 1978. Fine Structure of the Benioff Zone Beneath the Central Aleutian Arc. M.S. Thesis, University of Colorado, $148 \mathrm{pp}$.

Tsumura, K., 1973. Microearthquake activity in the Kanto district. In: Special Publication for the 50th Anniversary of the Great Kanto Earthquake, Earthquake Research Institute, Tokyo, pp. 67-87.

Veith, K.F., 1974. The Relationship of Island Arc Seismicity to Plate Tectonics. Ph.D. Thesis, Southern Methodist University, 162 pp.

Ward, S.N., 1983. Body wave inversion: moment tensors and depths of oceanic intraplate bending earthquakes. J. Geophys. Res., 88: 9315-9330.

Wickens, A.J. and Hodgson, J.H., 1967. Computer re-evaluation of earthquake mechanism solutions 1922-1962. Publ Dom. Obs., 33: 1-560.

Wilson, D.S. and Toldi, J.L., 1978. Down-dip stresses from deep earthquakes in the northwestern Pacific. EOS, Trans. Am. Geophys. Union, 59: 1195.

Wyss, M. and Molnar, P., 1972. Source parameters of intermediate and deep focus earthquakes in the Tonga arc. Phys. Earth Planet. Inter., 6: 279-292.

Yoshii, T., 1979. A detailed cross-section of the deep seismic zone beneath northeastern Honshu, Japan. Tectonophysics, 55: $349-360$. 